\title{
LIFE CYCLE COSTING ANALYSIS USING THE MECHANISTIC-EMPIRICAL PAVEMENT DESIGN GUIDE FOR FLEXIBLE PAVEMENTS
}

\author{
By \\ Mohd. Omar Sharif \\ A project presented to Ryerson University \\ In partial fulfillment of the requirements of the degree of \\ Master of Engineering \\ In the program of Civil Engineering
}

Toronto, Ontario, Canada, 2013

(C) Sharif Omar, 2013 


\begin{abstract}
AUTHOR'S DECLARATION
I hereby declare that I am the sole author of this project.

I authorize Ryerson University to lend this project to other institutions or individuals for the purpose scholarly research.
\end{abstract}

Author's Signature ___ Date

I further authorise Ryerson University to reproduce this project by photocopying or by other means, in total or in part, at the request of other institutions or individuals for the purpose of achloarly research.

Author's Signature

Date 


\section{BORROWER'S PAGE}

Ryerson University requires the signatures of all persons using or photocopying this project. Please sign below and give address and date.

\begin{tabular}{|c|c|c|c|}
\hline Name & $\begin{array}{c}\text { Signature of } \\
\text { Borrower }\end{array}$ & Address & Date \\
\hline & & & \\
\hline & & & \\
\hline & & & \\
\hline & & & \\
\hline & & & \\
\hline & & & \\
\hline & & & \\
\hline & & & \\
\hline & & & \\
\hline & & & \\
\hline & & & \\
\hline & & & \\
\hline & & & \\
\hline
\end{tabular}


Title: Life Cycle Costing Analysis Using The Mechanistic-Empirical Pavement Design Guide For Flexible Pavements

Written by: Mohd Omar Sharif

Master of Engineering, 2013

Department of Civil Engineering, Ryerson University

\begin{abstract}
The Mechanistic-Empirical Pavement Design Guide (MEPDG), developed by the American Association of State Highway and Transportation Officials (AASHTO) under the directive of the U.S. National Cooperative Highway Research Program (NCHRP) Project 1-37A, is the latest development in the concept and theories for the analysis and design of new pavements and of overlays for the existing pavements. While MEPDG is waiting for its full-scale implementation and to replace the traditional pavement design methods, it is desirable to make use of the performance prediction capacity of the MEPDG for accurate life-cycle costing analysis. The objective of this study is to review the state of the art and state of the practices for LCC and the new MEPDG methodology for flexible pavement design/preservation, and explore a framework for the integration of LCC into the new MEPDG, which would help the pavement agencies to evaluate the most economic (cost-effective) flexible pavement design for a new roadway section and overlay design for an existing flexible pavement as well as the preservation (maintenance and rehabilitation) time/strategy based on MEPDG methodology.
\end{abstract}




\section{ACKNOWLEDGEMENT}

I express my profound and sincere gratitude to my supervisor Dr. Arnold Yuan for his invaluable contribution, inspiring guidance, continuous support, and patience during the development of this project. It is true that I could not have come this far of my academic career and made this project possible without his encouragement and inspiring advices. I would like to thank Dr. Arnold Yuan for his kind words and always willingness to help that immensely inspired me to the success of this project. I would like to thank Dr. Ahmed El-Rabbany, the Program Director of Graduate Studies, Department of Civil engineering, for his consoling words and kindness he extended throughout my graduate studies. I would also like to thank Dr. Medhat Shehata for his valuable time and review comments which have made me more matured on the subject and will remain as an aspiration and learning words in my life.

I gratefully acknowledge the help and support extended by my fellow classmate Afzal Waseem for his valuable time and patience in guiding me learning DARWin-ME software and help solving other technical issues, which greatly helped in completing this study.

I would like to extend my warmth and special thanks my spouse, Fahmida Sumaiya, for her prayers, encouragements, and endurance during my tenure of study at Ryerson University. Finally, I thank Almighty Allah for blessing me with this success. May Your name be exalted, glorified, and honored (Aameen). 


\section{DEDICATION}

\section{To My Family, Friends}

\section{$\boldsymbol{E}$}

\section{To My Teachers}




\section{Table of Contents}

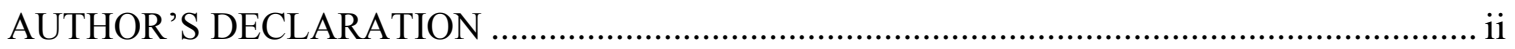

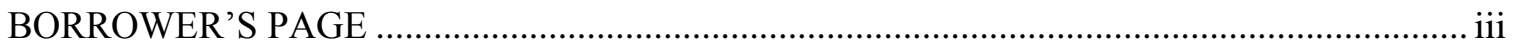

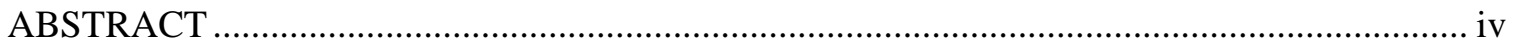

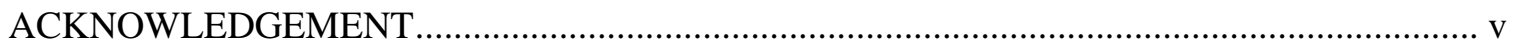

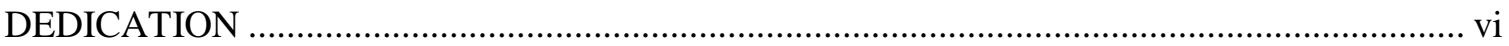

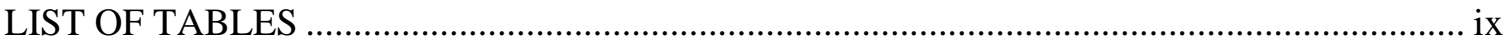

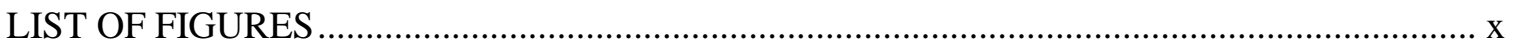

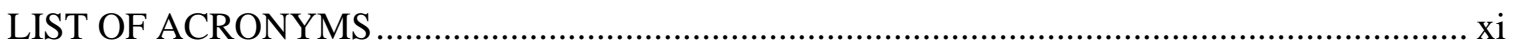

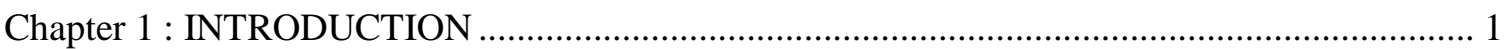

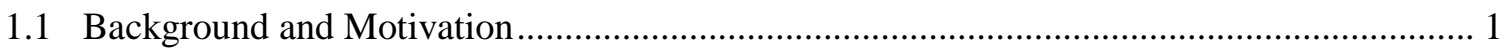

1.2 Objective and Significance of the Study / Project................................................................. 2

1.3 Scope and Methodology of the Study / Project ..................................................................... 3

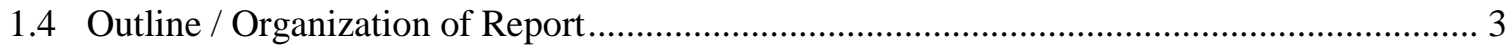

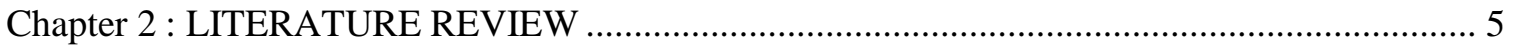

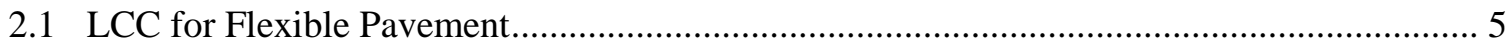

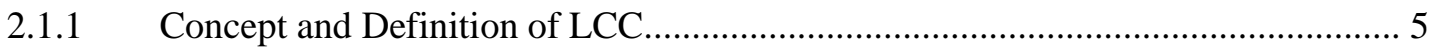

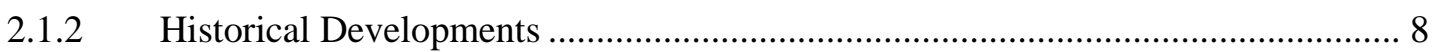

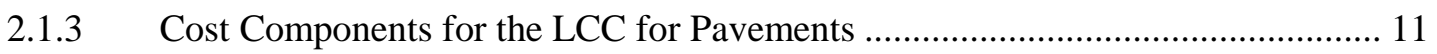

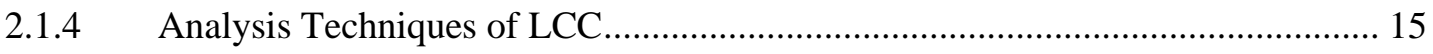

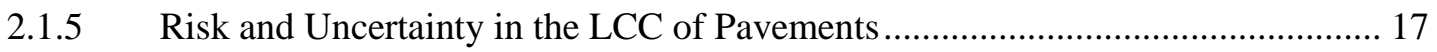

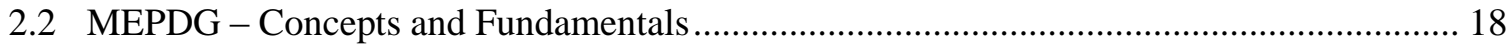

2.2.1 Historical Development of the Pavement Design Methods and MEPDG ............. 20

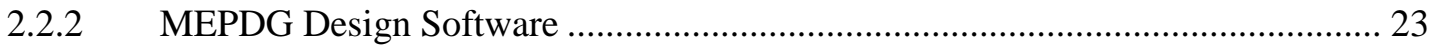

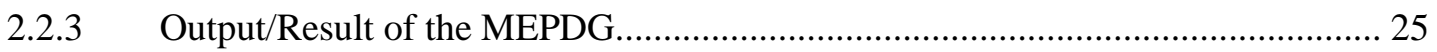

Chapter 3: FRAMEWORK AND PROCESS OF LCC FOR FLEXIBLEPAVEMENT ........ 27

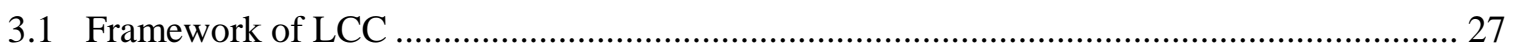

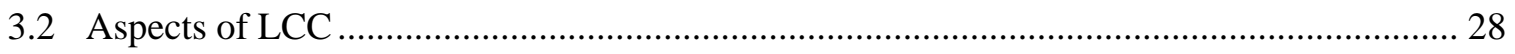

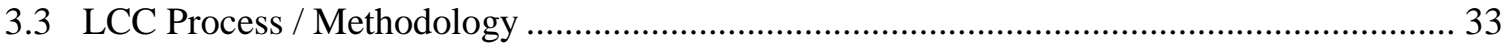

3.4 MEPDG Framework for Analysis/Design of a New Flexible Pavement .............................. 36

3.5 Identification of Feasible Maintenance and Rehabilitation Strategies ................................ 44

Chapter 4 : CASE STUDY - LCC OF A RECONSTRUCTED PAVEMENT SECTION .......... 48

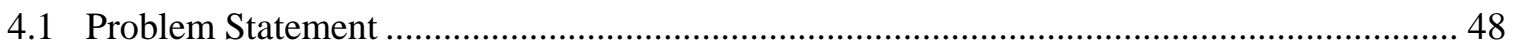


4.2 Special note on Flexible Pavement Local Calibration of the Rutting Model

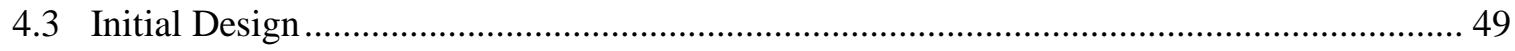

4.4 Determining criteria for estimation of Design Life and Service Life................................... 51

4.5 Determination of Actual Service Life of the Initial Design Section .................................... 52

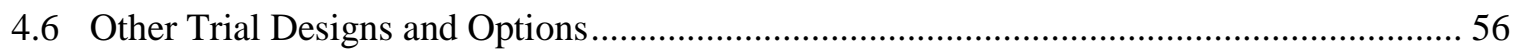

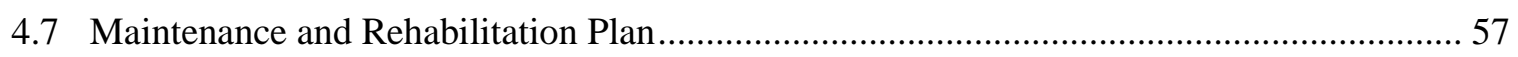

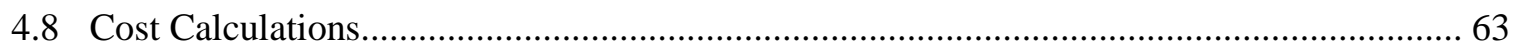

Chapter 5 : $\quad$ SUMMARY/CONCLUSIONS, MAJOR FINDINGS, AND

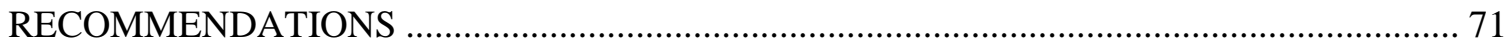

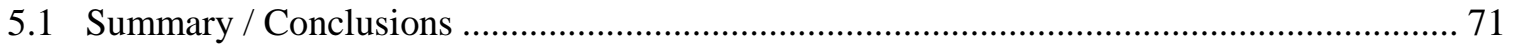

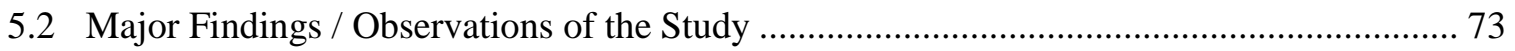

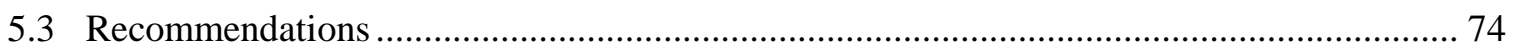

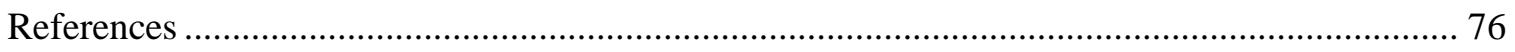

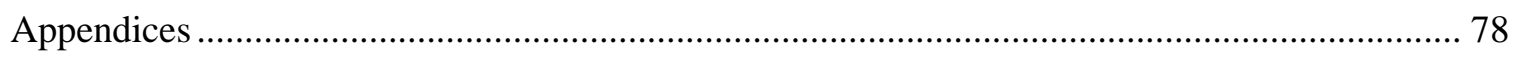

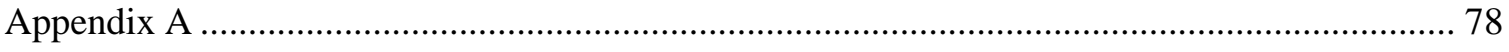

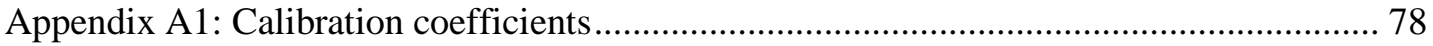

Appendix A2: Mechanical Properties of Pavement Layer Materials .................................... 80

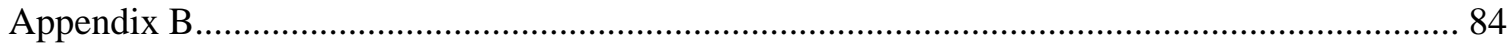

Appendix B1: DARWin-ME output for Initial Construction for Option 2 (Trial No 3) ....... 84

Appendix B2: DARWin-ME output for Initial Construction for Option 3 (Trial No 4) ....... 85

Appendix B3: DARWin-ME output for Initial Construction for Option 4(Trial No 6) ......... 86

Appendix B4 : DARWin-ME output for Initial Construction for Option 5 (Trial No 7) ...... 87

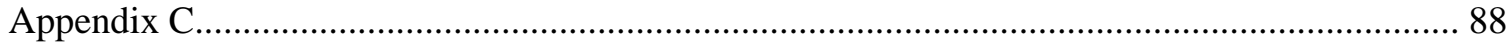

Appendix C1: DARWin-ME output for overlay for Option 2 (Trial No 3) ......................... 88

Appendix C2: DARWin-ME output for overlay for Option 3 (Trial No 4) .......................... 89

Appendix C3: DARWin-ME output for overlay for Option 4 (Trial No 6) …....................... 90

Appendix C4: DARWin-ME output for overlay for Option 5 (Trial No 7) .......................... 91 


\section{LIST OF TABLES}

Table 2-1: Economic Analysis and Design Methodologies [C-SHRP Technical Brief \# 23, April

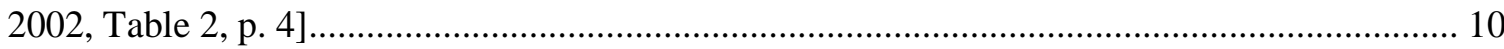

Table 2-2: Summary of work zone user costs[NCHRP (2004), Appendix C, Table C.9, p.C38] . 14 Table 3-1: Recommended minimum values for the analysis period [NCHRP (2004), Table C.1, p.

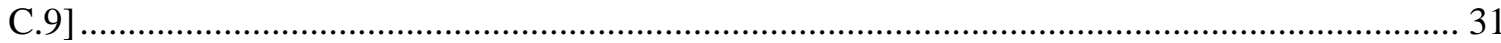

Table 3-2: Unit Costs for Initial Pavement Construction [Holt et al. (2011)] .............................. 32

Table 3-3: Unit Costs for Maintenance and Rehabilitation Activities [Holt et al. (2011)] ........... 32

Table 3-4: Performance criteria default values for flexible pavements in Ontario [MTO Interim

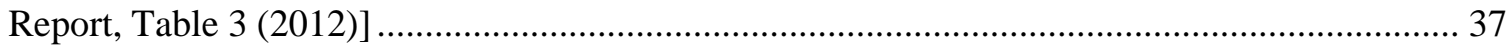

Table 3-5: Ontario typical IRI inputs values for flexible pavements [MTO Interim Report, Table 2 (2012)]

Table 3-6: Ontario Recommended Design Reliability Levels [MTO Interim Report, Table 4 (2012)]

Table 3-7: Ontario Recommended Percentage of Truck in design Lane [MTO Interim Report,

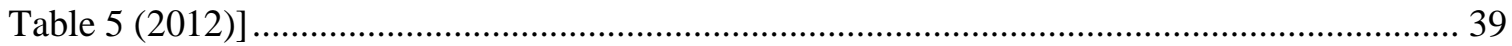

Table 3-8: Default Axle Configuration [MTO Interim Report, Table 6 (2012)]........................... 39

Table 3-9: Ontario Typical for Axle Spacing [MTO Interim Report, Table 7 (2012)] ................. 39

Table 3-10: Default values of Lateral Traffic Wander [MTO Interim Report, Table 8 (2012)] ... 40

Table 3-11: Default values of traffic distribution factors [MTO Interim Report, Table 10 (2012)]

Table 3-12: Ontario's Typical SuperPave and SMA asphalt concrete proerties [ MTO Interim

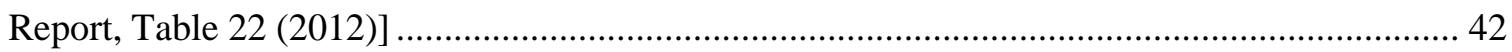

Table 3-13 Recommended Preservation Scheme for flexible pavement [ASHTO ( 2008)] ......... 45

Table 3-14: Recommended Dollar Values per vehicle Hour Delay in 2012 dollar [UDOT, (2012)]

Table 4-1: Primary input data for the reconstructed flexible pavement ...................................... 48

Table 4-2: Distress types and their respective threshold values ................................................ 51

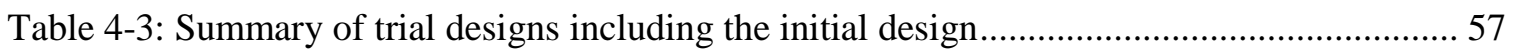

Table 4-4: Rehabilitation scheme for all the five trials (or options) ............................................. 61

Table 4-5: Life cycles of initial design and overlay (AC over AC) rehabilitation ......................... 61

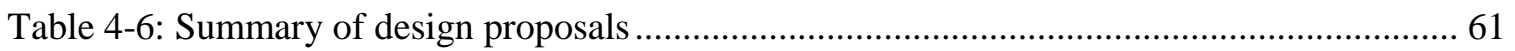

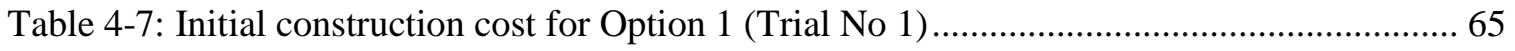

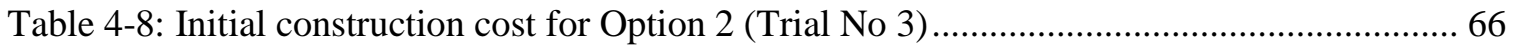

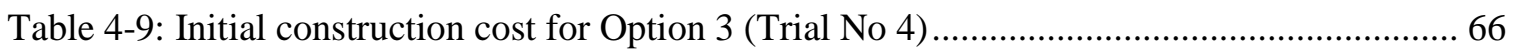

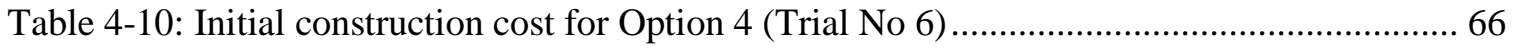

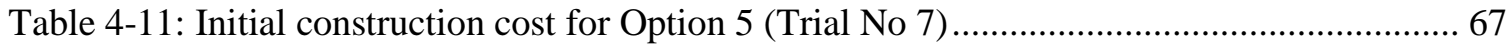

Table 4-12: Rehabilitation Action Plan [adapted from Holt et al (2011)]................................... 67

Table 4-13: Arbitrarily selected preventive maintenance and repair (PM\& R) action plan for a 50-

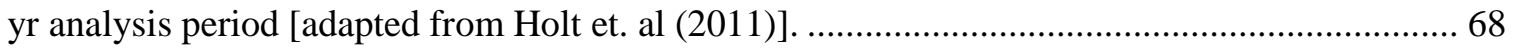

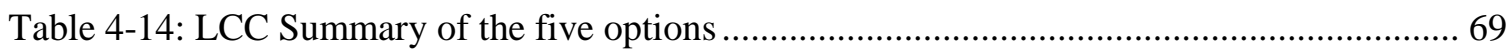




\section{LIST OF FIGURES}

Figure 2-1 Schematic diagram of life cycle cost streams of a typical pavement [Irfan (2010), Fig.

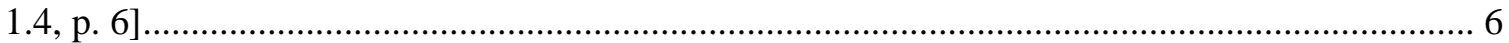

Figure 2-2 LCCA Flow Chart [Adapted from NCHRP (2004), Appendix C, Fig. C 5, P.3] ......... 7

Figure 2-3 Typical cost components used in conducting LCC of pavements .............................. 11

Figure 2-4 Design procedure of MEPDG [Adapted from Jannat (2012), Fig 2.2, p.11] ............. 20

Figure 2-5 A typical of DARWin-ME screen after completing all inputs and partway through a

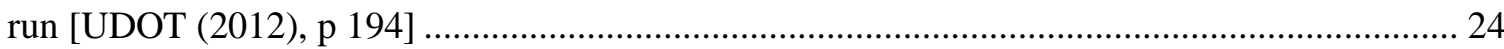

Figure 2-6 A typical summary page output of a DARWin-ME program run showing all the

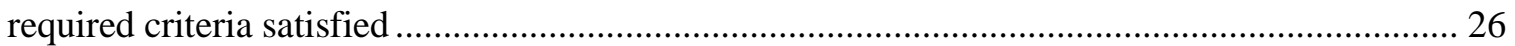

Figure 4-1 Input data for the Initial design of the reconstructed flexible pavement .................... 50

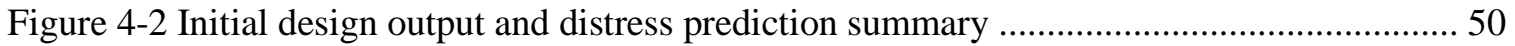

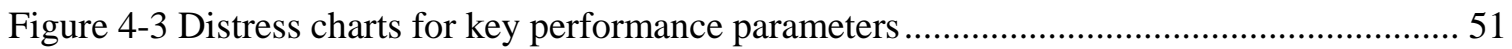

Figure 4-4 Performance level of the initial section at the age of $\mathbf{4 2}$ year ............................. 54

Figure 4-5 Performance level of the initial section at the age of 41 year ................................... 55

Figure 4-6 Distress charts for the initial design section at the age of 41 year ............................. 56

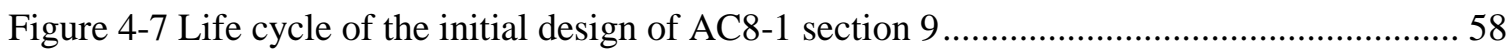

Figure 4-8 Rehab option for Trial No 1 (replaced HMA thickness $40 \mathrm{~mm}$ ) at age 33 year [IRI

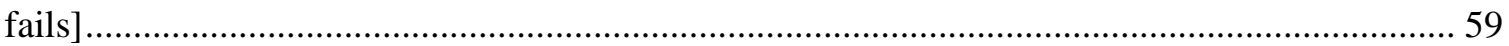

Figure 4-9 Rehab option for Trial No 1 (replaced HMA thickness $=40 \mathrm{~mm}$ ) at age 32 year....... 60

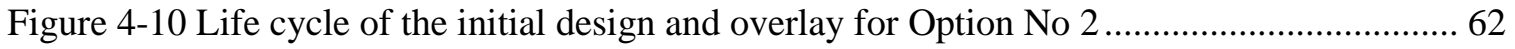

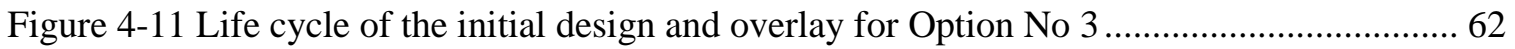

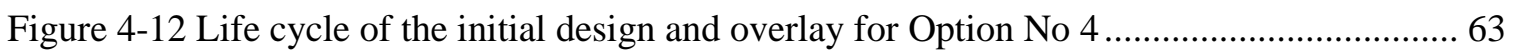

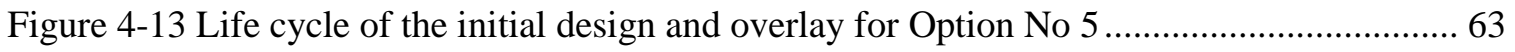

Figure 4-14 Graphical representation of LCC for the five options ......................................... 70

Figure 4-15 Indicative cost streams for Option 5 (Trial No 7) for 50 years analysis period......... 70 


\section{LIST OF ACRONYMS}

\begin{tabular}{|c|c|}
\hline AADT & Annual Average Daily Traffic \\
\hline AASHTO & American Association of State Highway and Transportation Officials \\
\hline $\mathrm{AC}$ & Asphalt Concrete \\
\hline C-SHRP & Canadian Strategic Highway Research Program \\
\hline ESALs & Equivalent Single Axle Loads \\
\hline EUAC & Equivalent Uniform Annual Cost \\
\hline FHWA & Federal Highway Administration \\
\hline HMA & Hot Mixed Asphalt \\
\hline IRI & International Roughness Index \\
\hline $\mathrm{LCC}$ & Life Cycle Costing \\
\hline LCCA & Life Cycle Costing Analysis \\
\hline MEPDG & Mechanistic-Empirical Design Guide \\
\hline MTO & Ministry of Transportation, Ontario \\
\hline NAW & Net Annualized Worth \\
\hline NCHRP & National Cooperative Highway Research Program \\
\hline NPV & Net Present Value \\
\hline NPW & Net Present Worth \\
\hline PMS & Pavement Management System \\
\hline PW & Present Worth \\
\hline
\end{tabular}




\section{Chapter 1 : INTRODUCTION}

\subsection{Background and Motivation}

The service life of a flexible pavement can be renewed and extended by doing rehabilitation such as overlays. But the advance determination of time to commence overlays and the frequency of overlays cannot be predicted unless the performance of the pavement with respect to time is known. The new Mechanistic-Empirical Pavement Design Guide (MEPDG), which is a performance based design and analysis tool, provides this opportunity to the pavement designers to predict the performance of the pavement at any time during its service life. Thus, the life cycle of a flexible road structure can be established and subsequently how many loops of life-cycles should require completing any period of analysis time continuum can be predicted by using the MEPDG methodology. Once the number of loops of life-cycles is established for a flexible pavement, the total costs also can be estimated using the techniques of life cycle costing (LCC).

Pavement design and analysis using the MEPDG is entirely software dependent and the design and analysis process is carried out with the use of software named DARWin-ME which has been exclusively developed for the MEPDG. The software offers a great flexibility to the pavement designer to consider different design features and materials to satisfy the required / targeted performance criteria, and the process can be repeated (iterated) by the pavement designer as many times as required until the desired performance criteria are met. Thus, incorporation of LCC into the new MEPDG will help the following: 
1. Determine the life cycle and the associated cost of a flexible pavement structure for a given analysis period.

2. Establish a shorter or longer frequency of rehabilitation scheme by selecting/changing overlay thickness and subsequently estimate the associated costs of a flexible pavement structure.

3. Establish the initial design and the associated cost by selecting/changing suitable material and layer thickness for a given frequency of life cycle.

4. Determine / predict the serviceable life or remaining service life of an existing flexible pavement.

\subsection{Objective and Significance of the Study / Project}

The objective of the project is to develop framework to determine the life cycle of a flexible pavement using the MEPDG methodology and estimate the LCC of the flexible pavement thus finding the economic design of a flexible pavement.

Although the AASHTO 1993 pavement design guide and other versions of pavement design guides had been used previously to do LCC for flexible pavements, the accuracy of the resulting costs is often a big concern because of the poor capability of those design guides in predicting the long-term performance along the pavement's life cycle. The use of MEPDG overcomes these limitations. The significance of integration of LCC into the new MEPDG methodology offers a great opportunity to obtain a better economic evaluation with a more accurate prediction of pavement distresses of an optimal structural design of a flexible pavement that can help the pavement agencies in following ways: 
- Select a life cycle (i.e., rehabilitation or overlay) strategy that is suitable to the transportation agencies

- Effective planning of budget and resource allocation for the future restoration/preservation scheme of pavements since the life cycle of the pavement is known.

\subsection{Scope and Methodology of the Study / Project}

The scope of study for this project for integration of LCC into the new MEPDG is limited to the flexible pavement only, and will include the following:

- Review the theories, principles and current state-of-the-art practices of LCC for flexible pavements.

- Review the new MEPDG methodology and associated software DARWin-ME for the analysis and design of flexible pavements.

- $\quad$ Carry out LCC of a flexible pavement road section using DARWin-ME

The study includes a case study of a selected flexible pavement section for which the DARWin-ME input parameters are taken from a section used by Waseem (2013) in his local calibration study.

\subsection{Outline / Organization of Report}

The organization of the report has been arranged in five chapters and is structured in the following order:

- Introduction and background/motivation have been presented in Chapter 1.

- A comprehensive literature review of LCC and MEPDG relevant to flexible pavements have been presented in Chapter 2. Topics covered in this chapter include 
fundamental concepts, techniques and the state-of-the-art practices of LCC currently being used in the pavement maintenance and rehabilitation, the basic concepts and the theories of MEPDG and the associated DARWin-ME software pertinent to the design and analysis of flexible pavements.

- Chapter 3 provides the framework and development of a methodology for the LCC of the MEPDG-based flexible pavements.

- A case study for LCC of the MEPDG-based flexible pavement analysis and design for a reconstructed flexible pavement section has been presented in Chapter 4 .

- Results, conclusions and recommendations of the study have been discussed in Chapter 5. 


\section{Chapter 2 : LITERATURE REVIEW}

This chapter provides a detailed literature review on LCC, the MEPDG and the associated software DARWin-ME which are relevant to flexible pavements only. The primary objective of this literature review is to:

- Study the concepts, theories and the state-of-the-art practices currently being used for LCC for the economic evaluation of flexible pavements.

- Study the concepts, theories, and practices of the MEPDG.

- Familiar with the operating software DARWin-ME for the MEPDG analysis and design of flexible pavement for new and overlay / rehabilitation projects.

These are presented in the following sections in a sequence.

\subsection{LCC for Flexible Pavement}

\subsubsection{Concept and Definition of LCC}

Concept of LCC - The decision to construct a new flexible pavement from two or more alternatives (or proposals) requires the ability to predict their performance and quantify their economic implications. Similarly, decisions for routine repair and maintenance and future rehabilitation activities for existing flexible pavements require economic analysis to ensure the best utilization of available funds [Papagiannakis and Masad, 2008]. In both cases, LCC is expected to reduce the total cost by selecting the suitable alternatives with economic designs and components to the total cost of service, maintenance, rehabilitation and disposal/salvage value including the initial cost of design, procurement and construction [Riggs et al. (1997)]. 
Definition of LCC - LCC stands for both Life Cycle Cost and Life Cycle Costing, where the former is defined as the sum of all costs incurred during the life span of the project [Dhillon, 2010], and the latter is defined as the process and technique to estimate that total cost. In this report and hereafter, LCC is referred to as Life Cycle Costing.

As defined by Dell'isola and Kirk (1981): "LCC is an economic assessment of an item, system, or facility, considering all the significant costs of ownership over its economic life, expressed in terms of equivalent dollars. It is a technique that satisfies the requirements for adequate analysis of total costs". LCC is considered to be an aid in budgeting and decision making.

The main objective of LCC is to obtain money value of a project in terms of present worth dollars comprising of the investment (initial) costs and the upkeep costs (i.e., preventive maintenance and rehabilitation (PM \& R) costs) for the economical evaluation and comparison of alternative projects / proposals over the same analysis period which would help in Life Cycle Costing Analysis (LCCA) to provide a vital piece of decisionmaking information in the Project Management System (PMS) [NCHRP (2004)]. Figure 2-1 below shows life cycle cost streams for a typical pavement economic analysis.

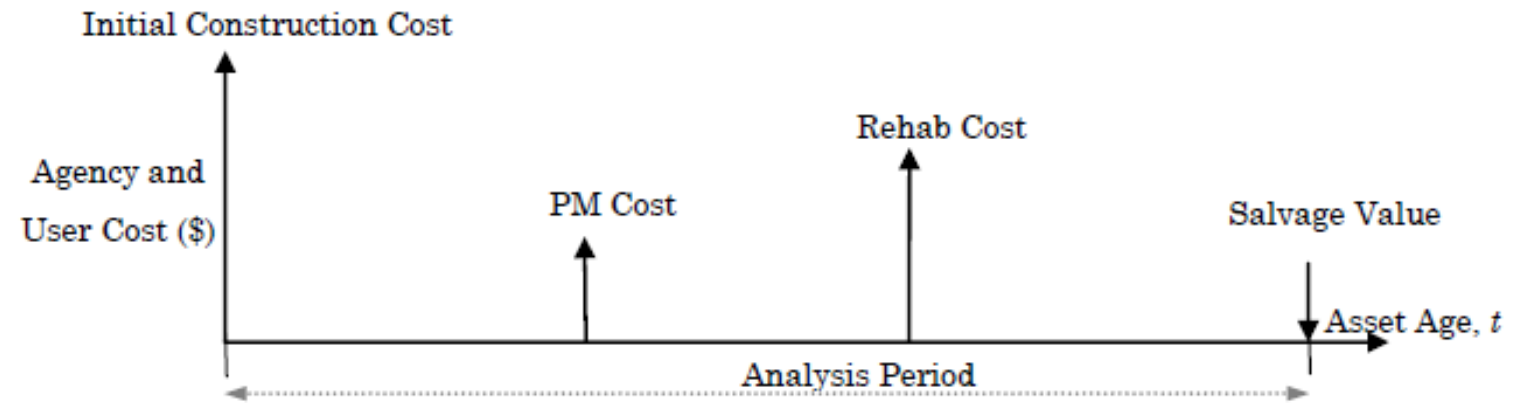

Figure 2-1 Schematic diagram of life cycle cost streams of a typical pavement [Irfan (2010), Fig. 1.4, p. 6] 
The basic difference between LCC and LCCA is that LCCA is a systematic process of conducting the economic analysis / evaluation while LCC is the economic indicator of the process. LCCA consists of well-defined sequential steps to determine the project's feasibility while LCC involves engineering economics to yield the economic or fiscal result of the LCCA.

Definition of LCCA - LCCA is simply defined as "a form of economic analysis used to evaluate the long-term economic efficiency between alternative investment options" [NCHRP, Appendix C]. However, a more detailed definition has been given by the US Federal Highway Administration (FHWA, 2001) as follows: "LCCA is an analysis technique that builds on the well-funded principles of economic analysis to evaluate the over-all long-term economic efficiency between competing alternative investment options. It does not address equity issues. It incorporates initial and discounted future agency, user, and other relevant costs over the life of alternative investments. It attempts to identify the best-value (the lowest long-term cost that satisfies the performance objective being sought) for investment expenditures" [Gransberg (2004)].

The sequential steps of LCCA for pavements are shown in Figure 2-2 below

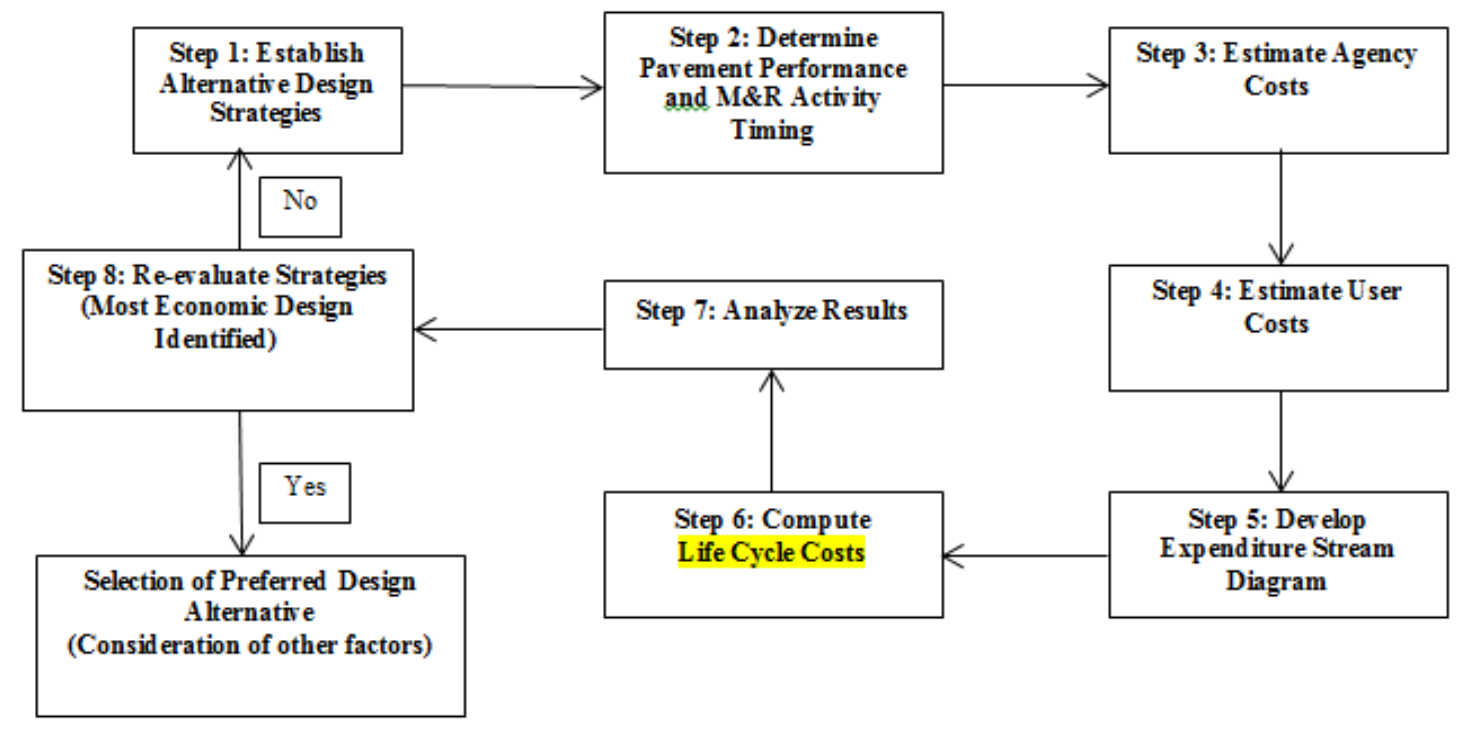

Figure 2-2 LCCA Flow Chart [Adapted from NCHRP (2004), Appendix C, Fig. C 5, P.3] 


\subsubsection{Historical Developments}

Although the concept of LCC was emerged during 1930s in the US, its actual recognition happened in the 1960s when the US government agencies adopted the concept as a means of enhancing the cost-effectiveness for the procurement of equipment. A brief chronological evolving of LCC has been presented below [Dell'isola and Kirk (1981)]:

- The General Accounting Office (GAO) of the United States used LCC for the bids of tractor acquisitions in 1933.

- During 1950s the American Telephone and Telegraph Company (AT\&T) adopted LCC for making comparative cost studies on their products.

- The guidelines for LCC were published in 1972in the US by Department of Deference for procuring equipment.

Since then, LCC has spread and adopted by many other countries for both project evaluation and product development studies [Dell'isola and Kirk (1981), Riggs et al. (1997)].

As mentioned by Guven (2006) and Reigle (2000) that for the economic evaluation of pavements, the US transportation agencies using federal fund often must conduct LCCA to justify their planning and design decisions [Guven (2006), Reigle (2000)]:

- It was a legislative requirement in the US according to the Intermodal Surface Transportation Efficiency Act of 1991 (ISTEA) to use of LCC in the design and engineering of bridges, tunnels, or pavements for both metropolitan and state wide transportation planning.

- $\quad$ The US National Highway system designation Act of 1995 required that the states to conduct an LCCA for each proposed National Highway System (NHS) project segment costing \$25 million or more.

- The 1998 Transportation Equity ACT for the $21^{\text {st }}$ Century, TEA-21, has removed the requirement to conduct LCCA in transportation investment decision making. 
However, it is still the intent of FHWA to encourage the use of LCCA for National Highway System (NHS) projects.

- The National Cooperative Highway Research Program's (NCHRP) 2003 report states that Federal Executive order 12893 (January 1994), required all federal agencies to use a "systematic analysis of expected benefits and cost ..... approximately discounted over the full life cycle of each project" in making major infrastructure investment decisions (NCHRP,2003).

\section{Status of LCC and the State-of-the-Practices of LCC in Canada}

According to survey report on LCCA, conducted by the University of Saskatchewan Civil Engineering Professor Dr. Gordon Sparksstates that Ontario has used LCC methods extensively for more than 25 years while Alberta, Manitoba and some other provinces have extensive experiences of using LCC for many years, where New Brunswick was planning to implement an asset management system by 2007, and Newfoundland and Labrador does not typically uses LCCA, but had hired a consultant to perform LCCA of alternative asphalt surface types for major projects [Guvan (2006)].

The Canadian Strategic Highway Research Program (C-SHRP) Technical Brief \# 23 dated April 2002 provides a good summary of state-of-the-art practices being used by the Canadian pavement agencies in different provinces for the economic analysis and design methodologies of flexible pavements across Canada. The summary is given in Table 2-1 below. In this this report, the 7\% discount rate is used although Ontario's discount rate for the year 2011 has been 5\% as reported by Holt [Holt et al., (2011)] and may be considered as the current discount rate for Ontario, and a 50-year period has been used for the economic analysis in order to define the pavement's life cycle which includes the initial service life and at least one overlay (major rehabilitation) activity. 
Table 2-1: Economic Analysis and Design Methodologies [C-SHRP Technical Brief \# 23, April 2002, Table 2, p. 4]

\begin{tabular}{|c|c|c|c|c|c|c|}
\hline \multirow[t]{2}{*}{ Agency } & \multirow[t]{2}{*}{ General Design Method(s) } & \multirow{2}{*}{$\begin{array}{c}\text { Design Life } \\
\text { (years) } \\
\text { New/Rehabilitation }\end{array}$} & \multicolumn{4}{|c|}{ Economic Analysis } \\
\hline & & & $\begin{array}{l}\text { Analysis } \\
\text { Method }\end{array}$ & $\begin{array}{l}\text { Period } \\
\text { (years) }\end{array}$ & $\begin{array}{c}\text { Discount } \\
\text { Rate } \\
(\%) \\
\end{array}$ & $\begin{array}{c}\text { Include } \\
\text { Salvage } \\
\text { Value? }\end{array}$ \\
\hline Alberta* & $\begin{array}{l}\text { AASHTO '93 } \\
\text { (new \& rehab) }\end{array}$ & $20 / 20$ & Present Worth & 30 & 4 & Yes \\
\hline Saskatchewan** & $\begin{array}{l}\text { Shell Method*** } \\
\text { Asphalt Institute }\end{array}$ & $15 / 15$ & Present Worth & 30 & 4 & Yes \\
\hline Manitoba & $\begin{array}{l}\text { AASHTO'93 } \\
\text { (new construction) } \\
\text { Asphalt Institute } \\
\text { (rehabilitation) } \\
\end{array}$ & $20 / 20$ & Present Worth & 30 & 5 & Yes \\
\hline Ontario & $\begin{array}{l}\text { AASHTO '93 } \\
\text { Asphalt Institute } \\
\text { Ontario Standards }\end{array}$ & $20 / 20$ & Present Worth & 30 & 7 & No \\
\hline New Brunswick & $\begin{array}{l}\text { AASHTO ' } 93 \\
\text { (now being considered for } \\
\text { implementation) } \\
\text { Rebound Values } * * * *\end{array}$ & $20 / 15$ & N/A & - & - & - \\
\hline Prince Edward Island & $\begin{array}{l}\text { Asphalt Institute } \\
\text { Thickness Design }\end{array}$ & $20 / 12$ & N/A & - & - & - \\
\hline Nova Scotia & $\begin{array}{l}\text { AASHTO '93 } \\
\text { Correlation Charts } \\
\text { using AADT \& Grain size } \\
\text { of subgrade }\end{array}$ & $20 /-$ & - & - & - & - \\
\hline
\end{tabular}

* Economic analysis not conducted between alternate pavement designs at time of construction. All pavements are considered to be an asphalt layer over a granular base layer unless traffic is extremely high at which point a subbase layer is considered.

** In Saskatchewan, most Rehabilitation projects are based on lowest initial cost and not Present Worth.

*** The structural design method used in Saskatchewan for flexible pavement employs Shell design charts calibrated so that actual thickness of granular base and subbase materials used are reflected in the curves.

**** Currently use rebound values (Dynaflect converted to Benkelman Beam values). 


\subsubsection{Cost Components for the LCC for Pavements}

The economic evaluation of the feasible maintenance and /or rehabilitation treatments of a pavement require costs of all components that are directly and indirectly influence the overall cost of the pavement. The cost components for conducting LCC for pavements are classified into two basic categories which include many other types of costs [TACPDMG (1997), NCHRP (2004)]:

1. Agency costs (also called direct cost), and

2. User costs (also known as indirect cost)

The hierarchical of costs components that are used in conducting LCC of a typical pavement are shown below in Figure 2-3.

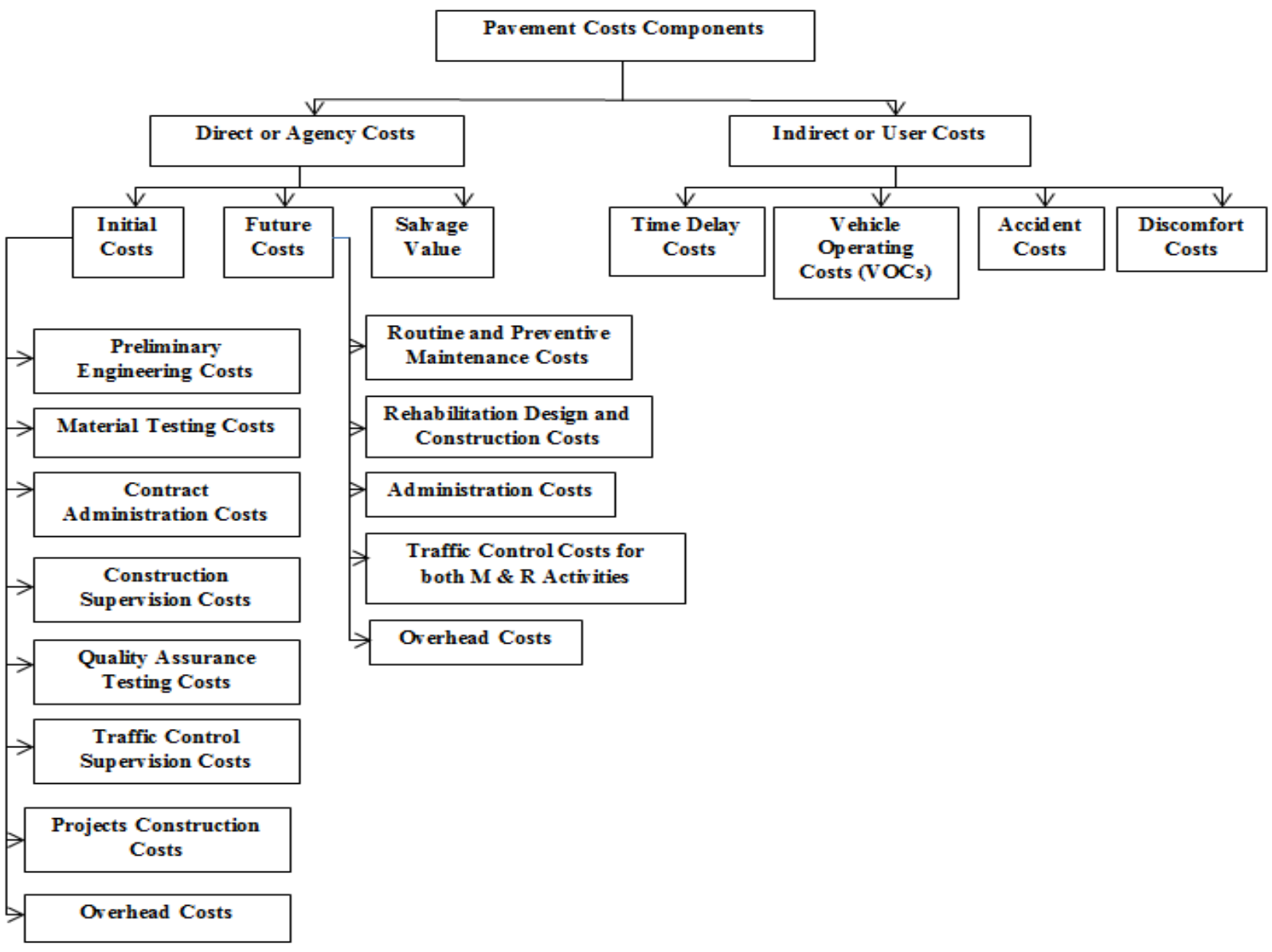

Figure 2-3 Typical cost components used in conducting LCC of pavements 
Agency costs: They are referred to as those costs which are incurred directly by the agency over the life of the pavement. Usually, agency costs are easy to quantify and therefore yield better estimation with respect to the actual cost. In general, agency costs are estimated based on unit prices which can be determined from historical data on previously bid jobs. Agency costs are subdivided into three groups and include the following types of costs. Basic economic formulas are commonly used to determine such agency costs [TAC-PDMG (1997), NCHRP (2004), UDOT (2012)]:

a) Initial costs - these costs are engineering and administrative in nature and include preliminary engineering, material testing and analyses, contract administration, construction supervision and quality assurance testing, traffic control supervision and construction cost of the project. Determination of accurate initial costs is possible only if the transportation agency maintains adequate accounting records including the overhead costs.

b) Future costs-these costs are future expected costs that would require to keep the pavement safe and serviceable against the anticipated distresses the pavement may experience, and include routine and preventive maintenance activities costs, rehabilitation design and construction costs, traffic control cost, administrative cost, and overhead cost. Cost of the routine and preventive maintenance is usually estimated based on the historical experience of the pavement management system (PMS). The rehabilitation scheme depends on pavement performance and is determined based on the performance analysis of the pavement.

c) Salvage value - it is the asset value (or remaining value) of the pavement at the end of the analysis period. There are two components which are used in 
estimating the salvage value [Guven (2006)]: (i) the first one is the residual value that refers to the net value from recycling the pavements [Walls and Smith, 1998], and (ii) the other component is the serviceable life, which is the remaining life in a pavement at the end of analysis period. The recommended methods of estimating salvage value of pavements include Prorated Life method and Reusable Material Value Method. According to the FHWA, the value of the pavement is determined by multiplying the cost of the latest rehabilitation activity by the percent design life remaining at the end of the analysis period [Guven, (2006)]. However, estimation of pavement salvage value is difficult to determine because of the complexity in estimating the actual value of the pavement materials in terms of reuse or discard to the designated location.

User costs: They are referred to as those costs which are incurred by the highway users over the service life of the pavement. In general, these are the cost that each driver would incur for using a highway system and the excess costs incurred by the user as a result construction/maintenance factors (e.g., detour requirements). These are very difficult to quantify and therefore yield estimation with higher margin. The estimation of these components involves different empirical formulas and procedures which have been established through experiments, and regression analysis of historical data. The RealCost software version 2.1, developed by the US FHWA Office of Asset Management, provides recommended process to estimate such costs and it requires lots of input data such as work zone duration, work zone length, hours of operation, work zone capacity, speed limit, numbers of lane open in each direction during construction activities, cars as percent of annual average daily traffic (AADT), single truck as percentage of AADT, 
speed limit under normal operating conditions, hourly traffic distribution, value of time for passenger cars and trucks, length of queue, etc.[Guven (2006)]. The user costs are comprised of the following cost components [TAC-PDMG (1997), NCHRP (2004)]:

a) Time delay costs - these costs are associated with the motorists delay costs due to road closure, traveling extra distance or rough detours.

b) Vehicle operation costs (VOCs) - associated with fuel consumption, tire wear, emissions, maintenance and repair, and depreciation due to pavement roughness

c) Accident costs - associated with the accidents due to rough or slippery roads and with the increased rate of accidents in construction zones

d) Discomfort costs - associated with rough roads

However, the current Pavement Design Guide recommends inclusion of time delay cost and vehicle operating costs in the LCCA of pavements [NCHRP (2004), Appendix C (p.10-11)]. LCCA2002 spread sheet program also used to estimate such user costs, and the total work zone user costs are summarized in tabular form in Table C.9 of Appendix C [NCHRP (2004)]. A typical format of table C.9 is shown below.

Table 2-2: Summary of work zone user costs[NCHRP (2004), Appendix C, Table C.9, p.C38]

\begin{tabular}{|l|l|l|l|l|}
\hline \multicolumn{1}{|c|}{ User Cost Components } & Passenger & \multicolumn{2}{c|}{ Trucks } & \multirow{2}{*}{ Totals, \$ } \\
& Cars & Single-unit & Combination & \\
\hline Work Zone (WZ) reduced speed delay & & & & \\
\hline Speed change delay & & & & \\
\hline Speed change Vehicle Operating Cost (VOC) & & & & \\
\hline Queue stopping delay & & & & \\
\hline Queue stopping VOC & & & & \\
\hline Queue idling VOC & & & & \\
\hline Queue reduced speed delay & & & & \\
\hline
\end{tabular}




\subsubsection{Analysis Techniques of LCC}

Several types of universally accepted economic models/formulas exist for the economic feasibility analysis of pavement projects. These models (mathematical equations) yield the common base of economic comparison between the projects/proposals in different formats. These economic models are being used by transportation agencies in many countries for comparing and selecting the most economic pavement alternatives. These models are also known as economic indicators, which include [TAC-PDMG (1997), NCHRP (2004), Haas et al (1997), Papagiannakis and Masad (2008), Guven (2006), Mazan (2002)]:

1. Present Worth (PW) method or Net present Worth (NPW) or Net Present Value (NPV) method (i.e., net benefits minus net costs method)

2. Equivalent Uniform Annual Cost (EUAC) method or Net Annualized Worth (NAW) method

3. Benefit over Cost Ratio (BCR) method

4. Incremental Benefit over Cost Ratio (IBCR) method

5. Rate-of-Return (RR) method

6. Incremental Rate-of-Return (IRR) method

The choice of appropriate indicator depends on the management, type of project and the number of alternatives to be compared, the degree of analysis required and the context of analysis (i.e., economic environment) in which the analysis is carried out. The type of economic techniques (indicators) used in different provinces across Canada are given earlier in Table 2-1.

Of the six economic evaluation methods mentioned above, the most common indicators used by the most transportation agencies are NPW (or NPV or PW) and EUAC, which are described below. 


\section{Present Worth (PW) or Net Present Worth (NPW) method}

(a) The PW is the present discounted monetary value of expected net benefits. This method consists of translating streams of benefits and costs into present worth (i.e., time zero) and calculate the net present worth of benefits minus costs.

(b) It can be used to determine the feasibility of a single alternative or to compare two or more alternatives, whereby the alternative with the largest NPW is best.

(c) It can also be used to compare two alternatives that have the same benefits, which is referred to as a fixed output comparison. The alternative with the lowest present worth of cost is best.

However, the PW comparisons are valid only when the length of analysis period of the alternatives is identical.

\section{Net Annualized Worth (NAW) or Equivalent Uniform Annual Cost (EUAC) method}

(a) The NAW method consists of translating streams of benefits and costs into equivalent annual amounts and calculates the net annual worth of benefits minus costs.

(b) It can be used to determine the feasibility of a single alternative or to compare two or more alternatives, whereby the alternative with the largest NAW is best.

(c) Similar to the PW method, NAW can be used to compare two alternatives that have the same benefits, which are referred to as a fixed output comparison. For the latter, the alternative with the lowest net annualized worth is best.

(d) Since annual costs and benefits are compared, there is no requirement that the alternatives have the same service lives. It is a preferred indicator when budgets are established on the annual basis. 


\section{Software for LCC of Pavements}

Over the years and with the benefits of computer usage, many organizations have developed software to conduct LCC, such as LCCA2002 spreadsheet program, which is operated in Microsoft Excel and uses Visual basic programming functions [NCHRP, 2004]. Other models, which have been developed for life cycle cost analysis of pavements, include the following [Zhang et al. (2010)]:

- RealCost, developed by the US FHWA Office of Asset Management (2004)

- PaLate, developed by Horvath et al. (2004)

\subsubsection{Risk and Uncertainty in the LCC of Pavements}

One of the two approaches namely deterministic or probabilistic is adopted in the LCCA procedures for the economic evaluation of pavements. As mentioned in the FHWA: "the deterministic analysis treats all inputs, estimates, projections, and assumptions as discrete values and computes a discrete NPV, that is, a single value is selected for each input parameter and the group of selected values are then used to compute a single projected life cycle cost”[NCHRP (2004), Appendix C].

In the probabilistic approach, life cycle costing analysis (LCCA) procedure utilizes the processing capabilities of today's computers to simulate and subsequently account for the simultaneous changes of input parameters. The probabilistic approach entails defining individual input parameters by a frequency (or probability) distribution, rather than by discrete values. For a given design strategy, sample input values are randomly drawn from the defined frequency distributions and the selected values are used to compute one forecasted life cycle value. The sampling process is commonly performed using Monte Carlo or Latin Hypercube techniques. The most commonly used frequency distributions 
in probabilistic LCCA are the normal and triangular distributions, with related variations. Values needed to define the normal distribution include the mean and standard deviation, whereas those needed to define the normal distribution include the minimum, maximum, and most likely values [Mallick and Korchi (2009); NCHRP (2004), Appendix C].Thus, the probabilistic approach intends to address the uncertainties in the inputs which has great effect on the overall LCC of a project.

However, analyses of uncertainties associated with the inputs (future costs, discount rate, and year of rehabilitation etc.) are not included in this study, and a deterministic approach has been followed throughout this report in the LCC process of flexible pavements.

\subsection{MEPDG - Concepts and Fundamentals}

As described in AASHTO (2008): "Mechanistic-Empirical Pavement Design Guide (MEPDG) is a state-of-the practice tool for the design and analysis of new and rehabilitated pavement structures, based on mechanistic-empirical(M-E) principles which means that the design and analysis procedure calculates pavement responses (stresses, strains, and deflections) and uses those responses to compute incremental damage over time. The procedure empirically relates the cumulative damage to observed pavement distresses".

As the name implies, the MEPDG methodology is comprised of two parts design aspects, namely: (a) mechanistic part, and (b) empirical part [NCHRP (2004), AASHTO (2008)].

(a) Mechanistic part (or components) - based on the application of the theories and principles of engineering mechanics, which uses a mathematical model (mathematical equations) to calculate pavement responses (stresses, strains, and 
deflection) due to loading for the predictions of the pavement performance history [AASHTO (2008), Jannat (2012)].

(b) Empirical part (or components) -based on the historical data or field/laboratory tests and relates the pavement response (stresses, strains, and deflections) to pavement's physical performance (distresses) [AASHTO (2008), Jannat (2012)].

The end result of the MEPDG model does not provide a design thickness of the pavement; rather it provides the performance of the pavement throughout its design service life in the form of some predetermined performance parameters. These performance parameters are then compared with the real values either determined from the laboratory tests or from PMS historical data [AASHTO (2008)].

The application of MEPDG methodology requires use of a software named DARWin-ME which has been exclusively developed for the purpose of MEPDG. The DARWin-ME can be described as follows: First, the traffic, climate, pavement structure are selected from the default database of DARWin-ME (or imported from other source files) to use as input parameters for the initial / trial design. Then, pavement performance parameters for the following distresses are predicted by running the DARWin-ME and compared with the values achieved [AASHTO (2008)]:

\section{- Terminal IRI}

- Permanent deformation of total pavement

- Asphalt Concrete (AC) bottom-up cracking (Alligator cracking)

- Total cracking (Reflective + Alligator)

- AC thermal fracture

- AC top-down fatigue cracking (Longitudinal cracking)

- Permanent deformation - AC only

- Chemically stabilized layer - fatigue fracture [if applicable] 
Figure 2-4 below shows the step-wise design procedure of the MEPDG using DARWinME design software.

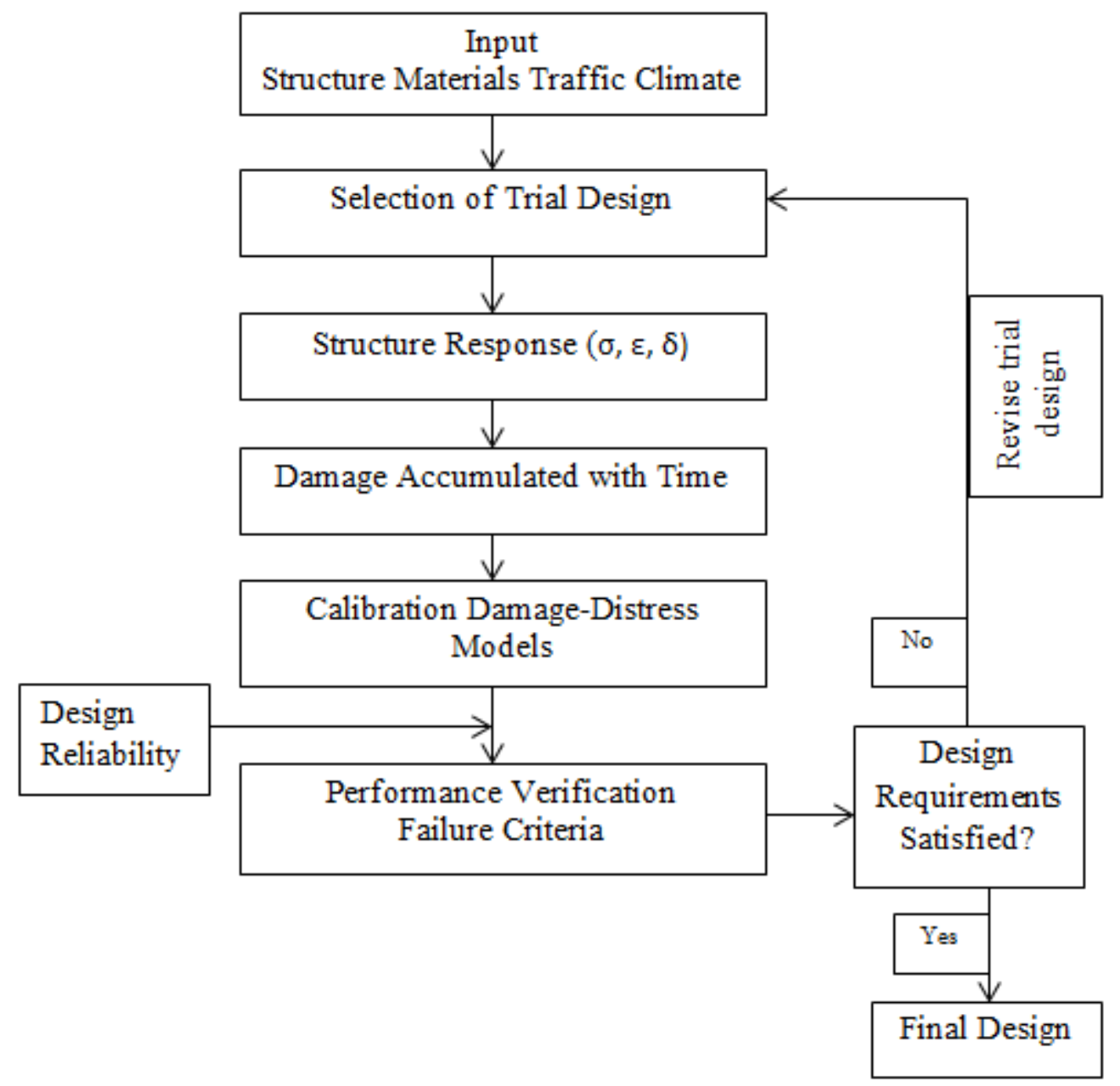

Figure 2-4 Design procedure of MEPDG [Adapted from Jannat (2012), Fig 2.2, p.11]

\subsubsection{Historical Development of the Pavement Design Methods and MEPDG}

The history of Mechanistic-Empirical Pavement Design Guide (MEPDG) itself is very short compared to the other pavement design methods. Although the concept of MEPDG emerged during mid-1990s, and the accumulation of information, data and process of establishing MEPDG had been surfaced almost a decade ago, but the current form of MEPDG was developed and published in the year 2004 under the patronage of 
AASHTO. A brief chronology of the evolution of pavement design has been given below which provides a historical background of MEPDG [TAC-PDMG (1997), Jannat (2012)]:

- The first empirical design methods for the flexible pavements emerged in the US during themid-1920 when the first soil classification were developed. The design was primarily accomplished based on experience.

- The California Bearing Ratio (CBR) method was developed in 1929 by the California Highway Department. CBR method is a strength-based design method and uses the concept of shear strength (or load-deformation) characteristics of the road bed soils, aggregate susbbase, and base materials, and an empirical design chart to determine the structural thickness of the pavement layers. CBR states the quality of the material in terms of an excellent base course (which is the standard crushed rock base) that has a CBR of 100. Once the CBR for the roadbed soil (subgrade) and other layers (subbase and base layers) are known, the thickness of overlying material can be determined to provide a satisfactory pavement.

- The Road Test Design methods, which may be considered as the foundation of today's AASHTO pavement design, started to take into shape during mid-1940s until late 1950s and the first AASHTO Interim Design guide for the Design of Pavement Structures was published in 1972, which is based on the results of road tests and subsequent formulation of empirical equations using regression analysis of the roadtest results adopted form 1950s.

- With the increase of traffic and availability of more tests data, the Interim Guide was up-dated/improved in 1986 and 1993 with the addition of material input parameters and design reliability. Most of the pavements, which are in use today have been 
designed and constructed as per AASHTO $(86,93)$ guides. With the advent of computer, the AASHTO (93) Guide even introduced software supported design method known as DARWin. The acronym of DARWin for Pavement is Design,

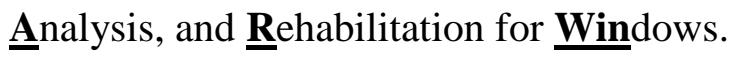

- To overcome the limitations in the empirical design equations in AASHTO $(86,93)$ and also to utilize mechanistic-based models and database relevant to the current state of knowledge of highway performance resulted in the formulation of MechanisticEmpirical Pavement Design Guide (MEPDG) under the directive of National Cooperative Highway Research Program (NCHRP) (Project1-37A) sponsored by the American Association of State Highway and Transportation Officials (AASHTO) in 2002. The final and current version of the guide was published in 2004. This current version is also known as AASHTO 2008 pavement design guide.

Although the aforementioned historical developments represent mainly the AASHTO developed pavement design methods / guides, Canada also developed its own pavement design guides which are still being followed across the country. In fact, Canada has its own long and proud history of building pavements as described in TAC - PDMG (1997):

- The granolithic pavement was built in Toronto in 1886 , which consisted of $150 \mathrm{~mm}$ bed of concrete with a wearing surface of cement and granite chips. The construction of first asphalt surface was recorded in 1888. The effort to construct highway began in early 1900s, and in recognition of this effort, the Trans-Canada Highway was built in 1950s.

- For the province of Ontario, the developed pavement design method is referred to as "Ontario Pavement Analysis of Costs (OPAC) Method [MTO 90]" was developed in 
early 1970s, which is supported by a computerized system. OPAC is a deflectionbased design method. The earlier version of OPAC has been improved and the new "OPAC 2000" is also used for pavement design in Ontario alongside the AASHTO methods [TAC-PDMG (1997)].

However, many highway agencies including Ministry of Transportation Ontario (MTO) are bracing for the adoption / implementation of MEPDG as the future pavement methodology. Currently, extensive activities are in progress in terms of data collection and calibration of the data in order to complete database for the empirical aspect of the design formulas and update the design/analysis software called DARWin-ME exclusively developed for the MEPDG.

\subsubsection{MEPDG Design Software}

The MEPDG is a software based pavement design and analysis methodology which cannot be implemented without computer use. The name of the MEPDG associated software is DARWin-ME, which is the next generation of AASHTOWare ${ }^{\circledR}$ pavement design software and has been developed as part of NCHRP project by AASHTO and NCHRP. The DARWin-ME analyzes inputs of a given trial design and predicts the performance of the trial design for the input design life in terms of key distress types and smoothness. To meet the targeted performance and reliability, the initial (or the trial) design input parameters may need to modify (i.e., re-entered as input). For this reason in MEPDG, a selected trial design is performed first to determine whether it meets the criteria of targeted performance.

The basic steps included in the MEPDG design process are listed below:

(1) Select a trial design strategy 
(2) Select the appropriate performance indicator criteria (threshold value) and design reliability level for the project

(3) Obtain all inputs for the pavement trial design under consideration

(4) Run the MEPDG software and examine the inputs and outputs for engineering reasonableness

(5) Revise the trial design, as needed

The key components of the DARWin-ME software for flexible pavement design requires the inputs of general project information, performance criteria, design life, pavement layers and materials, traffic, climate, and pavement design features/properties. Figure 2-5

below shows a typical DARWin-ME screen.

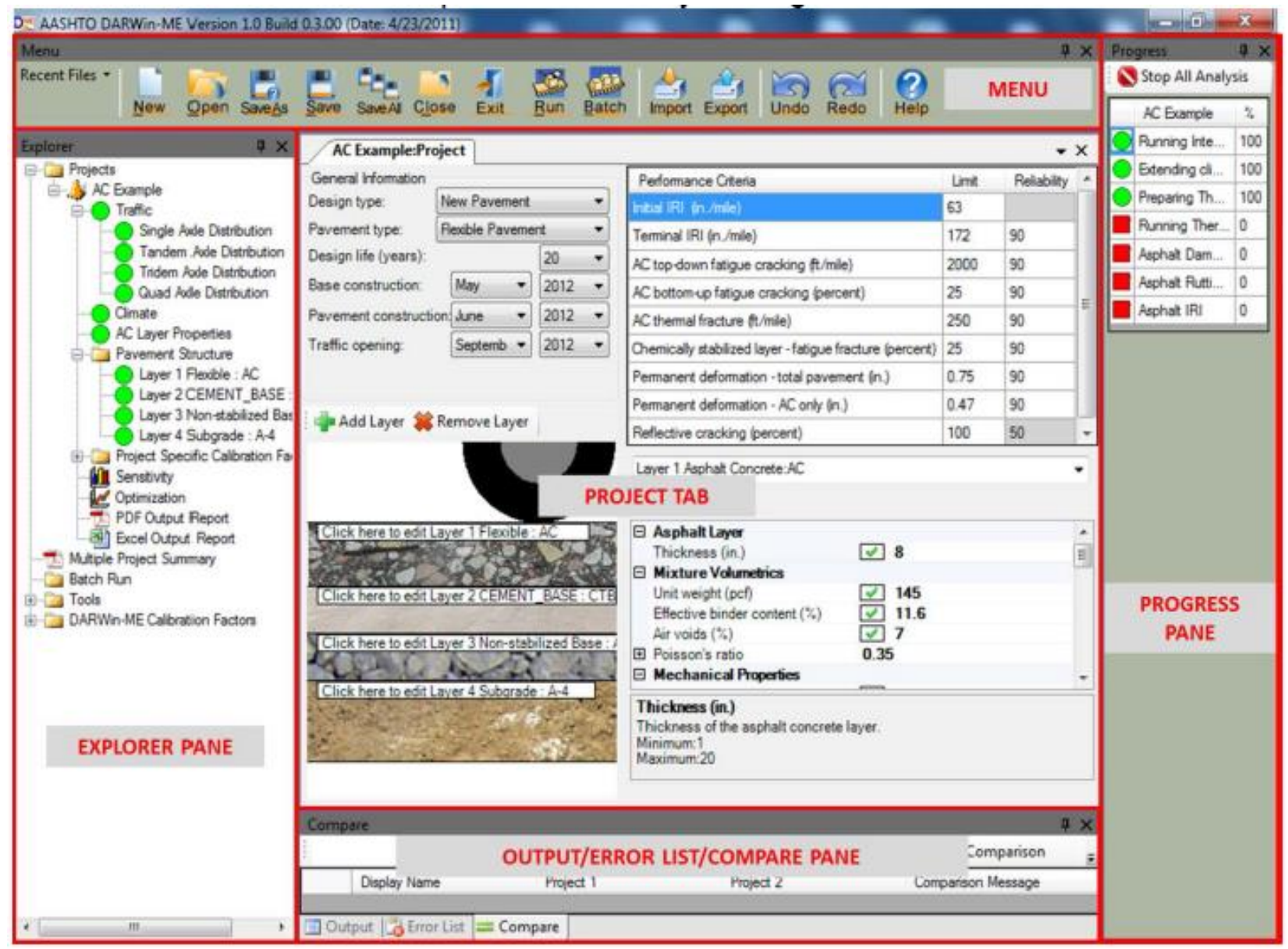

Figure 2-5 A typical of DARWin-ME screen after completing all inputs and partway through a run [UDOT (2012), p 194] 


\subsubsection{Output/Result of the MEPDG}

The final result or the output of the DARWin-ME is available by default in the following two formats [Jannat (2012)]:

- PDF (Portable Document Format)

- Microsoft Excel

The data contained in these outputs include input summary, climate summary, design pass/fail checks, material properties summary, distress and smoothness prediction summary and charts. The final results of the MEPDG are the pavement performance throughout the design service life of the pavement, not the design thicknesses of the pavement structure. Thus the output of the DARWin-ME software is a prediction of the distresses and smoothness against the set reliability targets. For flexible pavement the following performance prediction indicators are obtained.

\begin{tabular}{|l|c|}
\hline \multicolumn{1}{|c|}{ Distress Type } & Unit in MEPDG \\
\hline Terminal IRI & $\mathrm{m} / \mathrm{kM}$ \\
\hline Permanent deformation - total pavement & $\mathrm{mm}$ \\
\hline Total cracking (Reflective + Alligator) & percent \\
\hline AC - Bottom up fatigue cracking & percent \\
\hline AC top down fatigue cracking & $\mathrm{m} / \mathrm{kM}$ \\
\hline Permanent deformation - AC only & $\mathrm{mm}$ \\
\hline
\end{tabular}

These performance prediction indicators actually represent the following performance prediction indicators which are considered in the MEPDG for flexible pavements [Jannat, (2012)]:

(1) Alligator cracking

(2) Transverse cracking

(3) Longitudinal cracking

(4) Rutting

(5) Smoothness or International Roughness Index (IRI). 
The trial design is acceptable if distress/IRI at the specified reliability is less than the limiting performance (red line) over the entire deign period. The designer must alter the trial design to correct the problem if any key distress fails. However, the correction of the failed key distress depends on the judgment and restoration scheme of the pavement. This trial and error process allows the pavement designer to essentially build/model the pavement in the computer prior to building the pavement in the real-world to see if it will perform satisfactorily. Problems with design and materials for the given subgrade, climate, and traffic can be corrected and early failure can be predicted/avoided which is the true essence of the MEPDG methodology. Figure 2-6 below shows the summary page of a trial run of a flexible pavement section in the PDF format with all pass criteria.

DARWUE

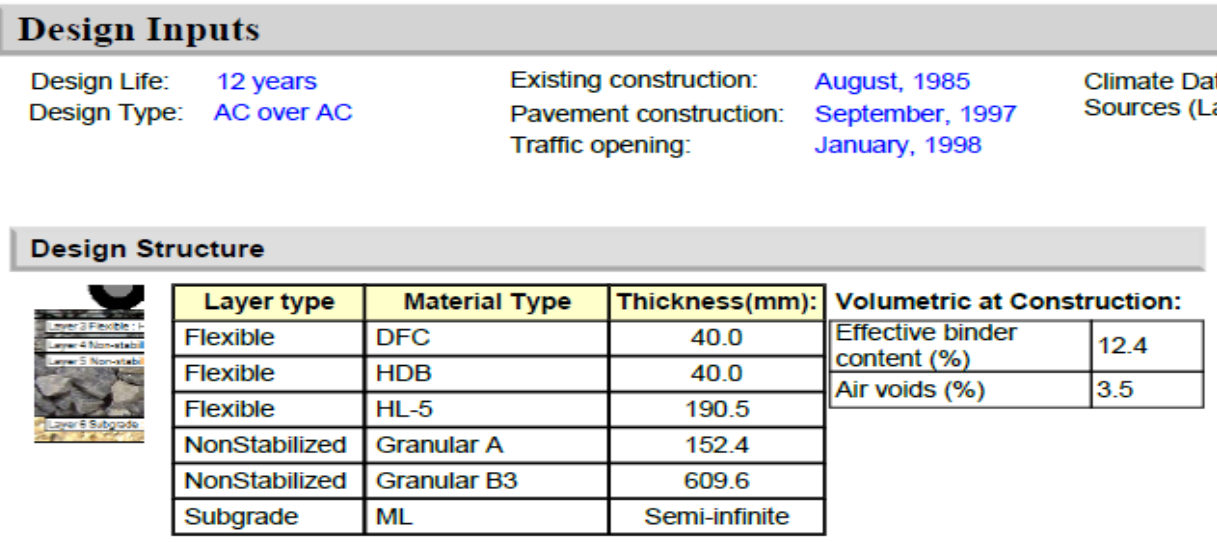

I11-1-Section 951

File Name: D:|Darwin Files\(25) Rehabiliated Sections|S951-I11|I11-1-Section 951.dgpx

$43.862,-79.37$

) $43.677,-79.631$

$43.172,-79.934$

43.107, -78.945

$43.983,-80.75$

Traffic

\begin{tabular}{|l|c|}
\hline \multicolumn{1}{|c|}{ Age (year) } & $\begin{array}{c}\text { Heavy Trucks } \\
\text { (cumulative) }\end{array}$ \\
\hline 1998 (initial) & 8,284 \\
\hline 2004 (6 years) & $5,446,320$ \\
\hline 2010 (12 years) & $10,892,600$ \\
\hline
\end{tabular}

\section{Design Outputs}

Distress Prediction Summary

\begin{tabular}{|c|c|c|c|c|c|}
\hline \multirow{2}{*}{ Distress Type } & \multicolumn{2}{|c|}{$\begin{array}{c}\text { Distress @ Specified } \\
\text { Reliability }\end{array}$} & \multicolumn{2}{|c|}{ Reliability (\%) } & \multirow{2}{*}{$\begin{array}{l}\text { Criterion } \\
\text { Satisfied? }\end{array}$} \\
\hline & Target & Predicted & Target & Achieved & \\
\hline Terminal IRI $(\mathrm{m} / \mathrm{km})$ & 2.30 & 1.37 & 50.00 & 99.15 & Pass \\
\hline Permanent deformation - total pavement (mm) & 19.00 & 5.64 & 50.00 & 100.00 & Pass \\
\hline Total Cracking (Reflective + Alligator) (percent) & 100.00 & 24.52 & - & - & - \\
\hline AC thermal fracture $(\mathrm{m} / \mathrm{km})$ & 189.40 & 5.97 & 50.00 & 100.00 & Pass \\
\hline AC bottom-up fatigue cracking (percent) & 25.00 & 0.00 & 50.00 & 100.00 & Pass \\
\hline AC top-down fatigue cracking $(\mathrm{m} / \mathrm{km})$ & 378.80 & 0.07 & 50.00 & 100.00 & Pass \\
\hline Permanent deformation - $\mathrm{AC}$ only $(\mathrm{mm})$ & 6.00 & 3.00 & 50.00 & 99.62 & Pass \\
\hline
\end{tabular}

Figure 2-6 A typical summary page output of a DARWin-ME program run showing all the required criteria satisfied 


\section{Chapter 3 : FRAMEWORK AND PROCESS OF LCC FOR FLEXIBLEPAVEMENT}

The purpose of conducting LCC of a flexible pavement using DARWin-ME is to

estimate costing of the most economic design of a pavement with the objective to implement a better economic strategy, support decision process in selecting a better economical design, and assess the relative costs of different rehabilitation options. While the MEPDG provides the tools to find the life cycle (service life) of a trial design, the LCC provides tools to estimate the costing of most economic trial design. Thus, the establishment of a framework of integrating LCC into the MEPDG would yield the process of determining the costing of the most economic life cycle of flexible pavement. In order to achieve this objective, the step-wise processes have been provided in the following sections for LCC and MEPDG.

\subsection{Framework of LCC}

For a given location and given traffic, the service life or the life cycle of a flexible pavement is a function of pavement's structural layers and time (or design life) which may be expressed by the following relationship:

Pavement's life cycle (or service life $)=\mathbf{f}\left(\mathbf{S}_{\mathbf{i}}, \mathbf{T}_{\mathrm{i}}, \mathrm{AADT}, \mathbf{C}\right) \ldots \ldots \ldots \ldots$....... Equation (1)

Where, $\mathrm{S}=$ pavement's structural layer, and suffix $\mathrm{i}=1,2,34$..

$\mathrm{T}=$ time or design life expressed in year, and suffix $\mathrm{i}=1,2,3,4 \ldots$.

AADT $=$ Average annual daily traffic, usually fixed (if growth rate $=0$ )

$\mathrm{C}=$ climate [usually, input data for climate are constant for a given location]

If the above relationship expressed by Equation (1) is true, then the framework of determining LCC of a flexible pavement by using the DARWin-ME has two approaches: 
Approach 1 - Determination of life cycle of an initial trial design by changing time $\mathrm{T}$ (i.e., design life) in the input data the DARWin-ME until getting the maximum at which the maximum limit for the critical mode of failure is reached while the pavement's structural layers remain unchanged. This approach helps to find and predict the actual or true service life and thus the life cycle for a selected trial design of pavement section.

Approach 2 - Determination of life cycle of an optimal initial design by changing the pavement's layer number and layer properties $S$ in the input data in the DARWin-ME while initial design life $\mathrm{T}$ remain unchanged. In this approach, the initially selected design is optimized by changing layer's material properties, thickness and layer number, which involves design optimization process. This approach helps to find optimal design of an initially selected section for the initial (or given) design life which is considered as service life or life cycle of the optimal design section.

In this report, the approach 1 has been considered to find the actual life cycle for an arbitrarily selected road section.

\subsection{Aspects of LCC}

In this report, the aspects of LCC framework of a flexible pavement have been adapted from Appendix C, Clause C.2 of NCHRP (2004) as follows:

1. Economic analysis technique

2. Real versus nominal dollars

3. Discount rate

4. Analysis period

5. Cost factors and rehabilitation timings

6. Unit costs

7. Approach to risk and uncertainty in LCC

All these aspects pertinent to our study for flexible pavements are discussed below. 
1. Economic analysis technique - As reported in the Technical Report \#23 of C-SHRP (2002) and shown in Table 2.1 earlier, the state-of-the-art practice being used for doing LCC in Ontario is the present-worth (PW) method. The present-worth method is also known as net present value (NPV) method or net present worth (NPW) method, which is determined as the net benefits (i.e., the benefits minus the costs) using the simple engineering economics formulas. If it is assumed that the benefits of keeping a roadway above some pre-established condition or ride quality level are the same for all design alternatives, the benefits component drops out and the formula for computing NPV is [NCHRP (2004), Equation C.1, p.C.5]:

$\mathrm{NPV}=$ initial Cost $+\sum(\text { Upkeep Cost })_{\mathrm{k}} *\left[1 /\left(1+\mathrm{i}_{\mathrm{dis}}\right)_{\mathrm{k}}^{\mathrm{n}}\right]$

Where,

$\mathrm{i}_{\text {dis }}=$ discount rate

$\mathrm{n}=$ year of expenditure

$\mathrm{k}=$ individual maintenance or rehabilitation activity

Once the NPV is estimated, the equivalent uniform annual costs (EUAC) can also be estimated using the following formula [NCHRP (2004), Equation C.2, p.C.6]:

$\mathrm{EUAC}=\mathrm{NPV} *\left[\left(\mathrm{i}_{\mathrm{dis}} *\left(1+\mathrm{i}_{\mathrm{dis}}\right)^{\mathrm{n}} /\left(\left(1+\mathrm{i}_{\mathrm{dis}}\right)^{\mathrm{n}}-1\right)\right]\right.$

Where,

$\mathrm{N}=$ number years into the future

$\mathrm{i}_{\mathrm{dis}}=$ discount rate

2. Real versus Nominal Dollars - The real (or constant) dollars reflect dollars with the same (or constant) purchasing power over time, whereas nominal (or inflated) dollars reflect dollars that fluctuate in purchasing power as a function of time. Because of simplicity, it is recommended that LCCA be conducted using real dollars [NCHRP 
(2004)]. In this report, the real dollar concept has been used. The use real dollar (i.e., real money) requires the use of real interest rates. The real interest rate is also referred to as the discount rate, because it discounts inflation [Papagiannakis and Masad (2008)].

3. Discount rate - As per the C-SHRP (2002) Technical Brief \#23, the discount rate used by the Province of Ontario is $7 \%$. The discount rate represents the real value of money over time and is used to convert future costs to present-day costs. The discount rate is a function of both the interest rate and inflation rate. The inflation rate is the rate of increase in the prices of goods and services (construction and upkeep of highways) and represents changes in the purchasing power of money. The mathematical relationship between the discount rate, the interest rate, and the inflation rate is given by [NCHRP, (2004), equation C.3, p.C.7]:

$\mathrm{i}_{\text {dis }}=\left[\left(1+\mathrm{i}_{\text {int }}\right) /\left(1+\mathrm{i}_{\text {inf }}\right)\right]-1=\left(\mathrm{i}_{\text {int }}-\mathrm{i}_{\text {inf }}\right) /\left(1+\mathrm{i}_{\text {inf }}\right)$

where,

$\mathrm{i}_{\text {dis }}=$ discount rate (decimal) [also known as real interest rate]

$\mathrm{i}_{\text {inf }}=$ inflation rate $($ decimal $)$

$\mathrm{i}_{\text {int }}=$ interest rate (decimal) [ also called market interest rate]

In our case in this report, a discount rate of $7 \%$ will be used as given in Table 2-1 [CSHRP (2002) Technical Brief \#23].

4. Analysis period - As defined by AASHTO: "an analysis period is the time period for which an economic analysis is to be conducted'[UDOT (2012), ATU (1997)]. Thus, the analysis period is defined as the time period over which the initial and future costs are evaluated for different design alternatives whereas pavement's design life is defined as the time period from original construction to a specified critical terminal condition at a 
selected level of reliability [UDOT (2012)]. In this report, the design life has been considered as the service life which may be defined as the time period for which the pavement would provide a satisfactory level of structural and riding quality performance before rehabilitation is necessary [ATU (1997)].

As a rule of thumb, the analysis period should be long enough to incorporate the costs of at least one rehabilitation activity for all design alternatives [AASHTO (2008)]. According to NCHRP (2004), the recommended analysis period for the different design strategies are given in Table 3-1 below:

Table 3-1: Recommended minimum values for the analysis period [NCHRP (2004), Table C.1, p. C.9]

\begin{tabular}{|l|l|}
\hline \multicolumn{1}{|c|}{ Design Strategy / Condition } & \multicolumn{1}{|c|}{ Recommended Minimum Analysis Period } \\
\hline Short-term or temporary design & $\begin{array}{l}\text { Analysis period = Minimum of expected life of } \\
\text { temporary pavement }\end{array}$ \\
\hline $\begin{array}{l}\text { Standard design; design period } \\
\text { of 10+ years }\end{array}$ & $\begin{array}{l}\text { Minimum of 30 to 40 years, depending on level of } \\
\text { traffic and roadway functional class. } \\
\text { Analysis period should include at least one } \\
\text { rehabilitation activity }\end{array}$ \\
\hline Long-life pavement designs & Minimum of 50 years \\
\hline
\end{tabular}

In our case, the economic analysis period is 50 years.

5. Cost factors and rehabilitation timings - Cost factors for the LCC of flexible pavements include agency costs (or direct costs) and user costs (or indirect costs). Although each of these costs consists of many other costs as shown in the hierarchical of cost components given in Figure 2.3 earlier, salvage value is not considered in Ontario [Technical Brief \# 23, C-SHRP (2002)] and only the construction cost will be included in this study for the economic evaluation of life cycle costing of a new flexible pavement. Rehabilitation timings which depend on the service life of the pavement have great impact on LCC results. Traditionally, the rehabilitation timings are predicted based on 
experience, survey reports and historical data. However, the DARWin-ME provides a performance based analysis tool to predict service life thus the anticipated rehabilitation timings of pavement in a better way.

6. Unit costs - Flexible pavements typically consist of Hot-Mix asphalt (HMA) pavement over a granular base and sub-base to distribute the traffic loads over the underlying layers. The asphalt concrete materials used in Ontario municipalities typically consist of Superpave asphalt mix designs [Holt et al. (2011)]. The unit costs for the initial construction and for the preventive maintenance and rehabilitations costs of a flexible pavement are given respectively in Table 3-2 and Table 3-3 below which have been adapted from Holet et al (2011).

Table 3-2: Unit Costs for Initial Pavement Construction [Holt et al. (2011)]

\begin{tabular}{|l|l|l|}
\hline Pavement layer & Description of Pavement layer & Unit Cost \\
\hline HMA & Superpave 12.5 FC2 (t) & $\$ 120.00$ \\
\cline { 2 - 3 } & Superpave 12.5 FC1 (t) & $\$ 115.00$ \\
\cline { 2 - 3 } & Superpave 12.5 (t) & $\$ 105.00$ \\
\cline { 2 - 3 } & Superpave 19 (t) & $\$ 96.00$ \\
\hline Base & Granular A (t) & $\$ 18.00$ \\
\hline Sub-base & Granular B (t) & $\$ 15.00$ \\
\hline
\end{tabular}

Table 3-3: Unit Costs for Maintenance and Rehabilitation Activities [Holt et al. (2011)]

\begin{tabular}{|l|l|}
\hline Description of maintenance and Rehabilitation Treatments & Unit costs \\
\hline Rout and seal $(\mathrm{m})$ & $\$ 5.00$ \\
\hline Spot repairs, mill and patch $\left(\mathrm{m}^{2}\right)$ & $\$ 35.00$ \\
\hline Asphalt base repair $\left(\mathrm{m}^{2}\right)$ & $\$ 45.00$ \\
\hline Mill HMA (t) & $\$ 15.00$ \\
\hline Resurface with Superpave 12.5 FC2 (t) & $\$ 120.00$ \\
\hline Resurface with Superpave 12.5 FC1 (t) & $\$ 115.00$ \\
\hline Resurface with Superpave 12.5 (t) & $\$ 105.00$ \\
\hline Resurface with Superpave 19 (t) & $\$ 96.00$ \\
\hline
\end{tabular}

7. Approach to risk and Uncertainty - No uncertainty and risk analysis have been considered in this study. 


\subsection{LCC Process / Methodology}

In this report, the methodology or process of LCC of a flexible pavement has been adapted from Appendix C, Clause C3 of NCHRP (2004), which includes seven (7) steps. These steps are discussed below.

\section{Step 1: Establish alternative pavement design strategies}

For a given project, at least two different initial structure types should be evaluated. At this stage, the probable types of preventive maintenance and rehabilitation (PM\&R) activities associated with each alternative are required to be established / selected, and critical distresses and modes of failure to be identified.

\section{Step 2: Determine pavement performance and $M \& R$ activity timing}

This step involves the determination of the performance life for each design alternatives and the timings of subsequent PM\&R treatments. There are three parts to this step [Appendix C, NCHRP (2004)]:

Determine initial performance life of design option - a pavement's service life is defined as that part of time from completion of construction until the condition of the pavement is considered to be unacceptable and rehabilitation or replacement is required. A procedure successfully used in the past for estimating pavement service life is failure analysis from the historical data. In our case, the MEPDG provides tools to determine directly by using the DARWin-ME software.

Determine repair and maintenance requirements - Highway agencies should establish decision criteria and /or functions (even though they may be subjective) that are used to 
define the type of repair. Decision criteria applied to select a type of repair option appropriate to the predicted physical condition of the pavement at time t. Time $t$ is defined as the time at which the calculated distress value or performance exceeds the critical level (amount and /or area) that causes the pavement to be repaired or maintained.

Determine the expected life of PM \& R activities - the amount and cost of routine maintenance should be considered to determine the significance of routine maintenance and rehabilitation on total life cycle costs. The timing of maintenance activities should be confirmed through an analysis of performance record, which would be determined from MEPDG analysis using DARWin-ME.

\section{Step 3: Estimate Direct /Agency Cost}

Step 3 involves estimating the agency costs for each alternative. These include design cost, initial construction cost, maintenance cost, rehabilitation cost, and salvage value. In our case, the initial construction cost, maintenance cost and rehabilitation costs are only to be estimated using the unit price.

\section{Step 4: Estimate Indirect / User costs}

Step 4 involves estimating the user costs for each alternative. These include time delay cost, vehicle operation cost (VOC), accident cost, and comfort cost. The time delay costs are the opportunity costs incurred as a result of additional time spent completing a journey because of work zone delays, whereas VOCs are highly related to the road roughness (smoothness) and operating conditions (free flow versus forced flow). The estimation of VOCs itself involves twelve (12) steps and require accurate data (from 
transportation planning department) and careful consideration in order to estimate a reasonable amount of cost. Also, these types of costs are included only for the preservation (maintenance and rehabilitation or reconstruction) works for an existing roadway, not for an initial / new construction [Appendix C, NCHRP (2004)].

However, for simplicity, the user costs are not included in our study/report for the economic evaluation of flexible pavements. Only the initial construction cost, maintenance cost and rehabilitation costs are to be estimated using the unit price.

\section{Step 5: Develop Expenditure Stream Diagram}

Expenditure stream diagrams are graphical representations of expenditures over time. They are developed for each alternative design strategy to help the designer/analyst visualize the magnitudes and timings of all expenditures projected for the analysis period

\section{Step 6: Compute Life Cycle Cost}

Once the expenditure stream for each alternative design strategy has been developed, the task of computing projected life cycle costs must be undertaken. Regardless of the computation approach (deterministic or probabilistic), the selected economic formula (NPW or EUAC) must be applied.

\section{Step 7: Analyze Results}

The results (i.e., estimated life cycle costs) must be analyzed and interpreted carefully to identify the most economic design strategy. In the analysis of deterministic results, it is common practice to compute the percent difference in life cycle costs of the competing designs. If the percent difference between the two lowest cost design alternatives is 
greater than some established minimum requirement - usually set according to the pavement agency's tolerance risk (5 and 10 percent are common) - then the lowest cost alternative is accepted as the most economical design. If, on the other hand, the percent difference is less than the established minimum requirement, then the life cycle costs of the two alternatives are considered equivalent, and therefore requires reevaluating the designs or allowing other factors to drive the design selection process [Appendix C, NCHRP (2004)].

\subsection{MEPDG Framework for Analysis/Design of a New Flexible Pavement}

The MEPDG is a software based pavement design and analysis method which requires information to be fed as input in order to obtain the output after the program run. In general, modeling of a new flexible pavement performance using the DARWin-ME involves the following steps to feed input information and obtain output of the program run [AASHTO (2008), Holt et al (2011), MTO Interim Report (2012)]:

\section{Step 1: $\quad$ General Input / General Information}

The inputs for general information are mainly for the identification, location and title of the site/project.

\section{Step 2: $\quad$ Selecting Design-Performance Criteria and Reliability Level}

Performance criteria- Performance criteria are used to ensure that a pavement design will perform satisfactorily over its design life. Recommended design-performance criteria default target values shown in Table 3-4 provides values for considerations by highway agencies for flexible pavements for Ontario. 
Table 3-4: Performance criteria default values for flexible pavements in Ontario [MTO Interim Report, Table 3 (2012)]

\begin{tabular}{|l|l|}
\hline \multicolumn{1}{|c|}{ Performance Criteria } & \multicolumn{1}{c|}{ Default Target values } \\
\hline $\begin{array}{l}\text { AC top-down fatigue cracking }(\mathrm{m} / \mathrm{km}) \\
{[\text { Longitudinal crack }]}\end{array}$ & 380 \\
\hline $\begin{array}{l}\text { AC bottom-up fatigue cracking (percent) } \\
\text { [Alligator crack] }\end{array}$ & $\begin{array}{l}\text { Freeway: } 10 \\
\text { Arterial: } 20 \\
\text { Collector/Local: } 35\end{array}$ \\
\hline $\begin{array}{l}\text { AC thermal fracture }(\mathrm{m} / \mathrm{km}) \\
{[\text { Transverse crack }]}\end{array}$ & 190 \\
\hline $\begin{array}{l}\text { Permanent deformation - total pavement }(\mathrm{mm}) \\
{[\text { Rut }]}\end{array}$ & 19 \\
\hline Permanent deformation - AC only $(\mathrm{mm})$ & 6 \\
\hline Total cracking (Reflective + Alligator) (percent) & 100 \\
\hline
\end{tabular}

Threshold Values of Pavement Performance - IRI is a good indication of pavement performance. The initial IRI represents the starting value and the terminal IRI represents the threshold value of IRI for specific design reliability in MEPDG. Table 3-5 below provides typical terminal IRI input values for Ontario.

Table 3-5: Ontario typical IRI inputs values for flexible pavements [MTO Interim Report, Table 2 (2012)]

\begin{tabular}{|c|c|}
\hline Highway Facility Type & Recommended Terminal IRI (m/km) \\
\hline Freeway & 1.9 \\
\hline Arterial & 2.3 \\
\hline Collector & 2.7 \\
\hline Local & 3.3 \\
\hline
\end{tabular}

Reliability - Design reliability $(\mathrm{R})$ is defined as the probability $(\mathrm{P})$ that the predicted distress will be less than the critical level over the design periods. For nearly all projects, it is necessary to consider reliability higher than 50 percent that the design will meet the performance criteria over the design life. The more important the project in terms of consequence of failure, the higher the desired level of reliability should be considered. Table 3-6 below shows the recommended design reliability level for Ontario Roadways.

Table 3-6: Ontario Recommended Design Reliability Levels [MTO Interim Report, Table 4 (2012)]

\begin{tabular}{|c|c|c|}
\hline \multirow{2}{*}{ Highway Functional Class } & \multicolumn{2}{|c|}{ Recommended Range of Reliability Levels (\%) } \\
\cline { 2 - 3 } & Urban & Rural \\
\hline Freeway & 95 & 95 \\
\hline Arterial & 90 & 85 \\
\hline Collector & 80 & 75 \\
\hline Local & 75 & 75 \\
\hline
\end{tabular}




\section{Step 3: $\quad$ Input about Traffic and Traffic distribution}

The determination of the thickness of structural layers of a flexible pavement design depends on the volume of traffic. Traffic is described as the number of vehicles using the road in terms of the Average daily Traffic (AADT), which is defined as the number of ESALs pass a single point two way of the roadway during the 24-hr period for the period of January 1 to December 31, and where the traffic volumes are assumed to be split 50:50 for both direction. The MEPDG uses a large range of traffic parameters, and the information about the traffic distribution for the roadways is embedded within the DARWin-ME as a default value.

Roadway-specific Inputs - the following input parameters are considered site-specific and needed to be obtained from the traffic or planning department:

- Initial Two-Way Average Annual Daily Truck Traffic (AADTT)

- Percent Truck in Design Lane

- Percent Truck in Design Direction

- Operational Speed

- Growth of Truck traffic

Traffic Volume - The volume of traffic is the total number of vehicles to pass over a roadway during its design life. The traffic volume is expressed in term of AADT, and the number (or quantity) of AADT are related to the classification of roadways (i.e., expressways, collectors, arterials, etc.) and traffic lanes of the roadways. Table 3-7 below shows the number of lane against the number of AADT and distribution for traffic for design lane Ontario. 
Table 3-7: Ontario Recommended Percentage of Truck in design Lane [MTO Interim Report, Table 5 (2012)]

\begin{tabular}{|c|c|c|}
\hline $\begin{array}{c}\text { Number of Lane in One } \\
\text { Direction }\end{array}$ & $\begin{array}{c}\text { AADT } \\
\text { (both Directions) }\end{array}$ & $\begin{array}{c}\text { Percentage of Trucks in design Lane } \\
(\boldsymbol{\%})\end{array}$ \\
\hline 1 & all & 100 \\
\hline 2 & $<15,000$ & 90 \\
& $>15,000$ & 80 \\
\hline 3 & $<25,000$ & 80 \\
& 25,000 to 40,000 & 70 \\
& $>40,000$ & 60 \\
\hline 4 & $<40,000$ & 70 \\
& $>40,000$ & 60 \\
\hline 5 & $<50,000$ & 60 \\
& $>50,000$ & 60 \\
\hline
\end{tabular}

Traffic Axle configuration, spacing, traffic wander, and hourly distribution - these values are part of the MEPDG database and are embedded into the DARWin-ME software as default values. The values related to the traffic axle configuration and axle spacing depend on the vehicle manufacturing specifications which are universally same regardless of the location. The values related to traffic wandering experimentally found to be universal although traffic distribution factor along with traffic growth factor depend on the development and the local need of the region / country. The DARWin-ME uses these default values to estimate the cumulative impact of the traffic over the design period for a given value of AADT to predict the performance of the road. These values are shown in the tables below for reference and no traffic growth factor (i.e., traffic growth $=0$ ) has been considered in this study:

Table 3-8: Default Axle Configuration [MTO Interim Report, Table 6 (2012)]

\begin{tabular}{|c|c|}
\hline Axle Configuration & Default Values \\
\hline Average Axle width $(\mathrm{m})$ & 2.59 \\
\hline Dual tire spacing $(\mathrm{mm})$ & 305 \\
\hline Tire pressure $(\mathrm{kPa})$ & 827.4 \\
\hline
\end{tabular}

Table 3-9: Ontario Typical for Axle Spacing [MTO Interim Report, Table 7 (2012)]

\begin{tabular}{|l|l|}
\hline \multicolumn{1}{|c|}{ Axle Type } & \multicolumn{1}{|c|}{ Average Axle Spacing within axle group (m) } \\
\hline Tandem & 1.45 \\
\hline Tridem & 1.68 \\
\hline Quad & 1.32 \\
\hline
\end{tabular}


Table 3-10: Default values of Lateral Traffic Wander [MTO Interim Report, Table 8 (2012)]

\begin{tabular}{|l|l|}
\hline \multicolumn{1}{|c|}{ Factors } & \multicolumn{1}{c|}{ Default values } \\
\hline Mean wheel Location $(\mathrm{mm})$ & 460 \\
\hline Traffic wander standard deviation $(\mathrm{mm})$ & 254 \\
\hline Design Lane width $(\mathrm{m})$ & 3.75 \\
\hline
\end{tabular}

Table 3-11: Default values of traffic distribution factors [MTO Interim Report, Table 10 (2012)]

\begin{tabular}{|l|l|}
\hline \multicolumn{1}{|c|}{ Traffic } & \multicolumn{1}{c|}{ Default Values } \\
\hline Monthly adjustment & 1.0 \\
\hline Hourly distribution & Default \\
\hline Traffic Growth factor & Site specific (usually 2\% to 4\% compounded) \\
\hline
\end{tabular}

\section{Step 4: $\quad$ Climate Input / Information}

The location of the project is defined by longitude and latitude in decimals of degrees. Since climate has a very significant effect on flexible pavement performance, therefore, a detailed climatic data are required in the DARWin-ME for predicting pavement distress. These data are used to predict the temperature and moisture content in each of the pavement layers.

In the DARWin-ME, a single weather station can be selected when the project is within reasonable proximity or up to six surrounding weather stations can be selected and combined into a virtual weather station for the project. This is all done automatically by the software after selection by the user. The use of more than one station is recommended so that a better estimate of the climate at the project site can be obtained. However, extra caution must be taken when creating virtual weather stations which may be at significantly different elevations and may yield biased results [AASHTO (2008)].

All of the climate data needed by the MEPDG are available from weather stations. The MEPDG has an extensive number of weather stations embedded in its software for use and implementation (currently 851 stations include Canada and the US).Currently, there are 34 weather stations in Ontario and the data for these are being updated by AASHTO. List of Stations are provided in the attachment in Appendix A. The user simply needs to know the longitude and latitude of the project and the software will automatically select six weather stations closest to that location. The longitude, latitude, elevation, and 
number of months of available data may be viewed by the user in selecting the weather stations to be used by the software to create a virtual weather station at the project location for the distress predictions. It is recommended that the selected weather station should be as nearest as possible to the project site [AASHTO (2008), Holt et al. (2011)].

\section{Step 5: $\quad$ New Flexible pavement Design Strategies}

The MEPDG design process requires the selection of a trial design with all inputs defined. The initial trial design may be determined using the Guide for Design of pavement Structures (AASHTO, 1993), other M-E based design procedures, a design catalog, or the user simply identifying the design features and layer thickness.

The MEPDG flexible pavement design procedure allows a wide variety of HMA mixtures, aggregate base layers, and foundation improvements. In setting up an initial new design strategy for flexible pavements, the designer should simulate the pavement structure and foundation as detailed a possible, and then combine layers, as needed. No more than 6 layers are recommended to begin the design iteration process [AASHTO (2008)]:

○ 2 HMA layers,

$\bigcirc$ an unbound aggregate base,

○ a stabilized base (or improved embankment if necessary),

$\bigcirc$ the subbase layer, and

$\bigcirc$ a rigid layer (if present) or the subgrade

\section{Hot Mixed Asphalt (HMA) concrete}

The commonly known predominant asphalt mixes are HL-1, HL-3, HL-8, and HL-8(HS). The Stone Mastic Asphalt (SMA) is considered to be higher strength asphalt concrete and

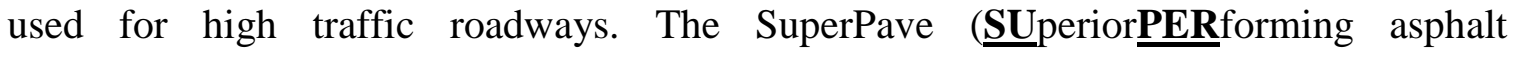
PAVments) mix design is an alternative asphalt mix design to the Hveem and Marshall methods. Superpave mix design procedure was adopted to improve rutting, low temperature cracking and fatigue cracking performance of asphalt concrete pavements. 
The HMA used for roadways in Ontario is primarily based on MTO's specification OPSS 1151 (MTO 2006). This specification provides guidance on the mix design of SuperPave and placement of the different types of mixes of SuperPaves commonly used for Ontario roadways. The properties of the HMA materials of Typical SuperPave and SMA asphalt concrete proerties are shown in Table 3-12 below.

Table 3-12: Ontario's Typical SuperPave and SMA asphalt concrete proerties [ MTO Interim Report, Table 22 (2012)]

\begin{tabular}{|c|c|c|c|c|c|}
\hline \multicolumn{2}{|c|}{ Asphalt Layers } & SP 12.5 & SP 19.0 & SP 25.0 & SMA 12.5 \\
\hline \multicolumn{2}{|c|}{ Thickness (mm) } & \multicolumn{4}{|c|}{ Project specific } \\
\hline \multicolumn{6}{|c|}{ Mixture Volumetric } \\
\hline \multicolumn{2}{|c|}{ Unit Weight $\left(\mathrm{kg} / \mathrm{m}^{3}\right)$} & See Note 1 & 2460 & 2469 & See Note 1 \\
\hline \multicolumn{2}{|c|}{ Effective Binder Content - by Volume (\%) } & 11.8 & 11.2 & 10.4 & 14.6 \\
\hline \multicolumn{2}{|c|}{ Air Voids $(\%)^{2}$} & \multicolumn{4}{|c|}{$\frac{1}{4.0}$} \\
\hline \multicolumn{2}{|c|}{ Poisson's Ratio ${ }^{3}$} & \multicolumn{4}{|c|}{0.35} \\
\hline \multicolumn{6}{|c|}{ Mechanical Properties } \\
\hline \multicolumn{2}{|c|}{ Dynamic Modulus } & \multicolumn{4}{|c|}{ "Input level: 3" selected } \\
\hline \multirow{4}{*}{$\begin{array}{l}\text { Aggregate } \\
\text { Gradation }\end{array}$} & $\%$ Passing the $19 \mathrm{~mm}$ Sieve & $100 \%$ & $96.9 \%$ & $89.1 \%$ & $100.0 \%$ \\
\hline & \% Passing the $9.5 \mathrm{~mm}$ Sieve & $83.2 \%$ & $72.5 \%$ & $63.3 \%$ & $73.1 \%$ \\
\hline & \% Passing the $4.75 \mathrm{~mm}$ Sieve & $54 \%$ & $52.8 \%$ & $49.3 \%$ & $29.7 \%$ \\
\hline & $\%$ Passing the 75 um Sieve & $4 \%$ & $3.9 \%$ & $3.8 \%$ & $9.3 \%$ \\
\hline \multicolumn{2}{|c|}{ G Star Predictive Model } & \multicolumn{4}{|c|}{ "Use viscosity based model (nationally calibrated)" selected } \\
\hline \multicolumn{2}{|c|}{ Reference Temperature } & \multicolumn{4}{|c|}{$21.1^{\circ} \mathrm{C}$} \\
\hline \multicolumn{2}{|c|}{ Asphalt Binder $^{4}$} & PG 64-28 & PG 58-28 & PG 58-28 & PG 70-28 \\
\hline \multicolumn{2}{|c|}{ Indirect Tensile Strength - $10 \operatorname{deg} . \mathrm{C}(\mathrm{MPa})$} & \multicolumn{4}{|c|}{ Calculated } \\
\hline \multicolumn{2}{|c|}{ Creep Compliance (1/GPa) } & \\
\hline \multicolumn{2}{|c|}{ Thermal } & \multicolumn{4}{|c|}{ “Input level: 3" selected } \\
\hline \multicolumn{2}{|c|}{$\begin{array}{l}\text { Thermal Conductivity (watt/meter-Kelvin) } \\
\text { Heat Canacity (ioule/kg-Kelvin) }\end{array}$} & \multicolumn{4}{|c|}{1.16} \\
\hline \multicolumn{2}{|c|}{ Heat Capacity (joule/kg-Kelvin) } & \multicolumn{4}{|c|}{963} \\
\hline \multicolumn{2}{|c|}{ Thermal Contraction } & \multicolumn{4}{|c|}{ Calculated } \\
\hline
\end{tabular}

Note 1: For SP 12.5, the unit weight is $2,460 \mathrm{~kg} / \mathrm{m}^{3}$. For SP 12.5FCl, FC2 and SMA 12.5, unit weight varies from different regions: Central and North regions $-2,520 \mathrm{~kg} / \mathrm{m}^{3} ;$ East region $-2,390 \mathrm{~kg} / \mathrm{m}^{3}$; West region $-2,530 \mathrm{~kg} / \mathrm{m}^{3}$

Note 2: For existing HMA layers, should use measured in-situ air voids.

Note 3: For new HMA mixtures, use calculated Poisson's ratio by expanding the row on 'Poisson's ratio' and set to 'true'. For the row on 'Is Poisson's Ratio calculated?' Refer to Mechanistic-Empincal Pavement Design Guide Table $11-3$ for other reference temperatures and open-graded HMA Poisson ratios.

Note 4: PGAC vanes based on locations and traffic loading conditions. Refer to MTO SuperPave Guide to select the proper PGAC grade. 
In general, the HL mixes conform to SMA and SuperPave mixes as follows [ARA, 2006]:

\begin{tabular}{|c|c|}
\hline HL Designation & $\begin{array}{c}\text { Comparable Superpave } \\
\text { Designation }\end{array}$ \\
\hline SMA & SMA \\
\hline DFC & Superpave 12.5FC2 \\
\hline HL-1 & Superpave 12.5FC1 \\
\hline HL-3 & Superpave 12.5 \\
\hline HL-8/HL-8(HS) & Superpave 19.0 \\
\hline LSBC & Superpave 37.5 \\
\hline
\end{tabular}

\section{Granular Base and Subbase}

The most commonly available aggregates used in pavement construction in Ontario consist of Granular A base and Granular B subbase. These materials, described in OPSS 1010 (MTO 2004). For roadways, the use of an open graded drainage layer has not been included in any of the pavements in this study with the assumption that adequate drainage is provided for the flexible pavement sections.

\section{Foundation and Subgrade Soils}

Subsurface investigations are included for pavement design which helps to obtain information about the horizontal and vertical variations in subsurface soil types, moisture contents, densities, water table depth, and location of rock strata need to be considered during the pavement design process.

When a water table is located near the surface (within $5 \mathrm{ft}$ ), a subsurface drainage system is recommended as part of the design strategy. The depth of water table that is entered into the MEPDG software is the depth below the final pavement surface. 
A rigid (or apparent rigid) layer is defined as the lower soil stratum that has a high resilient (or elastic) modulus greater than 100,000 psi. A rigid layer may consist of bedrock, severely weathered bedrock, hard pan, sandstone, shale, or even overconsolidated clays. The designer needs to review the results from the subsurface investigation and provide a foundation layer with a resilient modulus of at least 10,000 psi. If the subgrade has a resilient modulus less than 10,000 psi, the designer could consider improving or strengthening the subgrade soils [AASHTO (2008)].

For the design of new construction pavement structures, the subgrade resilient modulus to be obtained historically using an existing representative roadway located near the new project or from geotechnical investigation.

\section{Step 6: Interpretations and Analysis of the Trial Design}

After completing all the required input, the trial design is saved and run. The MEPDG software predicts the performance of the trial design in terms of key distress types and smoothness as specified reliability. The program outputs the following information: inputs, reliability of design, materials and other properties, and predicted performance. An unacceptable design is revised and re-run to establish its performance until all criteria are met.

\subsection{Identification of Feasible Maintenance and Rehabilitation Strategies}

A considerable amount of analysis and engineering judgment are required when determining specific treatments for a future feasible rehabilitation strategy for a newly constructed flexible pavement. Identification of the future feasible rehabilitation strategy 
for a newly constructed flexible pavement includes consideration of various pre-overlay treatments and repairs to address future deterioration of the pavement.

The estimation of the type and frequency of repair and maintenance is difficult to predict. Traditionally, historical data from PMS had been considered to assume repair scheme for the newly constructed flexible pavement although this may not reflect the true scenario. But the new MEPDG using DARWin-ME provides the necessary analysis tools to predict and select the most suitable and economic PM \& R scheme. However, the treatments necessary for preventive maintenance $(\mathrm{PM})$ or routine maintenance against different types of distresses can be considered / adopted from the AASHTO guides and charts. The recommended maintenance and rehabilitation schedules for HMA pavements are given in Table 3-13 below adapted from AASHTO [AASHTO (2008)].

Table 3-13 Recommended Preservation Scheme for flexible pavement [ASHTO ( 2008)]

\begin{tabular}{|c|c|c|c|}
\hline Pavement Type & Distress & $\begin{array}{l}\text { Preventive } \\
\text { Treatments }\end{array}$ & Repair Treatments \\
\hline \multirow{14}{*}{ Flexible and Composite } & \multirow{2}{*}{ Alligator Cracking } & Surface/fog seal & \multirow{2}{*}{ Full-depth repair } \\
\hline & & Surface patch & \\
\hline & Longitudinal Cracking & Crack sealing & Partial-depth repair \\
\hline & \multirow[b]{2}{*}{ Reflective Cracking } & Rout and seal cracks & \multirow{2}{*}{ Full-depth repair } \\
\hline & & $\begin{array}{l}\text { Saw and seal cuts above } \\
\text { joints in PCC layer }\end{array}$ & \\
\hline & \multirow{2}{*}{ Block Cracking } & Seal cracks & \multirow{2}{*}{ Chip Seal } \\
\hline & & Chip seal & \\
\hline & \multirow{2}{*}{ Depression } & \multirow{2}{*}{ None } & Leveling course \\
\hline & & & Mill surface \\
\hline & \multirow{2}{*}{ Rutting } & \multirow{2}{*}{ None } & Leveling course \\
\hline & & & Mill surface \\
\hline & Raveling & Rejuvenating seal & Chip seal/surface seal \\
\hline & \multirow{2}{*}{ Potholes } & Crack sealing & \multirow{2}{*}{$\begin{array}{l}\text { Full-depth or partial- } \\
\text { depth repairs }\end{array}$} \\
\hline & & Surface patches & \\
\hline
\end{tabular}


User Costs - In general, user costs are grouped into two [Papagiannakis and Masad (2008):

(a) Vehicle operating costs (VOCs), which includes:

- fuel consumption cost,

- Vehicle repair/maintenance costs (including parts and labor)

- $\quad$ Tire wear cost

- $\quad$ Other costs (i.e., motor oil and usage related deprecation)

(b) Non-vehicle operating costs, which includes:

- Travel delays due to lane closures for pavement PM\&R 9preventive maintenance and rehabilitation)

- Other (i.e., travel delays due to reduced speed caused pavement roughness, pavement-related occupational injuries, cargo damage/packing costs, and pavement condition related accidents)

However, as described by UDOT (2012): "it is difficult to determine whether or not one rehabilitation alternative results in a higher vehicle operating costs than another. The user costs associated with rehabilitation is determined using only costs associated with user delay, which is based on the construction periods and the traffic volumes that are affected by each of the rehabilitation alternatives. User costs associated with delays for future rehabilitation work can be substantial for heavy travelled roadways, especially when work is frequent". Several studies have been performed to model user costs [NCHRP (2004), Guven (2006), UDOT (2012)]. A simplified version to estimate the user delay costs only has been devised UDOT [UDOT (2012)] which is based on speed reduction through the work zone, and the recommended mean values and ranges for the value of time delay (in terms of US\$ value) shown in the Table 3-14 below are identified by UDOT [UDOT (2012)]. 
Table 3-14: Recommended Dollar Values per vehicle Hour Delay in 2012 dollar [UDOT, (2012)]

\begin{tabular}{|l|c|c|}
\hline \multicolumn{2}{|c|}{ Recommended Dollar Values per Vehicle Hour of Delay in 1012 Dollars } \\
\hline \multirow{2}{*}{ Vehicle Class } & \multicolumn{2}{c|}{ Value per vehicle hour } \\
\cline { 2 - 3 } & Value & Range \\
\hline Passenger Vehicle & $\$ 13.96$ & $\$ 12$ to $\$ 16$ \\
\hline Single-unit Trucks & $\$ 22.34$ & $\$ 20$ to $\$ 24$ \\
\hline Combination Trucks & $\$ 26.89$ & $\$ 25$ to $\$ 29$ \\
\hline
\end{tabular}

The following equation, proposed by the Utah Department of Transportation (UDOT), is the minimum when calculating user costs for travel delays only [UDOT (2012)]:

$\mathrm{UC}=(\mathrm{AVT})[\mathrm{L} / \mathrm{RS}-\mathrm{L} / \mathrm{IS}](\mathrm{ADT})((\mathrm{PT}(\mathrm{CP}))$

Where,

$\mathrm{UC}=$ User Cost

$\mathrm{AVT}=$ Value of delay time

$\mathrm{L}=$ project length

$\mathrm{RS}=$ reduced speed through construction zone

IS = initial speed prior to construction zone

$\mathrm{ADT}=$ Average daily traffic in current year

$\mathrm{PT}=$ percent of traffic affected by the construction project

$\mathrm{CP}=$ construction period in days

However, data on various factors like duration of construction, traffic, type of detour etc. which are required to estimate the user costs are unknown in many cases, and a fullblown (detailed and complete) user costs analyses are very time consuming and very difficult to quantify [UDOT (2012), ATU (1997)]. For simplicity, the user costs are not considered into this report as previously mentioned also in step 4 section 3.3. 


\section{Chapter 4 : CASE STUDY - LCC OF A RECONSTRUCTED PAVEMENT SECTION}

\subsection{Problem Statement}

A local road agency has identified a requirement to do LCC for a reconstructed flexible pavement of six-lane divided highway (3 lanes each way) road segment, for example, AC8-1 Section 9. The reconstructed flexible pavement has been designed in accordance with the MEPDG methodology using the DARWin-ME software as a design tool. The primary input information on the reconstructed flexible pavement section is given in Table 4-1 below:

Table 4-1: Primary input data for the reconstructed flexible pavement

\begin{tabular}{|l|l|}
\hline \multicolumn{1}{|c|}{ Data type } & \multicolumn{1}{c|}{ Description of the data } \\
\hline Location & $\begin{array}{l}\text { Latitude: } 43.107 \\
\text { Longitude: }-78.945\end{array}$ \\
\hline Road Classification & Highway \\
\hline Pavement Type & Flexible \\
\hline $\begin{array}{l}\text { Number of Lane in design } \\
\text { direction }\end{array}$ & 3 lanes (both ways total six lanes) \\
\hline Length of construction & $1000 \mathrm{~m}(1 \mathrm{~km})$ \\
\hline Analysis period & 50 years \\
\hline Reliability & $50 \%$ \\
\hline Traffic & AADT =14,125 \\
\cline { 2 - 2 } & Growth rate =0 \\
\cline { 2 - 2 } & No traffic cap \\
\hline Subgrade soil information & Soil type : ML with resilient Modulus, $\mathrm{M}_{\mathrm{R}}=35 \mathrm{MPa}$ \\
\hline Climate Month of \\
construction & Base Construction = August 1996 \\
\cline { 2 - 3 } & HMA Pavement Construction = September 1996 \\
\cline { 2 - 3 } & Traffic Opening = December 1997 \\
\hline
\end{tabular}




\subsection{Special note on Flexible Pavement Local Calibration of the Rutting Model}

It has been reported in various researches that the DARWin-ME rutting model for flexible pavements over predicts the rutting value compared to the actual field value [UDOT (2012), ATU (1997), Jannat (2012), Afzal (2013)]. The recommended local calibration coefficients used in this report for the new/reconstructed flexible pavement and for rehabilitation for flexible pavement are addressed as follows:

- AC Rutting

- $\operatorname{Br} 1=0.23$

- $\operatorname{Br} 2=1.02$

- $\operatorname{Br} 3=1.02$

- Subgrade Rutting

○ Granular subgrade rutting

- $\quad$ Bs1 $=3.062$

$\bigcirc$ Fine subgrade rutting

- $\mathrm{Bs} 1=0.0328$

\subsection{Initial Design}

The initial design has been provided along with the problem statement. It is unsure whether the AASHTO design guide or any other design chart or code has been followed to assume the structural layers and their thicknesses for the given data and required design performance parameters. The input data for the initial design structure of the reconstructed flexible pavement and the subsequent output data are given below along 
with the distress charts at $50 \%$ reliability for the required design performance parameters in Figure 4-1, 4-2 and 4-3 respectively.

\begin{tabular}{|c|c|c|c|c|c|c|c|c|c|}
\hline \multicolumn{10}{|c|}{ Design Inputs } \\
\hline \multirow{16}{*}{$\begin{array}{l}\text { Design Life: } \\
\text { Design Type: }\end{array}$} & \multirow{2}{*}{\multicolumn{2}{|c|}{$\begin{array}{l}11 \text { years } \\
\text { Flexible Pavement }\end{array}$}} & \multirow{3}{*}{\multicolumn{2}{|c|}{$\begin{array}{l}\text { Base construction: } \\
\text { Pavement construction: } \\
\text { Traffic opening: }\end{array}$}} & August, 1996 & \multirow{2}{*}{\multicolumn{2}{|c|}{$\begin{array}{l}\text { Climate Data } \\
\text { Sources }\end{array}$}} & \multicolumn{2}{|c|}{$43.107,-78.945$} \\
\hline & & & & & September, 1996 & & & \\
\hline & & & & & December, 1997 & & & \multicolumn{2}{|c|}{$\begin{array}{l}43.172,-79.934 \\
42.493,-79.272 \\
43.677,-79.631\end{array}$} \\
\hline & & & & & & & & \multicolumn{2}{|c|}{$43.862,-79.37$} \\
\hline & & & & & & & & \multicolumn{2}{|c|}{$42.85,-80.267$} \\
\hline & & & & & & & & \multicolumn{2}{|c|}{$43.117,-77.677$} \\
\hline & & & & & & & & \multicolumn{2}{|c|}{$42.571,-77.713$} \\
\hline & & & & & & & & \multicolumn{2}{|c|}{$42.08,-80.183$} \\
\hline & & & & & & & & \multicolumn{2}{|c|}{$42.109,-77.992$} \\
\hline & & & & & & & & \multicolumn{2}{|c|}{$41.803,-78.64$} \\
\hline & & & & & & & & \multicolumn{2}{|c|}{$43.983,-80.75$} \\
\hline & & & & & & & & \multirow{2}{*}{\multicolumn{2}{|c|}{$\begin{array}{l}43.033,-81.151 \\
44.117,-77.533\end{array}$}} \\
\hline & & & & & & & & \multirow{2}{*}{\multicolumn{2}{|c|}{$\begin{array}{l}44.117,-77.533 \\
42.643,-77.056\end{array}$}} \\
\hline & & & & & & & & & \\
\hline & & & & & & & & \multicolumn{2}{|c|}{$44.317,-77.633$} \\
\hline & & & & & & & & \multicolumn{2}{|c|}{$41.626,-80.215$} \\
\hline \multicolumn{7}{|c|}{ Design Structure } & \multicolumn{3}{|c|}{ Traffic } \\
\hline & Layer type & Mat & I Type & Thickness(mm): & \multicolumn{2}{|c|}{ Volumetric at Construction: } & \multirow{2}{*}{\multicolumn{2}{|c|}{ Age (year) }} & \multirow{2}{*}{\begin{tabular}{|c|} 
Heavy Trucks \\
(cumulative)
\end{tabular}} \\
\hline 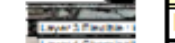 & Flexible & DFC & & 40.0 & \multirow{3}{*}{\begin{tabular}{|l} 
Effective binder \\
content $(\%)$ \\
Air voids $(\%)$ \\
\end{tabular}} & \multirow{2}{*}{12.4} & & & \\
\hline 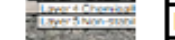 & Flexible & $\mathrm{HDB}$ & & 90.0 & & & & (initial) & 14,124 \\
\hline \multirow{4}{*}{ 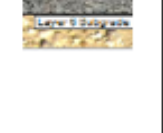 } & Flexible & $\mathrm{HL}-8$ & & 130.0 & & 3.5 & \multirow{2}{*}{\multicolumn{2}{|c|}{\begin{tabular}{|l|}
2002 (5 years) \\
2008 (11 years) \\
\end{tabular}}} & $8,512,490$ \\
\hline & Cement_Base & Ceme & tabilized & 100.0 & & & & & $17,025,000$ \\
\hline & NonStabilized & Granul & & 300.0 & & & & & \\
\hline & Subgrade & ML & & Semi-infinite & & & & & \\
\hline
\end{tabular}

Figure 4-1 Input data for the Initial design of the reconstructed flexible pavement

\section{Distress Prediction Summary}

\begin{tabular}{|c|c|c|c|c|c|}
\hline \multirow[t]{2}{*}{ Distress Type } & \multicolumn{2}{|c|}{$\begin{array}{c}\text { Distress @ Specified } \\
\text { Reliability }\end{array}$} & \multicolumn{2}{|c|}{ Reliability (\%) } & \multirow{2}{*}{$\begin{array}{l}\text { Criterion } \\
\text { Satisfied? }\end{array}$} \\
\hline & Tarqet & Predicted & Tarqet & Achieved & \\
\hline Terminal IRI (m/km) & 2.70 & 1.15 & 50.00 & 100.00 & Pass \\
\hline Permanent deformation - total pavement (mm) & $\quad 19.00$ & 5.23 & 50.00 & 100.00 & Pass \\
\hline AC bottom-up fatigue cracking (percent) & 25.00 & 0.00 & 50.00 & 100.00 & Pass \\
\hline Total Cracking (Reflective + Alligator) (percent) & 100.00 & 3.01 & - & - & - \\
\hline AC thermal fracture $(\mathrm{m} / \mathrm{km})$ & $\quad 189.40$ & 8.44 & 50.00 & 100.00 & Pass \\
\hline AC top-down fatigue cracking $(\mathrm{m} / \mathrm{km})$ & 378.80 & 0.00 & 50.00 & 100.00 & Pass \\
\hline Permanent deformation - AC only (mm) & 6.00 & 2.38 & 50.00 & 99.99 & Pass \\
\hline Chemically stabilized layer - fatigue fracture (percent) & 25.00 & 0.53 & - & - & - \\
\hline
\end{tabular}

Figure 4-2 Initial design output and distress prediction summary 

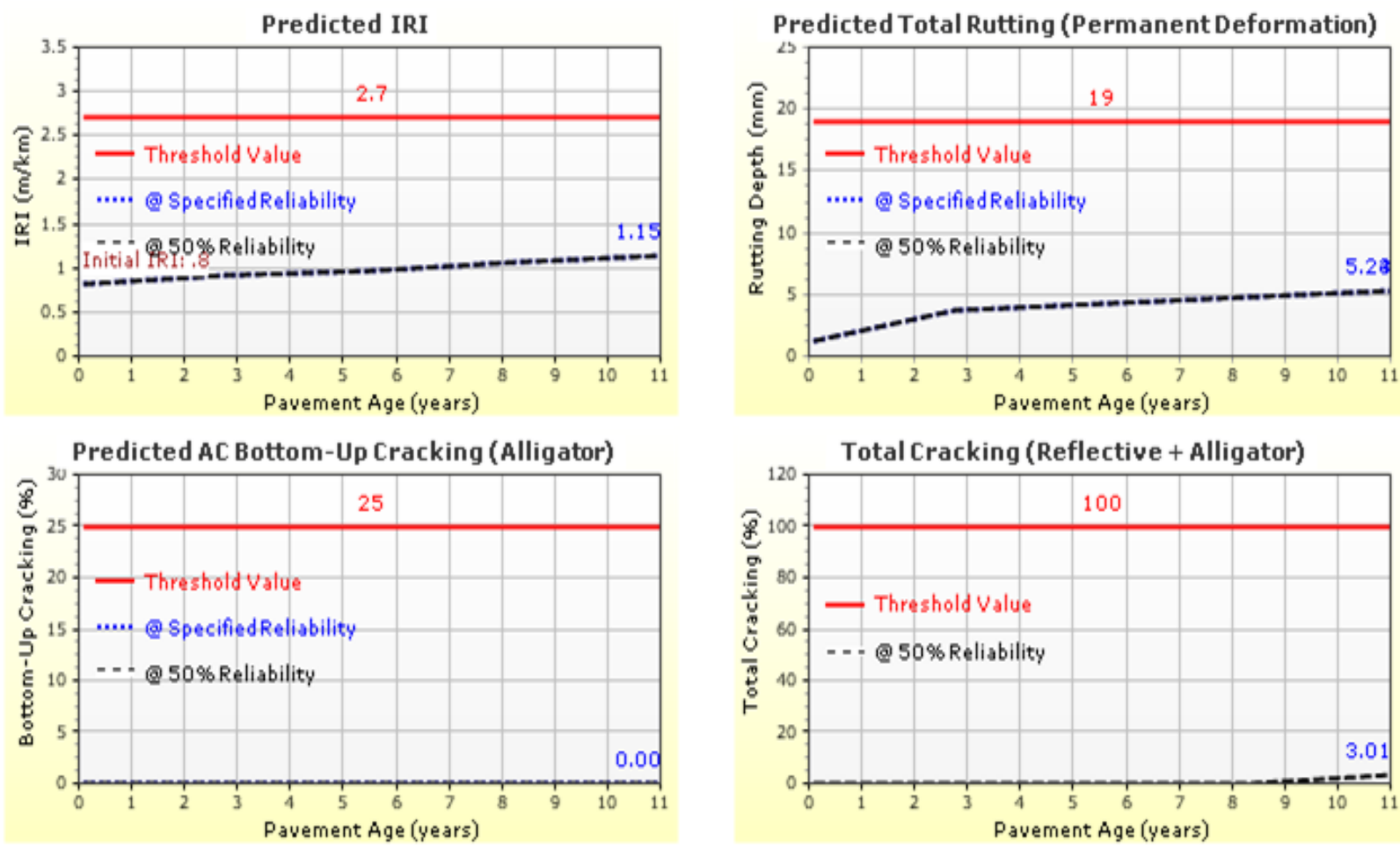

Figure 4-3 Distress charts for key performance parameters

\subsection{Determining criteria for estimation of Design Life and Service Life}

In general, there are different types of distresses in DARWin-ME output which depends

on the structural layer materials used in the trial design and are listed below in Table 4-2

with the default threshold values assumed for the analysis of this study:

Table 4-2: Distress types and their respective threshold values

\begin{tabular}{|c|c|c|}
\hline Distress type & $\begin{array}{c}\text { Target Value } \\
\text { (Threshold Value) }\end{array}$ & Comment \\
\hline Terminal IRI $(\mathrm{m} / \mathrm{km})$ & 2.70 & \\
\hline Permanent deformation - total pavement $(\mathrm{mm})$ & 19.00 & \\
\hline AC bottom-up fatigue cracking (percent) & 25.00 & \\
\hline Total cracking (Reflective + Alligator) (percent) & 100.00 & $\begin{array}{c}\text { may not be shown (depends on } \\
\text { material layers) }\end{array}$ \\
\hline AC thermal fracture $(\mathrm{m} / \mathrm{km})$ & 189.40 & \\
\hline AC top-down fatigue cracking $(\mathrm{m} / \mathrm{km})$ & 378.80 & \\
\hline Permanent deformation - AC only (mm) & 6.0 & \\
\hline Chemically stabilized layer - fatigue fracture (percent) & 25.00 & $\begin{array}{l}\text { may not be shown if the layer } \\
\text { is not included in the design }\end{array}$ \\
\hline
\end{tabular}


These threshold values are changeable and usually confirmed by the regional transportation agencies like Ministry of Transportation Ontario (MTO). It is essential that the analyst and the transportation agency decide the indicative failure distress in any of the following two ways:

(a) Any of the distresses which fails first (as shown in the DARWin-ME output distress curves) would be considered as the failure criterion and the respective pavement age is considered to be the expected design life, and one year grace period is allowed to define the service life [e.g., if the pavement age is found to be 30 year then the design life is 30 years and the service life is to be considered as 29 years]. This one year arbitrary allowance for the transportation agency's preparation for the implementation of rehabilitation works.

(b) Consider only a particular and most dominant distress type, for example IRI, as the failure criterion, and the pavement would be considered as failure only when the DARWin-ME predicted IRI curve crosses (i.e. exceeds) the threshold value, and the respective pavement age is considered to be the design life even though any other distress curve fails prior to the failure of IRI curve.

In our case and in this study, the determining criterion for failure has been considered as any of the distress which occurs first by exceeding the threshold limit line as described above in (a).

\subsection{Determination of Actual Service Life of the Initial Design Section}

The analysis of the output results of the first two columns show that the predicted values of distresses at the $50 \%$ reliability are way below the target distresses at the specified reliability (i.e., $50 \%$ reliability). Also, the analysis of the $3^{\text {rd }}$ and $4^{\text {th }}$ columns shows that 
the achieved performance values are way above (almost 200\% higher) the targeted performance values. This indicates that the 11 year design life of the initial section design of reconstructed flexible pavement does not necessarily represent the service life of the pavement as 11 year. This is very common in most cases that the initial section design life is not the actual service life of the pavement, and with the use of DARWin-ME, very easily the actual design life (or the service life) of the initial design section can be predicted simply by changing the design life in the input data and re-run the program. In this case the iteration of design life is only involved, while all other input remain unchanged.

However, the reverse is also true, that is, it is also possible to determine the pavement section thickness of different layers by changing thickness and material properties and number of layers, while keeping the initial design life fixed. Thus the selected section would represent / predict the actual / true service life of the selected section. In this case, the iteration involves different material properties of different layers, while input data of design life, traffic and climate remain unchanged.

In this report, actual design life (or the service life) has been determined for a given initial section design. After doing several iterations using design life as 15, 20, 30, 40, 42 and 50 years, and keeping all other input data unchanged, it was found that the IRI performance criterion of initial design section fails at the age of 42 year. The IRI of the initial section meets the satisfactory "pass" criteria until the age of 41 year. Therefore, it can be assumed that the predicted service life and the life cycle of the initial design section is 41 year. In this case, only the IRI has been considered to identify the early failure of the service life. Another simple way to identify the actual design life (i.e., 
service life) to run the DARWin-ME for higher value of design life, for example 50 years, and check the distress graphs where the predicted value (usually blue color) exceeds the threshold value (usually red color) which is considered to be the predicted service life of the road section. This would save time for doing several iterations for various design life. The output results of the 42 year and 41 year are given below in

Figure 4-4 and 4-5 respectively.

DARW'T́n

\section{Design Inputs}

\section{AC8-1 Section 9_ 42 yr \\ File Name: C:|Users|m2sharif|Documents|OMAR|ACB-1 Section 9 _ 42 yr.dgpx}

$\begin{array}{lllll}\text { Design Life: } & 42 \text { years } & \text { Base construction: } & \text { August, 1996 } & \text { Climate Data 43.107, -78.945 } \\ \text { Design Type: } & \text { Flexible Pavement } & \text { Pavement construction: } & \text { September, 1996 } & \text { Sources (Lat/Lon) } \\ & & \text { Traffic opening: } & \text { December, 1997 } & \end{array}$

\section{Design Structure}

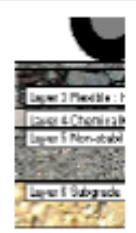

\begin{tabular}{|c|c|c|c|c|}
\hline Layer type & Material Type & Thickness(mm): & \multicolumn{2}{|c|}{ Volumetric at Construction: } \\
\hline Flexible & DFC & 40.0 & Effective binder & 12.4 \\
\hline Flexible & HDB & 90.0 & Content (\%) & 35 \\
\hline Flexible & HL-8 & 130.0 & & \\
\hline Cement_Base & Cement stabilized & 100.0 & & \\
\hline NonStabilized & Granular A & 300.0 & & \\
\hline Subgrade & $\mathrm{ML}$ & Semi-infinite & & \\
\hline
\end{tabular}

Traffic

\begin{tabular}{|c|c|}
\hline Age (year) & $\begin{array}{c}\text { Heavy Trucks } \\
\text { (cumulative) }\end{array}$ \\
\hline 1997 (initial) & 14,124 \\
\hline 2018 (21 years) & $42,250,500$ \\
\hline 2039 (42 years) & $104,976,000$ \\
\hline
\end{tabular}

\section{Design Outputs}

\begin{tabular}{|c|c|c|c|c|c|}
\hline \multirow[t]{2}{*}{ Distress Type } & \multicolumn{2}{|c|}{$\begin{array}{c}\text { Distress @ Specified } \\
\text { Reliability }\end{array}$} & \multicolumn{2}{|c|}{ Reliability (\%) } & \multirow{2}{*}{$\begin{array}{l}\text { Criterion } \\
\text { Satisfied? }\end{array}$} \\
\hline & Target & Predicted & Target & Achieved & \\
\hline Terminal IRI (m/km) & 2.70 & 2.75 & 50.00 & 46.76 & Fail \\
\hline Permanent deformation - total pavement (mm) & 19.00 & 7.89 & 50.00 & 100.00 & Pass \\
\hline AC bottom-up fatigue cracking (percent) & 25.00 & 0.00 & 50.00 & 100.00 & Pass \\
\hline Total Cracking (Reflective + Alligator) (percent) & 100.00 & 4.49 & - & - & - \\
\hline AC thermal fracture $(\mathrm{m} / \mathrm{km})$ & 189.40 & 1.50 & 50.00 & 100.00 & Pass \\
\hline AC top-down fatigue cracking $(\mathrm{m} / \mathrm{km})$ & 378.80 & 0.04 & 50.00 & 100.00 & Pass \\
\hline Permanent deformation - $\mathrm{AC}$ only (mm) & 6.00 & 4.73 & 50.00 & 78.38 & Pass \\
\hline Chemically stabilized layer - fatigue fracture (percent) & 25.00 & 1.09 & - & - & - \\
\hline
\end{tabular}

Figure 4-4 Performance level of the initial section at the age of 42 year 


\section{Design Inputs}

$\begin{array}{lllll}\text { Design Life: } & 41 \text { years } & \text { Base construction: } & \text { August, 1996 } & \text { Climate Data 43.107, -78.945 } \\ \text { Design Type: } & \text { Flexible Pavement } & \text { Pavement construction: } & \text { September, 1996 } \\ & & \text { Traffic opening: } & \text { Secember, 1997 } & \end{array}$

\begin{tabular}{|c|c|c|c|c|c|}
\hline \multicolumn{6}{|c|}{ Design Structure } \\
\hline \multirow{3}{*}{ 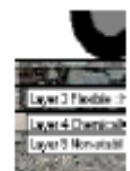 } & Layer type & Material Type & Thickness(mm): & \multicolumn{2}{|c|}{ Volumetric at Construction: } \\
\hline & Flexible & DFC & 40.0 & \multirow{2}{*}{$\begin{array}{l}\text { Effective binder } \\
\text { content (\%) }\end{array}$} & \multirow{2}{*}{12.4} \\
\hline & Flexible & HDB & 90.0 & & \\
\hline \multirow{4}{*}{ 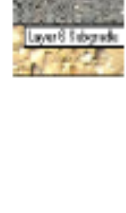 } & Flexible & HL-8 & 130.0 & \multirow{4}{*}{ Air voids (\%) } & \multirow{4}{*}{3.5} \\
\hline & Cement_Base & Cement stabilized & 100.0 & & \\
\hline & NonStabilized & Granular A & 300.0 & & \\
\hline & Subgrade & ML & Semi-infinite & & \\
\hline
\end{tabular}

Traffic
\begin{tabular}{|c|c|}
\hline Age (year) & $\begin{array}{c}\text { Heavy Trucks } \\
\text { (cumulative) }\end{array}$ \\
\hline 1997 (initial) & 14,124 \\
\hline 2017 (20 years) & $41,012,400$ \\
\hline 2038 (41 years) & $101,525,000$ \\
\hline
\end{tabular}

\section{Design Outputs}

\begin{tabular}{|l|c|c|c|c|c|c|}
\hline \multicolumn{1}{|c|}{ Distress Prediction Summary } \\
\hline \multicolumn{1}{|c|}{ Distress Type } & $\begin{array}{c}\text { Distress @ Specified } \\
\text { Reliability }\end{array}$ & \multicolumn{2}{|c|}{ Reliability (\%) } & $\begin{array}{c}\text { Criterion } \\
\text { Satisfied? }\end{array}$ \\
\cline { 2 - 7 } & Target & Predicted & Target & Achieved & \\
\hline Terminal IRI (m/km) & 2.70 & 2.70 & 50.00 & 50.19 & Pass \\
\hline Permanent deformation - total pavement (mm) & 19.00 & 7.82 & 50.00 & 100.00 & Pass \\
\hline AC bottom-up fatigue cracking (percent) & 25.00 & 0.00 & 50.00 & 100.00 & Pass \\
\hline Total Cracking (Reflective + Alligator) (percent) & 100.00 & 4.49 & - & - & - \\
\hline AC thermal fracture (m/km) & 189.40 & 1.39 & 50.00 & 100.00 & Pass \\
\hline AC top-down fatigue cracking (m/km) & 378.80 & 0.04 & 50.00 & 100.00 & Pass \\
\hline Permanent deformation - AC only (mm) & 6.00 & 4.67 & 50.00 & 79.72 & Pass \\
\hline Chemically stabilized layer - fatigue fracture (percent) & 25.00 & 1.07 & - & - & - \\
\hline
\end{tabular}

Figure 4-5 Performance level of the initial section at the age of 41 year

Thus, the actual service life, i.e., the life cycle of the initial section can be considered as 41 years, or other way it can be stated that the initial life cycle of the selected section (initial design section) is 41 years. The distress charts for 41 year are given below in Figure 4-6 


\section{Distress Charts}
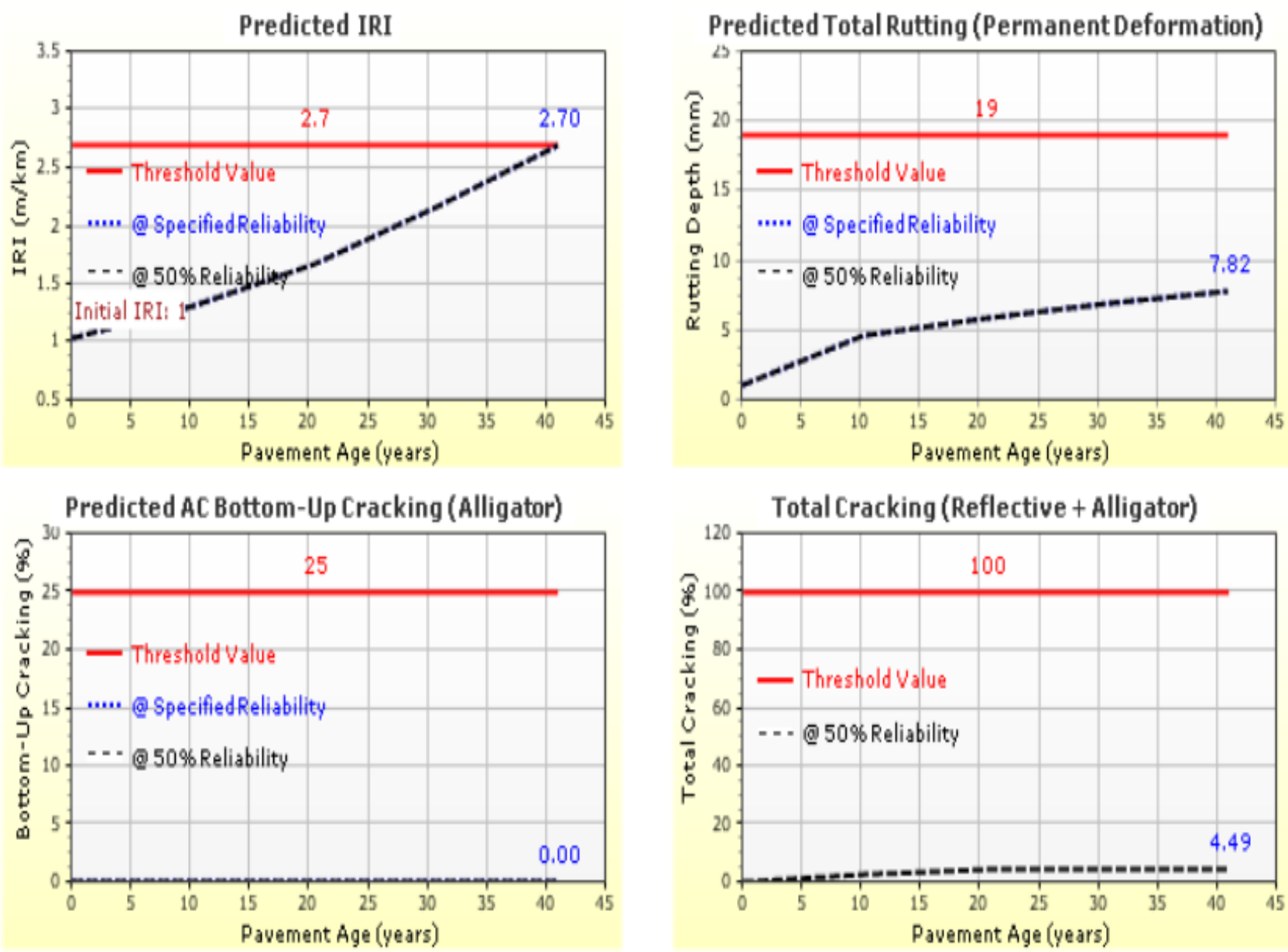

Figure 4-6 Distress charts for the initial design section at the age of 41 year

\subsection{Other Trial Designs and Options}

The LCC analyses require minimum two proposals [NCHRP (2004), appendix C] in order to compare the economic feasibilities. In our case, several more trial designs (proposals) have been studied in the analysis for making a better economic comparison. Since the deterministic approach has been adopted, all proposals have been arbitrarily selected for various structural layers. These are summarized below including the $1^{\text {st }}$ trial design described earlier in section 4-3 and 4-4. 
Table 4-3: Summary of trial designs including the initial design

\begin{tabular}{|c|c|c|c|c|c|c|}
\hline $\begin{array}{c}\text { Structural } \\
\text { Layer Types } \\
\begin{array}{c}\boldsymbol{Q} \\
\text { Service Life }\end{array}\end{array}$ & Material Type & $\begin{array}{c}\text { Option 1 } \\
\text { (Trial No 1) }\end{array}$ & $\begin{array}{c}\text { Option2 } \\
\text { (Trial No 3) }\end{array}$ & $\begin{array}{c}\text { Option 3 } \\
\text { (Trial No 4) }\end{array}$ & $\begin{array}{c}\text { Option 4 } \\
\text { (Trial No 6) }\end{array}$ & $\begin{array}{c}\text { Option 5 } \\
\text { (Trial No 7) }\end{array}$ \\
\hline Flexible & $\begin{array}{c}\text { Asphalt concrete } \\
\text { (DFC) }\end{array}$ & $40 \mathrm{~mm}$ & $30 \mathrm{~mm}$ & $40 \mathrm{~mm}$ & $50 \mathrm{~mm}$ & $50 \mathrm{~mm}$ \\
\hline Flexible & $\begin{array}{c}\text { Aspahlt Concrete } \\
\text { (HDB) }\end{array}$ & $90 \mathrm{~mm}$ & $50 \mathrm{~mm}$ & $90 \mathrm{~mm}$ & - & - \\
\hline Flexible & $\begin{array}{c}\text { Asphalt Concrete } \\
\text { (HL-8) }\end{array}$ & $130 \mathrm{~mm}$ & $80 \mathrm{~mm}$ & $130 \mathrm{~mm}$ & $70 \mathrm{~mm}$ & $70 \mathrm{~mm}$ \\
\hline Cement- Base & $\begin{array}{c}\text { Cement } \\
\text { stabilized }\end{array}$ & $100 \mathrm{~mm}$ & $100 \mathrm{~mm}$ & - & - & - \\
\hline Non-Stabilized & Granular A & $300 \mathrm{~mm}$ & $300 \mathrm{~mm}$ & $400 \mathrm{~mm}$ & $440 \mathrm{~mm}$ & $300 \mathrm{~mm}$ \\
\hline Subgrade & ML & semi-infinite & semi-infinite & semi-infinite & semi-infinite & semi-infinite \\
\hline Design Life & - & $\mathbf{4 1 ~ y e a r}$ & $\mathbf{4 0}$ year & $\mathbf{3 8}$ year & $\mathbf{2 5}$ year & $\mathbf{3 3}$ year \\
\hline Service Life & - & $\mathbf{4 0}$ year & $\mathbf{3 9}$ year & $\mathbf{3 7}$ year & $\mathbf{2 4}$ year & $\mathbf{3 2}$ year \\
\hline
\end{tabular}

The DARWin-ME output for Options 2, 3, 4 and 5 are provided in the Appendix.

\subsection{Maintenance and Rehabilitation Plan}

Although there are various preventive maintenance and rehabilitation (PM \& R) schemes available for flexible pavements, the selection appropriate PM \& R depends on the PMS's site survey report on existing road conditions, budget and importance of the road. However, in this report, the structural overlay which includes removal and replacement of selected pavement layers has been considered arbitrarily as the rehabilitation strategy, while only surface treatments like crack sealing, surface patch and chip sealing are considered as the preventive maintenance and repair strategy.

The reason for selecting these strategies is based on the assumptions that only the top surface of the pavement has been dilapidated since the predicted result from DARWinME shows performance failure in the IRI criterion only at the age of 41 year for the Trial No 1, whereas other performance criteria values remain well below the targeted values. 
An arbitrarily selected option has been analyzed for the overlay application as rehabilitation strategy for the Trial No 1: removal of existing top HMA surface layer up to a depth $40 \mathrm{~mm}$ and place $40 \mathrm{~mm}$ HMA (same properties of HDB as the initial design). The DARWin-ME analysis for the overlay AC over AC shows that the service life is 32 year while the IRI performance fails at 33 year. Thus it can be stated that the selected initial section has life cycle of 41 year and the life cycle of rehab section is 32 year which may be shown schematically in Figure 4-7 below. Although the threshold value (terminal value) of IRI is usually less than the Initial construction (if IRI of initial construction is 2.7 then terminal IRI for rehabilitation section usually is 2.3 ), but in our case we have considered the same initial IRI value as 2.7 in the DARWin-ME analysis for both initial construction and overlay/rehabilitation.

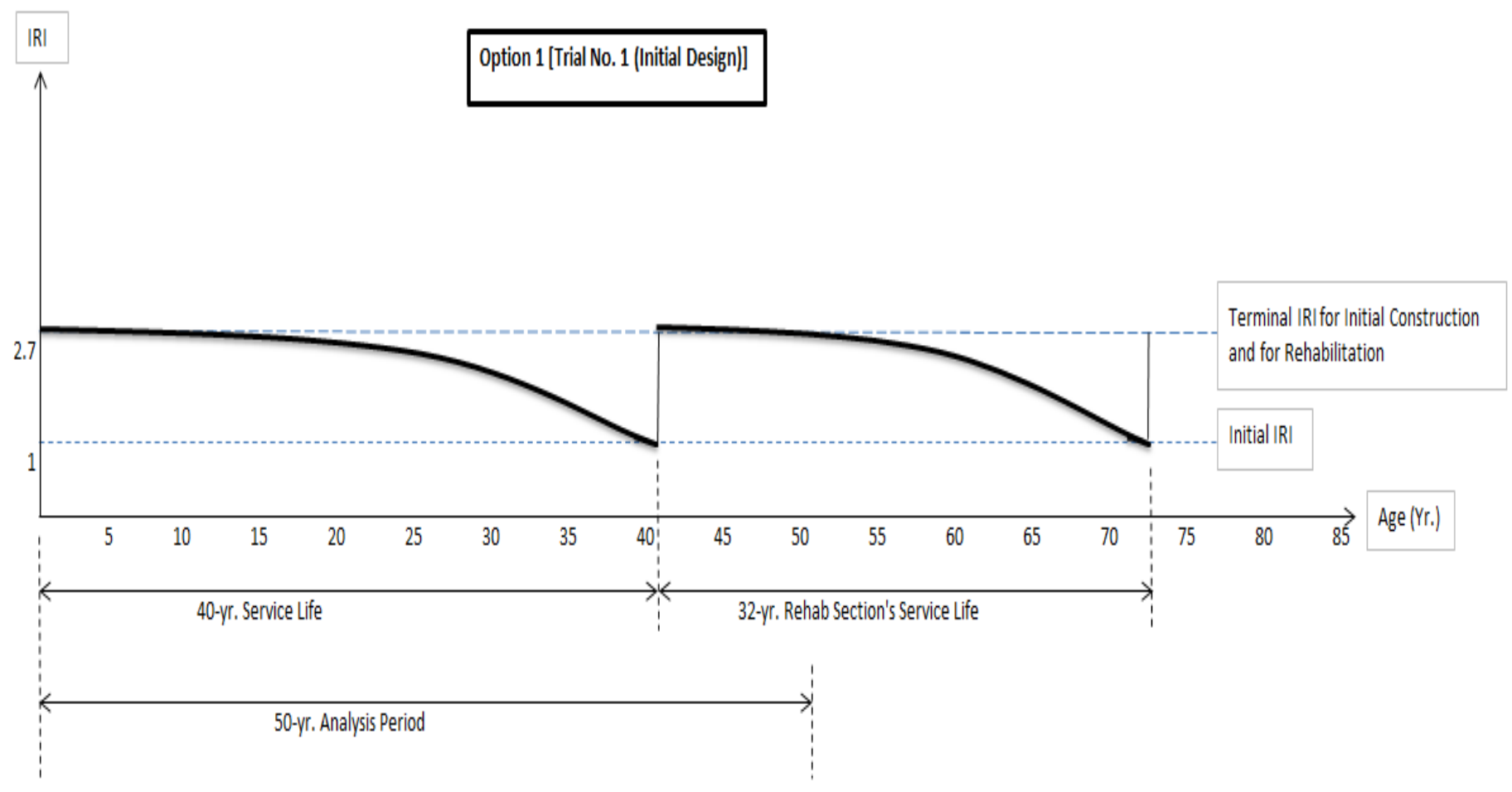

Figure 4-7 Life cycle of the initial design of AC8-1 section 9 
The DARWin-ME output for the arbitrarily selected overlay options are shown in Figure 4-8 and Figure 4-9 below.

DARWIIn

\section{AC8-1 Sec9_1st Rehab Overlay_option 1_33 yr}

File Name: C:|Users/m2sharifDocuments|OMAR/AC8-1 Sec9_ 1st Rehab Overlay_option 1_33 yr.dgpx

\section{Design Inputs}

$\begin{array}{lllll}\text { Design Life: } & 33 \text { years } & \text { Existing construction: } & \text { August, } 1996 & \text { Climate Data 43.107, -78.945 } \\ \text { Design Type: } & \text { AC over AC } & \text { Pavement construction: } & \text { September, 1996 } & \text { Sources (Latlon) } \\ & & \text { Traffic opening: } & \text { December, 1997 } & \end{array}$

\begin{tabular}{|c|c|c|c|c|c|}
\hline \multicolumn{6}{|c|}{ Design Structure } \\
\hline \multirow{3}{*}{ 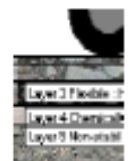 } & Layer type & Material Type & Thickness(mm): & \multicolumn{2}{|c|}{ Volumetric at Construction: } \\
\hline & Flexible & DFC & 40.0 & Effective binder & 12.4 \\
\hline & Flexible & HDB & 90.0 & Content (\%) & 12.4 \\
\hline \multirow{4}{*}{ 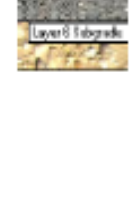 } & Flexible & $\mathrm{HL}-8$ & 130.0 & Hil vorus (\%) & 3.5 \\
\hline & \begin{tabular}{|l} 
Cement_Base \\
\end{tabular} & Cement stabilized & 100.0 & & \\
\hline & NonStabilized & Granular A & 300.0 & & \\
\hline & Subgrade & ML & Semi-infinite & & \\
\hline
\end{tabular}

Traffic

\begin{tabular}{|l|c|}
\hline \multicolumn{1}{|c|}{ Age (year) } & $\begin{array}{c}\text { Heavy Trucks } \\
\text { (cumulative) }\end{array}$ \\
\hline 1997 (initial) & 14,124 \\
\hline 2013 (16 years) & $31,478,900$ \\
\hline 2030 (33 years) & $75,586,600$ \\
\hline
\end{tabular}

\section{Design Outputs}

\begin{tabular}{|l|c|c|c|c|c|c|}
\hline Distress Prediction Summary & \multicolumn{7}{|c|}{} \\
\hline \multicolumn{1}{|c|}{ Distress Type } & $\begin{array}{c}\text { Distress @ Specified } \\
\text { Reliability }\end{array}$ & \multicolumn{2}{c|}{ Reliability (\%) } & $\begin{array}{c}\text { Criterion } \\
\text { Satisfied? }\end{array}$ \\
\cline { 2 - 7 } & Target & Predicted & Target & Achieved & Fail \\
\hline Terminal IRI (m/km) & 2.30 & 2.34 & 50.00 & 47.25 & Pass \\
\hline Permanent deformation - total pavement (mm) & 19.00 & 10.52 & 50.00 & 100.00 & - \\
\hline Total Cracking (Reflective + Alligator) (percent) & 100.00 & 6.69 & - & - & Pass \\
\hline AC thermal fracture (m/km) & 189.40 & 0.23 & 50.00 & 100.00 & Pass \\
\hline AC bottom-up fatigue cracking (percent) & 25.00 & 0.00 & 50.00 & 100.00 & Pass \\
\hline AC top-down fatigue cracking (m/km) & 378.80 & 0.05 & 50.00 & 100.00 & Pass \\
\hline Permanent deformation - AC only (mm) & 6.00 & 5.06 & 50.00 & 70.87 & Pass \\
Chemically stabilized layer - fatigue fracture (percent) & 25.00 & 11.40 & - & - & - \\
\hline
\end{tabular}

Figure 4-8 Rehab option for Trial No 1 (replaced HMA thickness $40 \mathrm{~mm}$ ) at age 33 year [IRI fails] 


\section{Design Inputs}

\begin{tabular}{|c|c|c|c|c|}
\hline Design & 32 years & Existing construction: & August, 1996 & $43.107,-78.945$ \\
\hline Design Type: & $A C$ over $A C$ & $\begin{array}{l}\text { Pavement construction: } \\
\text { Traffic opening: }\end{array}$ & $\begin{array}{l}\text { September, } 1996 \\
\text { December, } 1997\end{array}$ & ces (Lat/Lon) \\
\hline
\end{tabular}

\begin{tabular}{|c|c|c|c|c|c|}
\hline \multicolumn{6}{|c|}{ Design Structure } \\
\hline \multirow{7}{*}{ 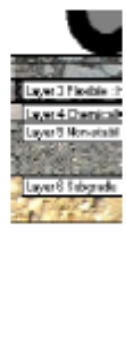 } & Layer type & Material Type & Thickness(mm): & \multicolumn{2}{|c|}{ Volumetric at Construction: } \\
\hline & Flexible & DFC & 40.0 & Effective binder & 12.4 \\
\hline & Flexible & HDB & 90.0 & Content (\%) & \\
\hline & Flexible & HL-8 & 130.0 & Air voids (\%) & 3.5 \\
\hline & Cement_Base & Cement stabilized & 100.0 & & \\
\hline & NonStabilized & Granular A & 300.0 & & \\
\hline & Subgrade & ML & Semi-infinite & & \\
\hline
\end{tabular}

Traffic

\begin{tabular}{|c|c|}
\hline Age (year) & $\begin{array}{c}\text { Heavy Trucks } \\
\text { (cumulative) }\end{array}$ \\
\hline 1997 (initial) & 14,124 \\
\hline 2013 (16 years) & $30,333,700$ \\
\hline 2029 (32 years) & $72,553,200$ \\
\hline
\end{tabular}

\section{Design Outputs}

\begin{tabular}{|c|c|c|c|c|c|}
\hline \multirow[t]{2}{*}{ Distress Type } & \multicolumn{2}{|c|}{$\begin{array}{c}\text { Distress @ Specified } \\
\text { Reliability }\end{array}$} & \multicolumn{2}{|c|}{ Reliability (\%) } & \multirow{2}{*}{$\begin{array}{l}\text { Criterion } \\
\text { Satisfied? }\end{array}$} \\
\hline & Target & Predicted & Target & Achieved & \\
\hline Terminal IRI (m/km) & 2.30 & 2.29 & 50.00 & 50.66 & Pass \\
\hline Permanent deformation - total pavement (mm) & 19.00 & 10.43 & 50.00 & 100.00 & Pass \\
\hline Total Cracking (Reflective + Alligator) (percent) & 100.00 & 6.69 & - & - & - \\
\hline AC thermal fracture $(\mathrm{m} / \mathrm{km})$ & 189.40 & 0.23 & 50.00 & 100.00 & Pass \\
\hline $\mathrm{AC}$ bottom-up fatigue cracking (percent) & 25.00 & 0.00 & 50.00 & 100.00 & Pass \\
\hline AC top-down fatigue cracking $(\mathrm{m} / \mathrm{km})$ & 378.80 & 0.05 & 50.00 & 100.00 & Pass \\
\hline Permanent deformation - $\mathrm{AC}$ only (mm) & 6.00 & 4.98 & 50.00 & 72.75 & Pass \\
\hline Chemically stabilized layer - fatigue fracture (percent) & 25.00 & 11.40 & - & - & - \\
\hline
\end{tabular}

Figure 4-9 Rehab option for Trial No 1 (replaced HMA thickness $=40 \mathrm{~mm}$ ) at age 32 year

Similarly, the rehabilitation schemes for the Options 2, 3, 4 and 5 have been selected arbitrarily and are summarized in Table 4.3 below including the Trial No 1 . In order to maintain the elevation of the road after the rehabilitation and with no addition / modification of drainage, the placement of new HMA has been considered to be the same depth of the removed layer(s). 
Table 4-4: Rehabilitation scheme for all the five trials (or options)

\begin{tabular}{|l|l|}
\hline $\begin{array}{l}\text { Overlay } \\
\text { /Rehab } \\
\text { scheme for }\end{array}$ & \\
\hline $\begin{array}{l}\text { Option 1 } \\
\text { (Trial No 1) }\end{array}$ & $\begin{array}{l}\text { Removal of existing HMA surface layer up to a depth of } 40 \mathrm{~mm} \text { and place } 40 \mathrm{~mm} \text { new } \\
\text { HMA with same properties of the top layer of the initial design }\end{array}$ \\
\hline $\begin{array}{l}\text { Option 2 } \\
\text { (Trial No 3) }\end{array}$ & $\begin{array}{l}\text { Removal of existing HMA surface layer up to a depth of } 80 \mathrm{~mm} \text { and place } 80 \mathrm{~mm} \text { new } \\
\text { HMA with same properties of the top layer of the initial design }\end{array}$ \\
\hline $\begin{array}{l}\text { Option 3 } \\
\text { (Trial No 4) }\end{array}$ & $\begin{array}{l}\text { Removal of existing HMA surface layer up to a depth of } 130 \mathrm{~mm} \text { and place } 130 \mathrm{~mm} \text { new } \\
\text { HMA with same properties of the top layer of the initial design }\end{array}$ \\
\hline $\begin{array}{l}\text { Option 4 } \\
\text { (Trial No 6) }\end{array}$ & $\begin{array}{l}\text { Removal of existing HMA surface layer up to a depth of } 70 \mathrm{~mm} \text { and place } 70 \mathrm{~mm} \text { new } \\
\text { HMA with same properties of the top layer of the initial design }\end{array}$ \\
\hline $\begin{array}{l}\text { Option 5 } \\
\text { (Trial No 7) }\end{array}$ & $\begin{array}{l}\text { Removal of existing HMA surface layer up to a depth of } 70 \mathrm{~mm} \text { and place } 70 \mathrm{~mm} \text { new } \\
\text { HMA with same properties of the top layer of the initial design }\end{array}$ \\
\hline
\end{tabular}

The life cycles all the five trials are summarized for the initial service life and rehabilitated (overlay AC over AC) service life in the Table 4-4 and Table 4-5 below, and schematically shown in Figure 10, 11, 12 and 13 for Option No 2, 3, 4 and 5 respectively.

The DARWin-ME output for options 2, 3, 4 and 5 have been provided in the Appendix.

Table 4-5: Life cycles of initial design and overlay (AC over AC) rehabilitation

\begin{tabular}{|l|c|c|c|c|c|}
\hline & $\begin{array}{c}\text { Initial Design } \\
\text { Option 1 }\end{array}$ & $\begin{array}{c}\text { Option 2 } \\
\text { (TrialNo 3) }\end{array}$ & $\begin{array}{c}\text { Option 3 } \\
\text { (TrialNo 4) }\end{array}$ & $\begin{array}{c}\text { Option 4 } \\
\text { (TrialNo 6) }\end{array}$ & $\begin{array}{c}\text { Option 5 } \\
\text { (TrialNo 7) }\end{array}$ \\
\hline Initial design life & 41 year & 40 year & 38 year & 25 year & 33 year \\
\hline Initial service life & 40 year & 39 year & 37 year & 24 year & 32 year \\
\hline $\begin{array}{l}\text { Service life after rehabilitation } \\
\text { (overlay AC over AC) }\end{array}$ & $\mathbf{3 2}$ year & $\mathbf{3 8}$ year & 37 year & $\mathbf{1 6}$ year & 25 year \\
\hline
\end{tabular}

Table 4-6: Summary of design proposals

\begin{tabular}{|c|c|c|c|c|}
\hline & $\begin{array}{l}\text { Service } \\
\text { Life }\end{array}$ & Initial Conditions & Overlay (Rehab) & $\begin{array}{l}\text { R \& M (Repair } \\
\text { \&Maint. }\end{array}$ \\
\hline Option 1 & 40 year & $\begin{array}{l}3 \text { HMA layers (DFC+HDB+HL-8) + 1-layer } \\
\text { cement-stabilized + 1-layer GBC }\end{array}$ & 1-overlay@41-yr & regular $\mathrm{R} \& \mathrm{M}$ \\
\hline Option 2 & 39 year & $\begin{array}{l}3 \text { HMA layers (DFC+HDB+HL-8) + 1-layer } \\
\text { cement-stabilized + 1-layer GBC }\end{array}$ & 1-overlay@40-yr & regular $\mathrm{R} \& \mathrm{M}$ \\
\hline Option 3 & 37 year & 3 HMA layers (DFC+HDB+HL-8) + 1-layer GBC & 1-overlay @38-yr & regular $\mathrm{R} \& \mathrm{M}$ \\
\hline Option 4 & 24 year & 2 HMA layers (DFC+HL-8) + 1-layer GBC & $\begin{array}{l}\text { 2-overlay } \\
1^{\text {st }} \text { overlay @ 25yr } \\
2^{\text {nd }} \text { overlay @ 40yr }\end{array}$ & regular $\mathrm{R} \& \mathrm{M}$ \\
\hline Option 5 & 32 year & 2 HMA layers (DFC+HL-8) + 1-layer GBC & 1-overlay @33-yr & regular R\&M \\
\hline
\end{tabular}




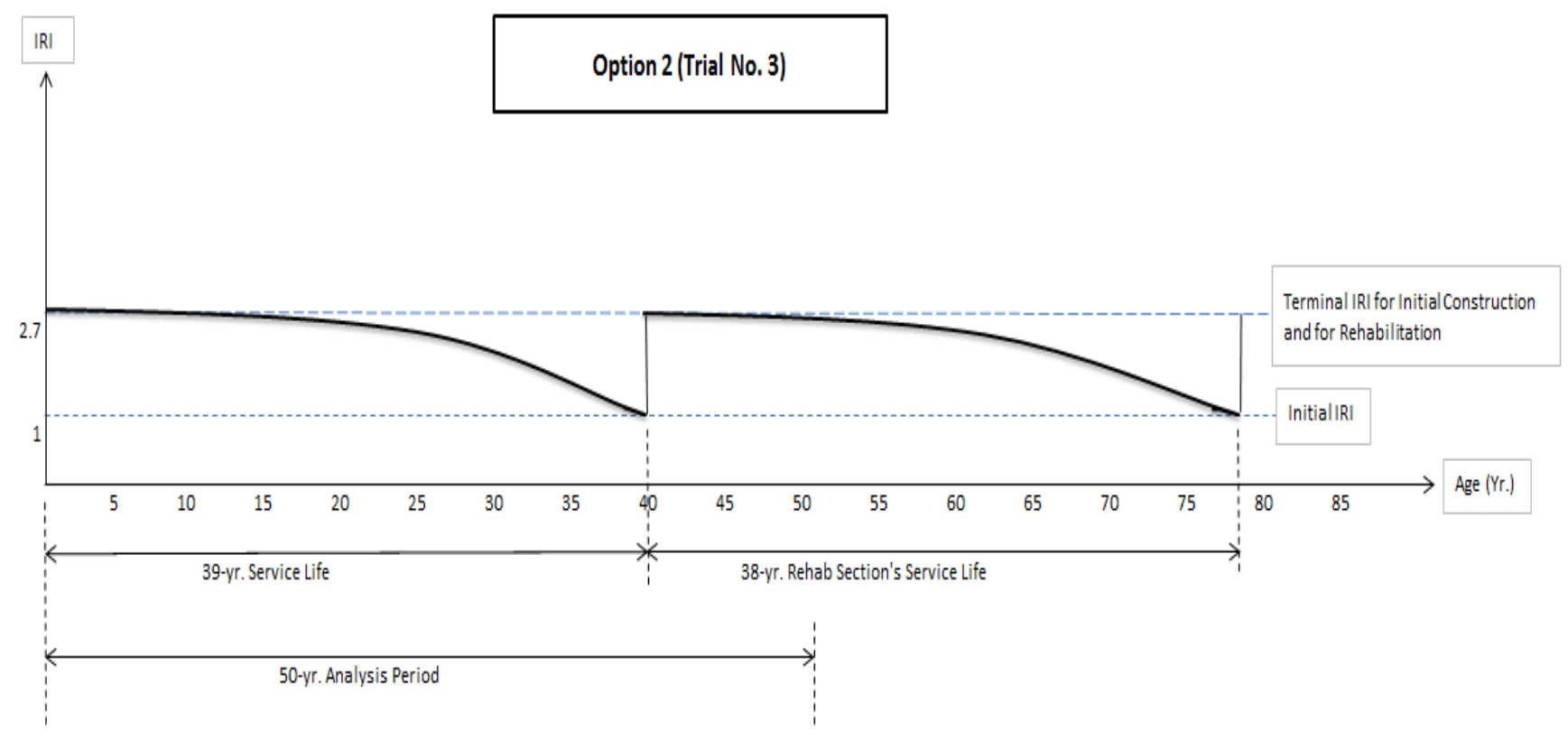

Figure 4-10 Life cycle of the initial design and overlay for Option No 2

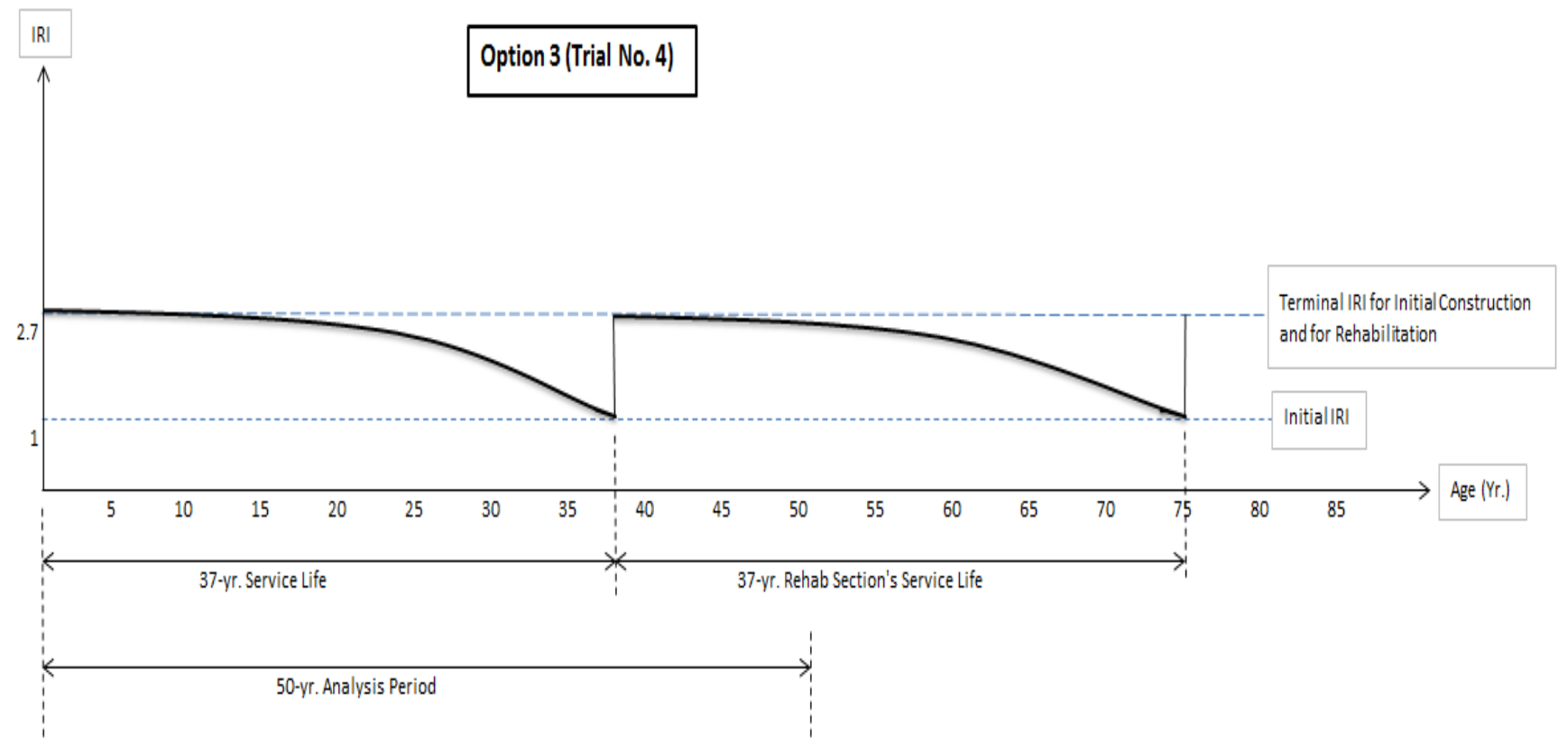

Figure 4-11 Life cycle of the initial design and overlay for Option No 3 


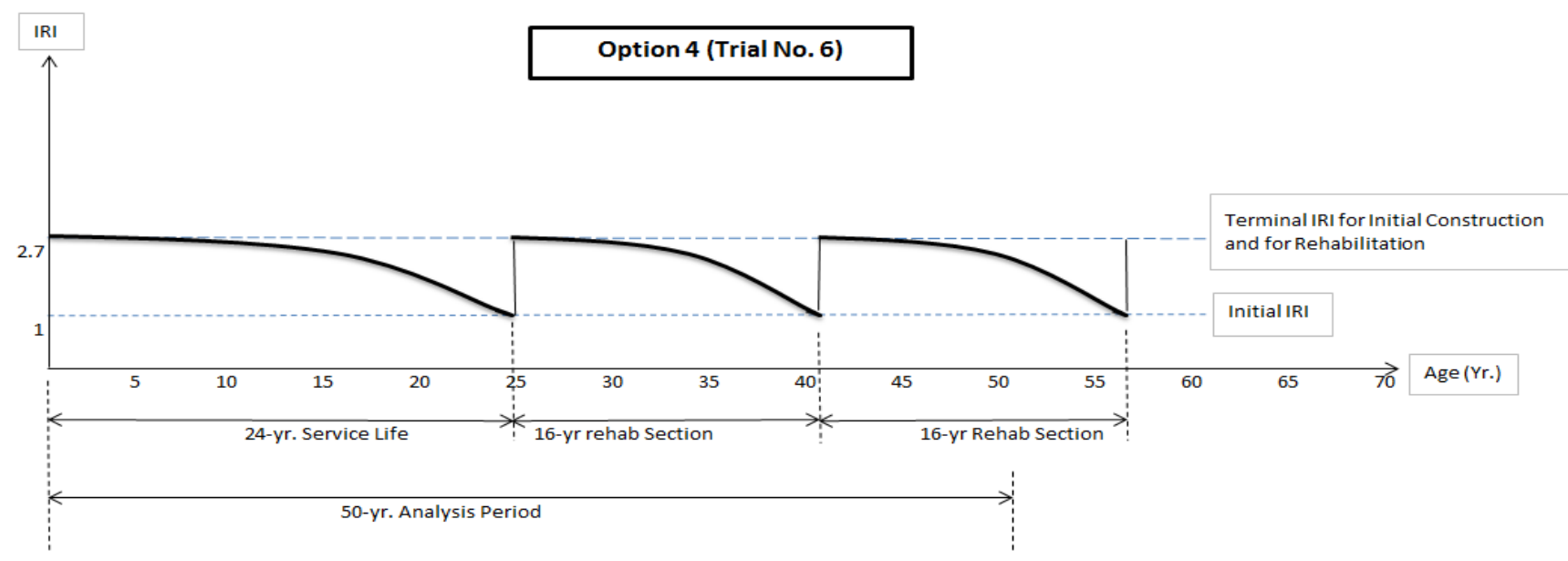

Figure 4-12 Life cycle of the initial design and overlay for Option No 4

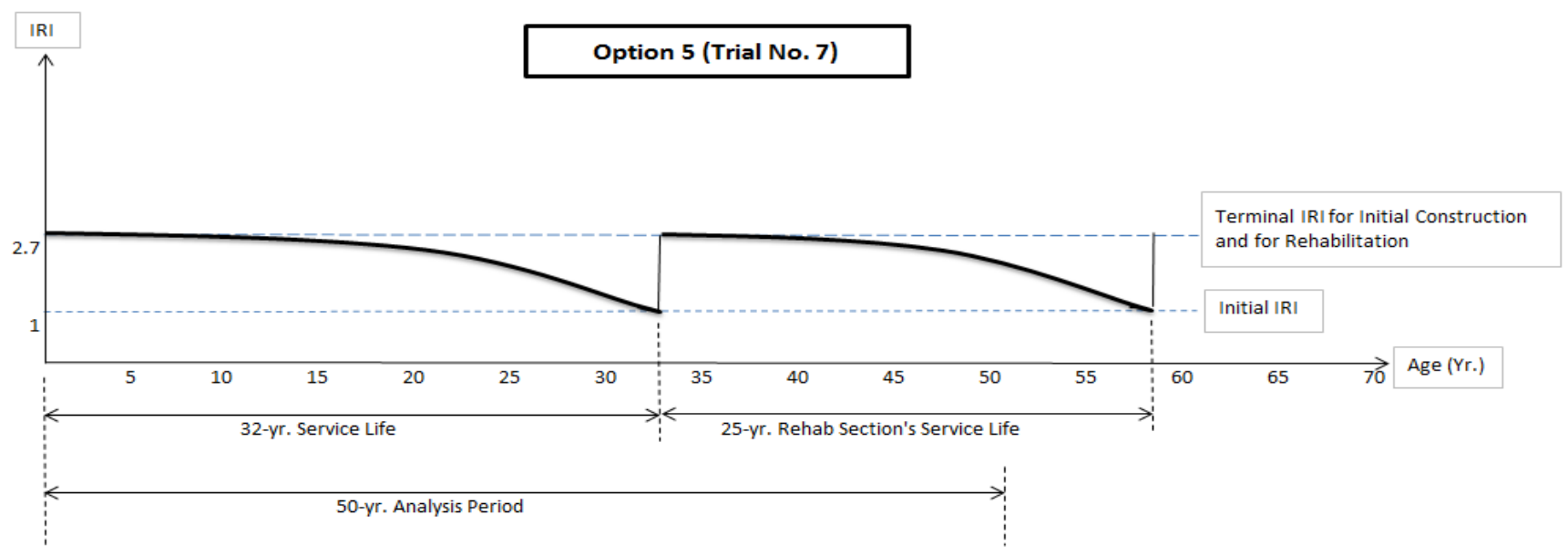

Figure 4-13 Life cycle of the initial design and overlay for Option No 5

\subsection{Cost Calculations}

As mentioned in the AASHTO (2008) the results that show greater than $15 \%$ benefit in estimating LCC would be used to determine the pavement type, whereas results that show a $15 \%$ or less benefit is considered the competing candidates are equivalent. The Net present Worth (NPW) method has been used in estimating the life cycle costs. Although the initial design input data shows base construction date as 1996 and traffic opening in 1997, we consider in this report as the initial construction and traffic opening date as the 
current year of 2013 for simplicity. Also, the unit costs of flexible HMA top layer (layer 1) is considered as Superpave $12.5 \mathrm{FC} 2$, flexible HMA $2^{\text {nd }}$ layer is considered as Superpave $12.5 \mathrm{FC1}$ and the HMA $3^{\text {rd }}$ layer HL- 8 has been considered as Superpave 19. The breakdown of initial construction cost and rehabilitation costs are shown below.

\section{Cost of $1^{\text {st }}$ layer HMA}

3 lanes each direction $=\left(3^{*} 2\right) @ 3.75 \mathrm{~m}$ each lane width $=22.5 \mathrm{~m}$

Layer thickness $=40 \mathrm{~mm}=0.04 \mathrm{~m}$

Length $=1 \mathrm{~km}=1000 \mathrm{~m}$

Unit weight $=2520 \mathrm{~kg} / \mathrm{m}^{3}$

Total weight $=(22.5 \mathrm{~m} * 0.04 \mathrm{~m} * 1000 \mathrm{~m}) * 2520 \mathrm{~kg} / \mathrm{m}^{3}=2,268,000 \mathrm{~kg}=2,268$ ton

Cost $=2,268$ ton @ \$ 120.00 per ton $=\$ 272,160$

\section{Cost of $2^{\text {nd }}$ layer HMA}

3 lanes each direction $=\left(3^{*} 2\right) @ 3.75 \mathrm{~m}$ each lane width $=22.5 \mathrm{~m}$

Layer thickness $=90 \mathrm{~mm}=0.09 \mathrm{~m}$

Length $=1 \mathrm{~km}=1000 \mathrm{~m}$

Unit weight $=2460 \mathrm{~kg} / \mathrm{m}^{3}$

Total weight $=(22.5 \mathrm{~m} * 0.09 \mathrm{~m} * 1000 \mathrm{~m}) * 2460 \mathrm{~kg} / \mathrm{m}^{3}=4,981,500 \mathrm{~kg}=4,981.5$ ton

Cost=4981.5 ton @ \$115.00=\$572,873

\section{Cost of $3^{\text {rd }}$ layer HMA}

3 lanes each direction $=(3 * 2) @ 3.75 \mathrm{~m}$ each lane width $=22.5 \mathrm{~m}$

Layer thickness $=130 \mathrm{~mm}=0.13 \mathrm{~m}$

Length $=1 \mathrm{~km}=1000 \mathrm{~m}$

Unit weight $=2460 \mathrm{~kg} / \mathrm{m}^{3}$

Total weight $=(22.5 \mathrm{~m} * 0.13 \mathrm{~m} * 1000 \mathrm{~m}) * 2460 \mathrm{~kg} / \mathrm{m}^{3}=7,195,500 \mathrm{~kg}=7195.5$ ton

Cost=7195.5 ton @ \$96.00=\$690,768 


\section{Cost of $4^{\text {th }}$ layer Cement Stabilized}

3 lanes each direction $=(3 * 2) @ 3.75 \mathrm{~m}$ each lane width $=22.5 \mathrm{~m}$

Layer thickness $=100 \mathrm{~mm}=0.10 \mathrm{~m}$

Length $=1 \mathrm{~km}=1000 \mathrm{~m}$

Unit weight $=2400 \mathrm{~kg} / \mathrm{m}^{3}$

Total weight $=(22.5 \mathrm{~m} * 0.10 \mathrm{~m} * 1000 \mathrm{~m}) * 2400 \mathrm{~kg} / \mathrm{m}^{3}=5,400,000 \mathrm{~kg}=5400$ ton

Cost $=5,400$ ton @ $\$ 25.00=\$ 135,000$

\section{Cost of $5^{\text {th }}$ layer Non Stabilized Granular A}

3 lanes each direction $=(3 * 2) @ 3.75 \mathrm{~m}$ each lane width $=22.5 \mathrm{~m}$

Layer thickness $=300 \mathrm{~mm}=0.30 \mathrm{~m}$

Length $=1 \mathrm{~km}=1000 \mathrm{~m}$

Unit weight $=2170 \mathrm{~kg} / \mathrm{m}^{3}$

Total weight $=(22.5 \mathrm{~m} * 0.30 \mathrm{~m} * 1000 \mathrm{~m}) * 2170 \mathrm{~kg} / \mathrm{m}^{3}=14,647,500 \mathrm{~kg}=14,647.5$ ton

Cost $=14,647.5$ ton @ $\$ 18.00=\$ 263,655$

Table 4-7: Initial construction cost for Option 1 (Trial No 1)

\begin{tabular}{|l|l|l|l|l|l|}
\hline \multicolumn{1}{|c|}{$\begin{array}{c}\text { Pavement } \\
\text { Layertype }\end{array}$} & \multicolumn{1}{|c|}{$\begin{array}{c}\text { Material type } \\
\text { Amount, Quantity }\end{array}$} & $\begin{array}{c}\text { Amount } \\
(\mathrm{mm})\end{array}$ & $\begin{array}{c}\text { Quantity per } \\
\mathrm{km}(\text { ton })\end{array}$ & $\begin{array}{c}\text { Price per unit } \\
\text { Quantity }\end{array}$ & Cost \\
\hline Flexible HMA & $\begin{array}{l}\text { DFC [Superpave } \\
12.5 \text { FC2], mm (ton) }\end{array}$ & 40 & 2268 & $\$ 120.00$ & $\$ 272,160$ \\
\hline Flexible HMA & $\begin{array}{l}\text { HDB [Superpave } \\
12.5 \text { FC1], }\end{array}$ & 90 & $4,981.5$ & $\$ 115.00$ & $\$ 572,873$ \\
\hline Flexible HMA & HL-8 [Superpave 19] & 130 & 7195.5 ton & $\$ 96.00$ & $\$ 690,768$ \\
\hline Cement Base & Cement Stabilized & 100 & 5400 ton & $\$ 25.00$ & $\$ 135,000$ \\
\hline Non Stabilized & Granular A & 300 & $14,647.5$ ton & $\$ 18.00$ & $\$ 263,655$ \\
\hline $\begin{array}{l}\text { Subgrade } \\
\text { Compaction }\end{array}$ & ML (inorganic silt) & - & & & \\
\hline Total initial cost & & & & & $\$ 1,934,456$ \\
\hline
\end{tabular}


Table 4-8: Initial construction cost for Option 2 (Trial No 3)

\begin{tabular}{|l|l|l|l|l|l|}
\hline \multicolumn{1}{|c|}{$\begin{array}{c}\text { Pavement } \\
\text { Layer type }\end{array}$} & \multicolumn{1}{|c|}{$\begin{array}{c}\text { Material type } \\
\text { Amount, Quantity }\end{array}$} & $\begin{array}{c}\text { Amount } \\
(\mathrm{mm})\end{array}$ & $\begin{array}{c}\text { Quantity per } \\
\mathrm{km} \text { (ton) }\end{array}$ & $\begin{array}{c}\text { Price per unit } \\
\text { Quantity }\end{array}$ & Cost \\
\hline Flexible HMA & $\begin{array}{l}\text { DFC [Superpave } \\
12.5 \text { FC2], mm (ton) }\end{array}$ & 30 & 1701 & $\$ 120.00$ & $\$ 204,120$ \\
\hline Flexible HMA & $\begin{array}{l}\text { HDB [Superpave } \\
12.5 \text { FC1], }\end{array}$ & 50 & 2768 & $\$ 115.00$ & $\$ 318,320$ \\
\hline Flexible HMA & HL-8 [Superpave 19] & 80 & 4428 ton & $\$ 96.00$ & $\$ 425,088$ \\
\hline Cement Base & Cement Stabilized & 100 & 5400 ton & $\$ 25.00$ & $\$ 135,000$ \\
\hline Non Stabilized & Granular A & 300 & $14,647.5$ ton & $\$ 18.00$ & $\$ 263,655$ \\
\hline $\begin{array}{l}\text { Subgrade } \\
\text { Compaction }\end{array}$ & ML (inorganic silt) & - & & & \\
\hline Total initial cost & & & & \\
\hline
\end{tabular}

Table 4-9: Initial construction cost for Option 3 (Trial No 4)

\begin{tabular}{|l|l|l|l|l|l|}
\hline \multicolumn{1}{|c|}{$\begin{array}{c}\text { Pavement } \\
\text { Layer type }\end{array}$} & \multicolumn{1}{|c|}{$\begin{array}{c}\text { Material type } \\
\text { Amount, Quantity }\end{array}$} & $\begin{array}{c}\text { Amount } \\
(\mathrm{mm})\end{array}$ & $\begin{array}{c}\text { Quantity per } \\
\mathrm{km} \text { (ton) }\end{array}$ & $\begin{array}{c}\text { Price per unit } \\
\text { Quantity }\end{array}$ & Cost \\
\hline Flexible HMA & $\begin{array}{l}\text { DFC [Superpave } \\
12.5 \text { FC2], mm (ton) }\end{array}$ & 40 & 2268 & $\$ 120.00$ & $\$ 272,160$ \\
\hline Flexible HMA & $\begin{array}{l}\text { HDB [Superpave } \\
12.5 \text { FC1], }\end{array}$ & 90 & $4,981.5$ & $\$ 115.00$ & $\$ 572,873$ \\
\hline Flexible HMA & HL-8 [Superpave 19] & 130 & 7195.5 ton & $\$ 96.00$ & $\$ 690,768$ \\
\hline Non Stabilized & Granular A & 400 & 19,530 ton & $\$ 18.00$ & $\$ 351,540$ \\
\hline $\begin{array}{l}\text { Subgrade } \\
\text { Compaction }\end{array}$ & ML (inorganic silt) & - & & & \\
\hline Total initial cost & & & & \\
\hline
\end{tabular}

Table 4-10: Initial construction cost for Option 4 (Trial No 6)

\begin{tabular}{|l|l|l|l|l|l|}
\hline \multicolumn{1}{|c|}{$\begin{array}{c}\text { Pavement } \\
\text { Layer type }\end{array}$} & \multicolumn{1}{|c|}{$\begin{array}{c}\text { Material type } \\
\text { Amount, Quantity }\end{array}$} & $\begin{array}{c}\text { Amount } \\
(\mathrm{mm})\end{array}$ & $\begin{array}{c}\text { Quantity per } \\
\mathrm{km} \text { (ton) }\end{array}$ & $\begin{array}{c}\text { Price per unit } \\
\text { Quantity }\end{array}$ & Cost \\
\hline Flexible HMA & $\begin{array}{l}\text { DFC [Superpave } \\
12.5 \text { FC2], mm (ton) }\end{array}$ & 50 & 2835 & $\$ 120.00$ & $\$ 340,200$ \\
\hline Flexible HMA & HL-8 [Superpave 19] & 70 & 3875 ton & $\$ 96.00$ & $\$ 372,000$ \\
\hline Non Stabilized & Granular A & 440 & 21,483 ton & $\$ 18.00$ & $\$ 386,694$ \\
\hline $\begin{array}{l}\text { Subgrade } \\
\text { Compaction }\end{array}$ & ML (inorganic silt) & - & & & \\
\hline \multicolumn{7}{|l|}{ Total initial cost } & & & $\$ 1,098,894$ \\
\hline
\end{tabular}


Table 4-11: Initial construction cost for Option 5 (Trial No 7)

\begin{tabular}{|l|l|l|l|l|l|}
\hline \multicolumn{1}{|c|}{$\begin{array}{c}\text { Pavement } \\
\text { Layer type }\end{array}$} & \multicolumn{1}{|c|}{$\begin{array}{c}\text { Material type } \\
\text { Amount, Quantity }\end{array}$} & $\begin{array}{c}\text { Amount } \\
(\mathrm{mm})\end{array}$ & $\begin{array}{c}\text { Quantity per } \\
\mathrm{km} \text { (ton) }\end{array}$ & $\begin{array}{c}\text { Price per unit } \\
\text { Quantity }\end{array}$ & Cost \\
\hline Flexible HMA & $\begin{array}{l}\text { DFC [Superpave } \\
12.5 \text { FC2], mm (ton) }\end{array}$ & 50 & 2835 & $\$ 120.00$ & $\$ 340,200$ \\
\hline Flexible HMA & HL-8 [Superpave 19] & 70 & 3875 ton & $\$ 96.00$ & $\$ 372,000$ \\
\hline Non Stabilized & Granular A & 300 & $14,647.5$ ton & $\$ 18.00$ & $\$ 263,655$ \\
\hline $\begin{array}{l}\text { Subgrade } \\
\text { Compaction }\end{array}$ & ML (inorganic silt) & - & & & \\
\hline Total initial cost & & & & $\$ 975,855$ \\
\hline
\end{tabular}

The costs of rehabilitation for all the five trials (options) are summarized in Table 4-12

below.

Table 4-12: Rehabilitation Action Plan [adapted from Holt et al (2011)]

\begin{tabular}{|c|c|c|c|c|c|c|}
\hline $\begin{array}{l}\text { Rehabilitation } \\
\text { Activity }\end{array}$ & $\begin{array}{l}\text { Description of pavement } \\
\text { layer Amount (quantity) }\end{array}$ & Amount & $\begin{array}{l}\text { Quantity } \\
\text { per km }\end{array}$ & $\begin{array}{l}\text { Price per } \\
\text { unit of } \\
\text { quantity }\end{array}$ & Cost & $\begin{array}{l}\text { Net Present worth } \\
P W=F(1+i)^{-n}\end{array}$ \\
\hline \multirow{2}{*}{$\begin{array}{l}\text { Option } 1 \\
\text { 4lyears after } \\
\text { initial } \\
\text { construction }\end{array}$} & mill HMA, mm (t) & 40 & 2268 & $\$ 15.00$ & $\$ 34,020$ & $\begin{array}{l}\$ 34,020(1+0.07)^{-41} \\
=\$ 2,124\end{array}$ \\
\hline & $\begin{array}{l}\text { Resurface with DFC } \\
\text { (Superpave } 12.5 \mathrm{FC} 2 \text { ) }\end{array}$ & 40 & 2268 & $\$ 120.00$ & $\$ 272,160$ & $\begin{array}{l}\$ 272,160(1+0.07)^{-41} \\
=\$ 16,986\end{array}$ \\
\hline \multirow{2}{*}{$\begin{array}{l}\text { Option } 2 \\
\text { 40years after } \\
\text { initial } \\
\text { construction }\end{array}$} & mill HMA, mm (t) & 80 & 4536 & $\$ 15.00$ & $\$ 68,040$ & $\begin{array}{l}\$ 68,040(1+0.07)^{-40} \\
=\$ 4,544\end{array}$ \\
\hline & $\begin{array}{l}\text { Resurface with DFC } \\
\text { (Superpave } 12.5 \text { FC2) }\end{array}$ & 80 & 4536 & $\$ 120.00$ & $\$ 544,320$ & $\begin{array}{l}\$ 544,320(1+0.07)^{-40} \\
=\$ 36,350\end{array}$ \\
\hline \multirow{2}{*}{$\begin{array}{l}\text { Option } 3 \\
\text { 38years after } \\
\text { initial } \\
\text { construction }\end{array}$} & mill HMA, mm (t) & 130 & 7371 & $\$ 15.00$ & $\$ 110,565$ & $\begin{array}{l}\$ 110,565(1+0.07)^{-38} \\
=\$ 8,454\end{array}$ \\
\hline & $\begin{array}{l}\text { Resurface with DFC } \\
\text { (Superpave } 12.5 \text { FC2) }\end{array}$ & 130 & 7371 & $\$ 120.00$ & $\$ 884,520$ & $\begin{array}{l}\$ 884,520(1+0.07)^{-38} \\
=\$ 67,628\end{array}$ \\
\hline \multirow{4}{*}{$\begin{array}{l}\text { Option } 4 \\
25 y e a r s \text { after } \\
\text { initial } \\
\text { construction } \\
\text { and } 16 \text { years } \\
\text { after } 1^{\text {st }} \text { rehab } \\
\text { (overlay) }\end{array}$} & mill HMA, mm (t) & 70 & 3969 & $\$ 15.00$ & $\$ 59,535$ & $\begin{array}{l}\$ 59,535(1+0.07)^{-25} \\
=\$ 10,970\end{array}$ \\
\hline & $\begin{array}{l}\text { Resurface with DFC } \\
\text { (Superpave } 12.5 \text { FC2) }\end{array}$ & 70 & 3969 & $\$ 120.00$ & $\$ 476,280$ & $\begin{array}{l}\$ 476,280(1+0.07)^{-25} \\
=\$ 87,755\end{array}$ \\
\hline & mill HMA, mm (t) & 70 & 3969 & $\$ 15.00$ & $\$ 59,535$ & $\begin{array}{l}\$ 59,535(1+0.07)^{-40} \\
=\$ 3,976\end{array}$ \\
\hline & $\begin{array}{l}\text { Resurface with DFC } \\
\text { (Superpave } 12.5 \text { FC2) }\end{array}$ & 70 & 3969 & $\$ 120.00$ & $\$ 476,280$ & $\begin{array}{l}\$ 476,280(1+0.07)^{-40} \\
=\$ 31,807\end{array}$ \\
\hline \multirow{2}{*}{$\begin{array}{l}\text { Option } 5 \\
\text { 33years after } \\
\text { initial } \\
\text { construction }\end{array}$} & mill HMA, mm (t) & 70 & 3969 & $\$ 15.00$ & $\$ 59,535$ & $\begin{array}{l}\$ 59,535(1+0.07)^{-33} \\
=\$ 6,385\end{array}$ \\
\hline & $\begin{array}{l}\text { Resurface with DFC } \\
\text { (Superpave } 12.5 \text { FC2) }\end{array}$ & 70 & 3969 & $\$ 120.00$ & $\$ 476,280$ & $\begin{array}{l}\$ 476,280(1+0.07)^{-33} \\
=\$ 51,074\end{array}$ \\
\hline
\end{tabular}


Table 4-13: Arbitrarily selected preventive maintenance and repair (PM\& R) action plan for a 50-yr analysis period [adapted from Holt et. al (2011)].

\begin{tabular}{|c|c|c|c|c|c|c|}
\hline $\begin{array}{l}\text { Years after } \\
\text { initial } \\
\text { construction }\end{array}$ & $\begin{array}{c}\text { pavement Layer } \\
\text { Amount (Quantity) }\end{array}$ & Amount & $\begin{array}{l}\text { Quantity } \\
\text { per km }\end{array}$ & $\begin{array}{l}\text { Unit } \\
\text { price }\end{array}$ & Cost & $\begin{array}{c}\text { Net present worth } \\
P W=F(1+i)^{-n} \\
i=7 \%, n=\text { year }\end{array}$ \\
\hline 5 & Rout and seal, m (m) & 200 & 200 & $\$ 5.00$ & $\$ 1,000$ & $\begin{array}{l}\$ 1000(1+0.07)^{-5} \\
=\$ 713\end{array}$ \\
\hline 10 & Rout and seal, m (m) & 500 & 500 & $\$ 5.00$ & $\$ 2,500$ & $\begin{array}{l}\$ 2500(1+0.07)^{-10} \\
=\$ 1,271\end{array}$ \\
\hline 10 & $\begin{array}{llll}\text { Spot repairs, } & \text { mill } & 40 \\
\mathrm{~mm} / \text { patch, } & 40 & \mathrm{~mm}, & \% \\
\text { area }\left(\mathrm{m}^{2}\right) & & & \end{array}$ & 5 & 750 & $\$ 35.00$ & $\$ 26,250$ & $\begin{array}{l}\$ 26250(1+0.07)^{-10} \\
=\$ 13,345\end{array}$ \\
\hline 15 & Rout and seal, m (m) & 750 & 750 & $\$ 5.00$ & $\$ 3,750$ & $\begin{array}{l}\$ 3750(1+0.07)^{-15} \\
=\$ 1,360\end{array}$ \\
\hline 20 & Rout and seal, m (m) & 1000 & 1000 & $\$ 5.00$ & $\$ 5,000$ & $\begin{array}{l}\$ 5000(1+0.07)^{-20} \\
=\$ 1,293\end{array}$ \\
\hline 20 & $\begin{array}{lccc}\text { Spot repairs, } & \text { mill } & 40 \\
\mathrm{~mm} / \text { patch, } & 40 & \mathrm{~mm}, & \% \\
\text { area }\left(\mathrm{m}^{2}\right) & & & \end{array}$ & 10 & 1500 & $\$ 35.00$ & $\$ 52,500$ & $\begin{array}{l}\$ 52500(1+0.07)^{-20} \\
=\$ 13,567\end{array}$ \\
\hline 25 & Rout and seal, m (m) & 1250 & & $\$ 5.00$ & $\$ 6,250$ & $\begin{array}{l}\$ 6250(1+0.07)^{-25} \\
=\$ 1,152\end{array}$ \\
\hline 25 & $\begin{array}{l}\text { Resurface }\left(1^{\text {st }} \text { rehab }\right) \text { for } \\
\text { Option } 4 \text { (Trial No 6) }\end{array}$ & - & - & - & - & - \\
\hline 30 & Rout and seal, m (m) & 1500 & & $\$ 5.00$ & $\$ 7,500$ & $\begin{array}{l}\$ 7500(1+0.07)^{-30} \\
=\$ 986\end{array}$ \\
\hline 30 & $\begin{array}{llll}\text { Spot repairs, } & \text { mill } & 40 \\
\mathrm{~mm} / \text { patch, } & 40 & \mathrm{~mm}, & \% \\
\text { area }\left(\mathrm{m}^{2}\right) & & & \\
\end{array}$ & 10 & 750 & $\$ 35.00$ & $\$ 26,250$ & $\begin{array}{l}\$ 26250(1+0.07)^{-30} \\
=\$ 3,449\end{array}$ \\
\hline 32 & $\begin{array}{l}\text { Resurface (rehab) for } \\
\text { Option } 5 \text { (Trial No 7) }\end{array}$ & - & - & - & - & - \\
\hline 35 & Rout and seal, m (m) & 1750 & & $\$ 5.00$ & $\$ 8,750$ & $\begin{array}{l}\$ 8750(1+0.07)^{-35} \\
=\$ 820\end{array}$ \\
\hline 38 & $\begin{array}{l}\text { Resurface (rehab) for } \\
\text { Option } 3 \text { (Trial No 4) }\end{array}$ & - & - & - & - & - \\
\hline 40 & Rout and seal, m (m) & 2000 & & $\$ 5.00$ & $\$ 10,000$ & $\begin{array}{l}\$ 10,000(1+0.07)^{-40} \\
=\$ 668\end{array}$ \\
\hline 40 & $\begin{array}{lrrr}\text { Spot repairs, } & \text { mill } & 40 \\
\mathrm{~mm} / \text { patch, } 40 & \mathrm{~mm}, \quad \% \\
\text { area }\left(\mathrm{m}^{2}\right) & & & \\
\end{array}$ & 10 & 750 & $\$ 35.00$ & $\$ 26,250$ & $\begin{array}{l}\$ 26250(1+0.07)^{-40} \\
=\$ 1,753\end{array}$ \\
\hline 40 & $\begin{array}{l}\text { Resurface (rehab) for } \\
\text { Option } 2 \text { (Trial No 3) }\end{array}$ & - & - & - & - & - \\
\hline 40 & $\begin{array}{l}\text { Resurface }\left(2^{\text {nd }} \text { rehab) for }\right. \\
\text { Option } 4 \text { (Trial No 6) }\end{array}$ & - & - & - & - & - \\
\hline 41 & $\begin{array}{l}\text { Resurface (rehab) for } \\
\text { Option } 1 \text { (Trial No 1) }\end{array}$ & - & - & - & - & - \\
\hline 46 & Rout and seal, $\mathrm{m}(\mathrm{m})$ & 200 & 200 & $\$ 5.00$ & $\$ 1,000$ & $\begin{array}{l}\$ 1000(1+0.07)^{-46} \\
=\$ 45\end{array}$ \\
\hline 50 & Rout and seal, m (m) & 500 & 500 & $\$ 5.00$ & $\$ 2,500$ & $\begin{array}{l}\$ 2500(1+0.07)^{-50} \\
=\$ 85\end{array}$ \\
\hline \multicolumn{6}{|c|}{ Total preventive maintenance and repair (PM \& R) cost (discounted) } & $\$ 40,507$ \\
\hline
\end{tabular}


Life cycle costs comparisons of all the five options are presented in the Table 4-14 below.

Table 4-14: LCC Summary of the five options

\begin{tabular}{|l|r|r|r|r|r|}
\hline \multirow{2}{*}{ Item } & \multicolumn{5}{|c|}{ Design Alternatives } \\
\cline { 2 - 6 } & \multicolumn{1}{|c|}{$\begin{array}{c}\text { Option 1 } \\
\text { (Trial No 1) }\end{array}$} & $\begin{array}{c}\text { Option 2 } \\
\text { (Trial No3) }\end{array}$ & $\begin{array}{c}\text { Option 3 } \\
\text { (Trial No 4) }\end{array}$ & $\begin{array}{c}\text { Option 4 } \\
\text { (Trial No 6) }\end{array}$ & $\begin{array}{c}\text { Option 5 } \\
\text { (Trial No 7) }\end{array}$ \\
\hline Initial Cost & $\$ 1,934,456$ & $\$ 1,346,183$ & $\$ 1,887,341$ & $\$ 1,098,894$ & $\$ 975,855$ \\
\hline Rehab Cost (Discounted) & $\$ 19,110$ & $\$ 40,894$ & $\$ 76,082$ & $\$ 134,508$ & $\$ 57,459$ \\
\hline Preventive Maintenance & $\$ 40,507$ & $\$ 40,507$ & $\$ 40,507$ & $\$ 40,507$ & $\$ 40,507$ \\
and Repair(PM\&R) & & & & & \\
Cost(discounted) & & & & & \\
\hline Total Cost & $\$ 2,034,491$ & $\$ 1,427,584$ & $\$ 2,003,930$ & $\$ 1,273,909$ & $\$ 1,073,821$ \\
\hline
\end{tabular}

Since the LCC difference between the lowest two options (Option 4 and Option 5) is more than $15 \%$, therefore, Option 5 (Trial No. 7) is considered to be most economic option for the design of the proposed road section. However, the cost calculations considered here are indicative only and include only the construction item's costs. The real-world cost items and quantities would be required to do the actual costing.

The graphical representation of these five options is shown in Figure 4-14, and also, the cost streams of the most economic trial design [Option 5 (Trial No 7)] is shown in Figure 4-15 below. 


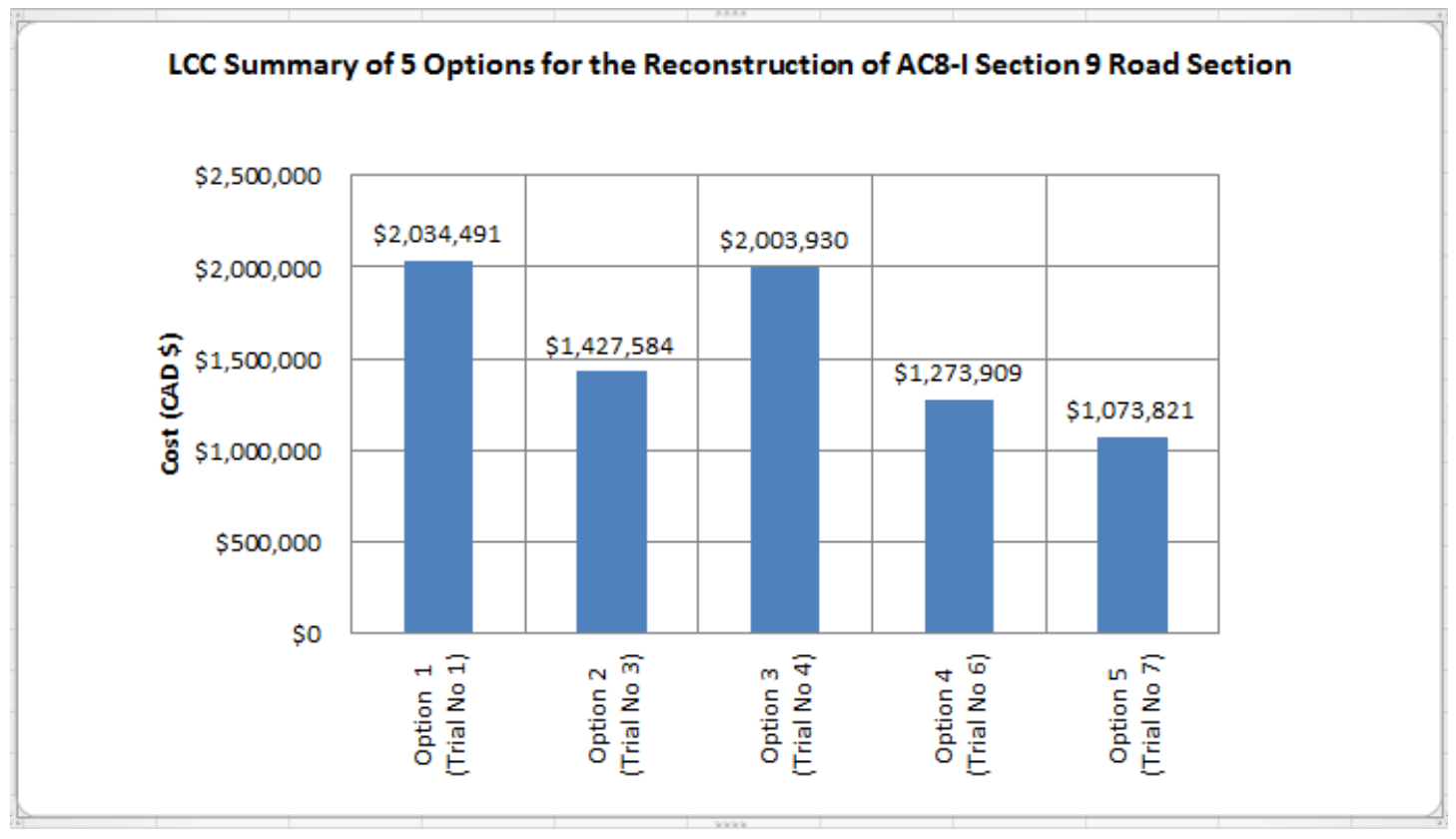

Figure 4-14 Graphical representation of LCC for the five options

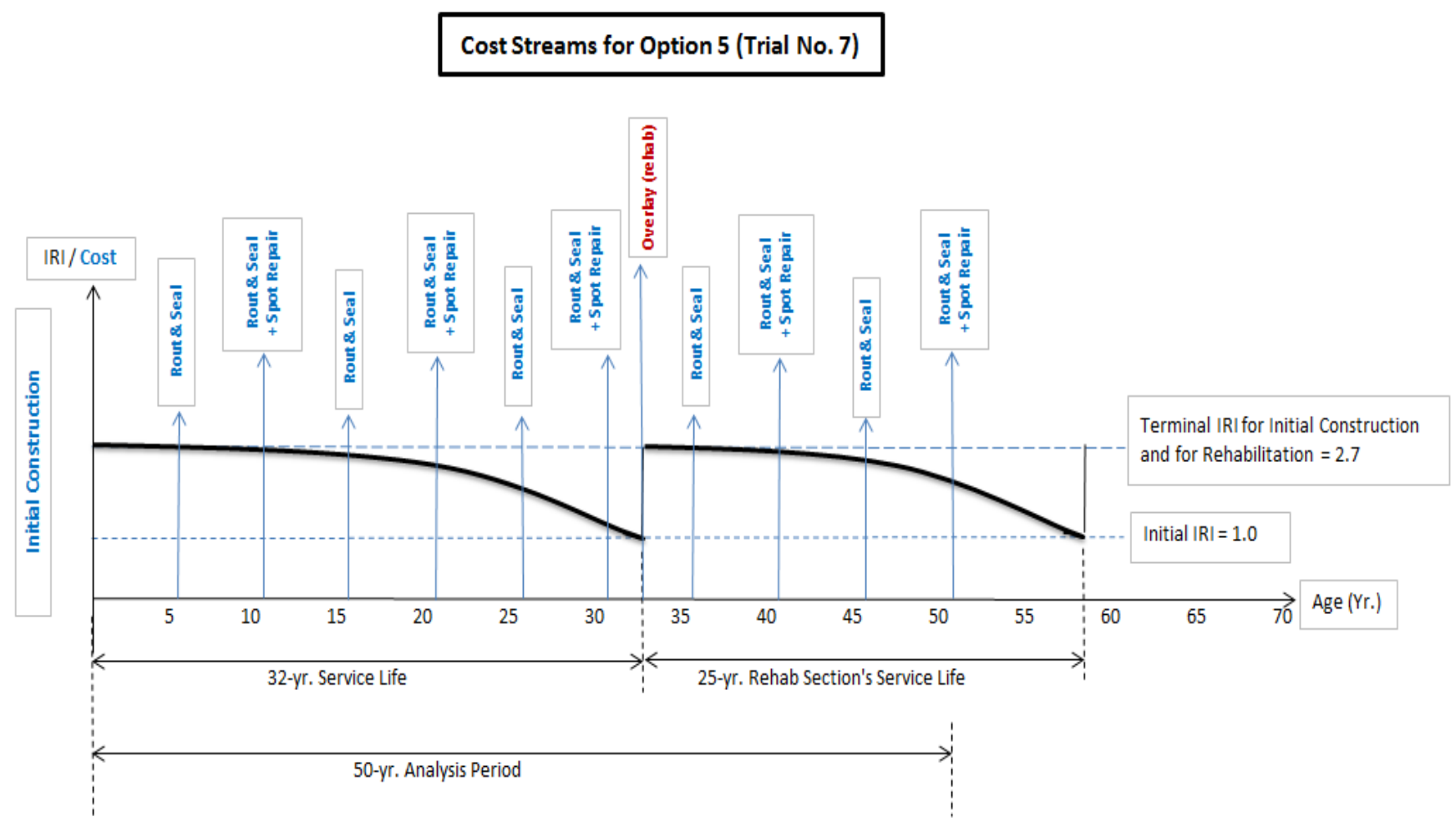

Figure 4-15 Indicative cost streams for Option 5 (Trial No 7) for 50 years analysis period 


\section{Chapter 5 : SUMMARY/CONCLUSIONS, MAJOR FINDINGS, AND RECOMMENDATIONS}

\subsection{Summary / Conclusions}

The determination of life cycle, which may be considered as service life, is crucial in estimating the life cycle costing for any pavement management system (PMS). Since the service life of pavements is measured in terms of performance, therefore, one complete life cycle may be considered when the pavement's performance reaches to the terminal value(s). The new DARWin-ME provides an excellent tool in identifying / predicting the actual service life for any trial section and vice versa (that is, identifying an optimal trial section for a given design life). Thus, the new MEPDG methodology helps the pavement designers to predict the true service life of any selected trial section or select an optimal trial section for a given service life, which is the essence of DARWin-ME. In both ways, it helps the PMS to decide whether to select a longer or shorter life cycle of the pavement in order to predict allocation of budget and resources.

In this report, the approach 1 (discussed in section 3.1) where the actual service life has been predicted for an arbitrarily selected trial section is considered and its life cycle cost has been estimated. Although the initial design life of the trial section was considered as 11 years, the DARWin-ME analysis indicates that the actual service life until failure of IRI performance criteria is 41 years, and the service life of the rehabilitation has been predicted as 32 years. Similarly, several trial sections with different layers and thickness have been analyzed and total five options including the $1^{\text {st }}$ trial have been considered for LCC analysis. 
In this report, it was found that the DARWin-ME analysis yielded almost the same service life for Options 1, 2 and 3, although thickness of structural layers were different, and Option 3 did not contain a major structural component of $100 \mathrm{~mm}$ thick cement stabilized layer. On the other hand, Options 4 and 5 had same layer materials and the only difference in granular layer thickness, the thickness was $440 \mathrm{~mm}$ in Option 4 while 300 $\mathrm{mm}$ was in Option 5. But DARWin-ME yielded higher service life (32 year) for Option 5 compared to the Option 4 (24 year). It was not clear why it happened although Option 4 should yield larger service life.

Although, the use of DARWin-ME easily predicts the actual life cycle of any trial section for any input data, the estimation of LCC is a difficult task and includes many different types of cost components, and the true value of LCC depends on the accuracy of these cost components. Since DARWin-ME allows the analysis of HMA layers thickness of minimum $25.4 \mathrm{~mm}$ to the maximum of $500 \mathrm{~mm}$, stabilized layer thickness of minimum $100 \mathrm{~mm}$ to the maximum of $600 \mathrm{~mm}$, and granular material layer thickness of minimum $25.4 \mathrm{~mm}$ to the maximum of $9144 \mathrm{~mm}$, the combination matrix would generate finitely many trial sections. In addition, the DARWin-ME also allows to changes in mechanical properties of layer materials. Thus, it is a great challenge and mammoth task for the analyst to determine the most economical trial section using the DARWin-ME.

No uncertainty has been considered in this report at any stage of input data, quantity of construction materials and its cost, and in the selection of preventive maintenance and rehabilitation (PM \&R) scheme and its estimation. Although the DARWin-ME allows to do sensitivity analysis and optimization, sensitivity analysis and optimization are not conducted. However, the framework described in this report may be considered as the 
basis to estimate life cycle costing of flexible pavements by selecting required cost components and degree of uncertainty.

\subsection{Major Findings / Observations of the Study}

In addition to having a sound knowledge in mechanical properties of pavement materials, a good knowledge in the DARWin-ME is essential in conducting LCC of pavements. The most significant parameters which greatly influence the pass/fail of the analysis of pavement trial section are found to be as follows:

- Project specific (local) calibration of the material properties

- Threshold values (terminal values) of the distresses, and

- Reliability factor.

The correct values of local calibration greatly influence the service life. It was found that the threshold values of distresses reach much earlier in AC rutting and subgrade rutting with default values of 1.0 compared to the calibrated values (given in section 4.2).

In addition to the terminal values, the third influential factor in DARWin-ME analysis is the reliability factor. It has been found that the failure in distresses reaches earlier for higher degree of reliability compared to the lower degree of reliability. It is also essential to define the key distress for the pavement's failure criterion, because early failure in rutting may not necessarily be the only reason to call for the time for overlay. On the other hand, early distress failure only in IRI requires further investigation, when the other distress curves show considerable amount of life (age) is still remaining prior to failure occurs. 
In this analysis, the distress charts of Option 1 (Trial No 1) show that failure in IRI occurs earlier (after age 41) whereas failures in total rutting and other distress cracking are likely to occur beyond 50 years. Similar results are observed in Option 2 (Trial No. 3) and Option 3 (Trial No 4). This indicates that these trial sections are likely to be over designed and may not be economical. But the distress charts of Option 5 (Trial No 7) show that failures in IRI and the total rutting are occurring almost at the same age (in the vicinity of 33 year), which indicates a balanced and economical design, and this was found to be correct as Option 5 (Trial No 7) yielded the lowest cost [Table 4-14].

No salvage value has been considered for estimating life cycle costing of 50-yr analysis period. However, the remaining service life of overlay for Option 1, 2, and 3 are 22 years, 28 years and 25 years respectively which is visually clear in Figure 4-7, Figure 4-10, and Figure 4-11 may have significant cost impact compared to the remaining service life of 6 years and 7 years for Option 4 and 5 as shown in Figure 4-12 and Figure 4-13 respectively. Ignoring salvage value of large remaining life may have yielded a biased cost comparison between the design options (alternatives).

\subsection{Recommendations}

- Although DARWin-ME provides easy tools to predict the performance of the flexible pavement with respect to time thus helps to identify the actual life cycle (service life) of the pavement's trial section, it greatly depends on the local (or project specific) calibration coefficients. However, there is no verification measure available whether predicted initial service life is the correct one, because initial service life will have impact on predicting the actual due time for the rehabilitation works. 
- While determining the service life of rehabilitation, the DARWin-ME provides easy tools to conduct the first time rehabilitation, and if the same life span is assumed as the life cycle for the $2^{\text {nd }}$ or $3^{\text {rd }}$ rehabilitation for LCC estimation, which may not be the true case. In order to obtain an accurate service life it is highly essential that the applicable true values (such as material properties, strength, air void etc.) for the existing layers are collected for conducting LCC for an overlay design. Therefore, only one overlay's service life would yield a more accurate LCC estimation for the overall life-cycle of the pavement, and inclusion of two or more overlay in the LCC may yield a biased total cost.

- This study was done without considering the uncertainty and the risk analysis. It is recommended that further studies are made considering the sensitivity analysis and optimization by addressing the uncertainty and risk factors for the determination of a better and more accurate LCC for the flexible pavements using the DARWin-ME.

- It is the fundamental requirement in the DARWin-Me analysis to define the determining distress type as the failure criteria of the flexible pavement by selecting distress type(s), because earlier failure in rutting may not necessarily be the only reason to call for the time for overlay. On the other hand, early distress failure in IRI only require further studies when the other distress curves show considerable amount of life (age) is still remaining prior to failure occurs.

- Salvage values, especially when the remaining service life is significantly large, should be considered in the life cycle costing analysis in order to make an unbiased economic comparison between the design alternatives / proposals. 


\section{References}

- Appendix C of NCHRP: Guide for Mechanistic-Empirical Design of New and Rehabilitated Pavement Structure, Final Report, March 2004

- AASHTO 2008: Mechanistic-Empirical Pavement Design Guide

- Holt A., Sullivan S., Hein D.K.; "Life Cycle Cost Analysis of Municipal Pavements in Southern and Eastern Ontario" - paper prepared for presentation at the Effects of Increased Loading on Pavements Session of the 2011 Annual Conference of the Transportation Association of Canada, Edmonton, Alberta, September, 2011.

- Ontario's Default Parameters of AASHTOWare Pavement ME Design - Interim Report, MTO, November, 2012

- Pavement Structural Design Practices Across Canada - Canadian Strategic Highway Research Program (C-SHRP): C-SHRP Technical Brief \# 23, April 2002.

- Jannat, G.,E.; Database Development for Ontario's Local Calibration of Mechanistic-Empirical Pavement Design Guide (MEPDG) Distress Model; MASc. Thesis, 2012, Ryerson University.

- Waseem, A.; Methodology Development and Local Calibration of MEPDG Permanent deformation Models for Ontario's Flexible Pavements; MASc. Thesis, 2013, Ryerson University.

- Pavement Design Manual of Instruction, Utah Department of transportation (UDOT), January 2012

- Pavement Design Manual, Alberta Transportation and Utilities (AT \& U), June 1997.

- Gransberg, D. D.; "Life Cycle Evaluation Criteria for Design-Build Highway Pavement projects" - MASc. Thesis, University of Colorado, 2004.

- Reigle,J.A.; "Development of an Integrated Project-Level Pavement Management Model using Risk Analysis" - Ph.D. Thesis, West Virginia University.

- Guven, Z; "Life Cycle Cost Analysis of Pavements: State-of-the-Art Practices" MASc Thesis, Clemson University, 2006 
- Papagiannakis, A.T, and Masad, E.A.; Pavement Design and Materials; John Wiley \& Sons, Inc., 2008

- Mallick, R. B., and Korchi, T.E.; Pavement Engineering - Principles and Practice; CRC Press, 2009.

- Transportation Association of Canada (TAC) - Pavement Design and Management Guide, Ottawa, Ontario, 1997

- Dell'lsola, A.J., and Kirk, S.J.; Life Cycle Costing For Design Professionals; McGraw-Hill Book Company, 1981.

- Riggset al.; Engineering Economics; $2^{\text {nd }}$ Canadian Edition; McGraw-Hill Ryerson Limited, 1997.

- Dhillon, B.S.; Life Cycle costing for Engineers, CRC Press, 2010

- Hudson, W. R., Hass, R., and Uddin, W.; Infrastructure Management: Integrating Design, Construction, Maintenance, Rehabilitation, and Renovation; McGrawHill, 1997

- Farran, M.; Life Cycle Cost for Rehabilitation of Public Infrastructures: Application to Montreal Metro System; MASc. Thesis, Concordia University, Montreal, Quebec, Canada, ProQuest Dissertation and thesis, 2007.

- Irfan, M; “ A Framework for Developing Optimal Pavement Life cycle Activity Profiles: - Ph.D. thesis, Purdune University, 2010

- Zhang H., Keoleian, G. A., Lepech, M. D., and Kendall, A.; Life-Cycle Optimization of pavement Overlay Systems; Journal of Infrastructure System, ASCE, 2010, Vol. 16(4) 310-322. 


\section{Appendices}

\section{Appendix A}

\section{Appendix A1: Calibration coefficients}

\section{Calibration Coefficients}

\begin{tabular}{|c|c|}
\hline \multicolumn{2}{|l|}{ AC Fatigue } \\
\hline \multirow{6}{*}{$\begin{array}{l}N_{f}=0.00432 * C * \\
C=10^{N} \\
M=4.84\left(\frac{V_{b}}{V_{G}+V_{b}}-0.69\right)\end{array}$} & k1: 0.007566 \\
\hline & k2: 3.9492 \\
\hline & k3: 1.281 \\
\hline & Bf1: 1 \\
\hline & Bf2: 1 \\
\hline & Bf3: 1 \\
\hline
\end{tabular}

\begin{tabular}{|c|c|c|}
\hline \multicolumn{3}{|l|}{ AC Rutting } \\
\hline \\
\hline \multirow{2}{*}{\multicolumn{2}{|c|}{$\begin{array}{l}\overline{\varepsilon_{r}}=k_{z} \beta_{r 1} 10^{\kappa_{1}} T^{* 12 r_{r} N^{* 3 D_{r 3}}} \\
k_{z}=\left(C_{1}+C_{2} * \text { depth }\right) * 0.328196^{\text {depth }}\end{array}$}} & $\varepsilon_{p}=$ plastic strain $($ in $/$ in $)$ \\
\hline & & $\varepsilon_{r}=$ resilient strain $(i n / i n)$ \\
\hline \multicolumn{2}{|c|}{$C_{1}=-0.1039 * H_{\alpha}^{2}+2.4868 * H_{\alpha}-17.342$} & $T=$ layer temperature $\left({ }^{\circ} \mathrm{F}\right)$ \\
\hline \multicolumn{2}{|c|}{$C_{2}=0.0172 * H_{\alpha}^{2}-1.7331 * H_{\alpha}+27.428$} & $N=$ number of load repetitions \\
\hline \multicolumn{3}{|c|}{$\begin{array}{l}\text { Where: } \\
H_{a c}=\text { total AC thickness }(\text { in })\end{array}$} \\
\hline \multicolumn{3}{|c|}{\begin{tabular}{|l|l|} 
K1: -3.35412 & $K 2: 1.5606$ \\
\end{tabular}} \\
\hline Br2: 1.02 & Br3: 1.02 & Br1: 0.23 \\
\hline \multicolumn{3}{|c|}{ AC Rutting Standard Deviation } \\
\hline \multicolumn{2}{|c|}{$0.24^{*}$ Pow(RUT, 0.8026$)+0.001$} & \\
\hline
\end{tabular}

\begin{tabular}{|c|c|c|}
\hline \multicolumn{3}{|c|}{ Thermal Fracture } \\
\hline \multicolumn{2}{|c|}{$\begin{array}{l}C_{f}=400 * N\left(\frac{\log C / h_{a c}}{\sigma}\right) \\
\Delta C=\left(k^{*} \beta t\right)^{n+1} * A^{*} \Delta K^{n} \\
A=10^{\left(4.389-2.52 * \log \left(E^{*} \sigma_{m}{ }^{*} n\right)\right.}\end{array}$} & $\begin{array}{l}C_{f}=\text { observed amount of thermal cracking }(f t / 500 f t) \\
k=\text { refression coefficient determined through field calibration } \\
N()=\text { standard normal distribution evaluated at() } \\
\sigma=\text { standard deviation of the log of the depth of cracks in the pavments } \\
C=\text { crack depth(in) } \\
h_{a c}=\text { thickness of asphalt layer (in) } \\
\Delta C=\text { Change in the crack depth due to a cooling cycle } \\
\Delta K=\text { Change in the stress intensity factor due to a cooling cycle } \\
A, n=\text { Fracture parameters for the asphalt mixture } \\
E=\text { mixture stiff nosss } \\
\sigma_{\mathrm{N}}=\text { Undamaged mixture tensile strength } \\
\beta_{t}=\text { Calibration parameter }\end{array}$ \\
\hline Level $1 \mathrm{~K}: 1.5$ & \multicolumn{2}{|c|}{ Level 1 Standard Deviation: $0.1468{ }^{*}$ THERMAL + 65.027} \\
\hline Level $2 \mathrm{~K}: 0.5$ & \multicolumn{2}{|c|}{ Level 2 Standard Deviation: $0.2841{ }^{*}$ THERMAL + 55.462} \\
\hline Level $3 \mathrm{~K}: 1.5$ & \multicolumn{2}{|c|}{ Level 3 Standard Deviation: $0.3972{ }^{*}$ THERMAL + 20.422} \\
\hline
\end{tabular}




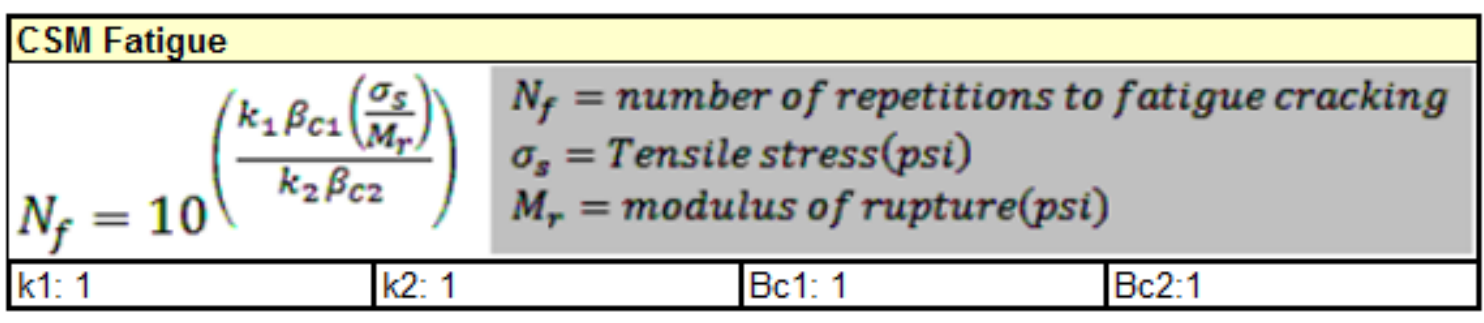

\begin{tabular}{|c|c|}
\hline ubgrade Rutting & \\
\hline$\delta_{a}(N)=\beta_{s_{1}} k_{1} \varepsilon_{v} h\left(\frac{\varepsilon_{0}}{\varepsilon_{r}}\right)\left|e^{-\left(\frac{\rho}{N}\right)^{\beta}}\right|$ & $\begin{array}{l}\delta_{a}=\text { permanent deformation for the layer } \\
N=\text { number of repetitions } \\
\varepsilon_{v}=\text { average veritcal strain }(\mathrm{in} / \mathrm{in}) \\
\varepsilon_{0_{1}, \beta, \rho=\text { material properties }} \\
\varepsilon_{r}=\text { resilient strain }(\mathrm{in} / \mathrm{in})\end{array}$ \\
\hline Granular & Fine \\
\hline Bs1: 3.062 & Bs1: 0.0328 \\
\hline $\begin{array}{l}\text { Standard Deviation (BASERUT) } \\
0.1477^{\star} \text { Pow(BASERUT 0.6711)+0.001 }\end{array}$ & $\begin{array}{l}\text { Standard Deviation (BASERUT) } \\
0.1235^{*} \text { Pow(SUBRUT 0. 5012)+0.001 }\end{array}$ \\
\hline
\end{tabular}

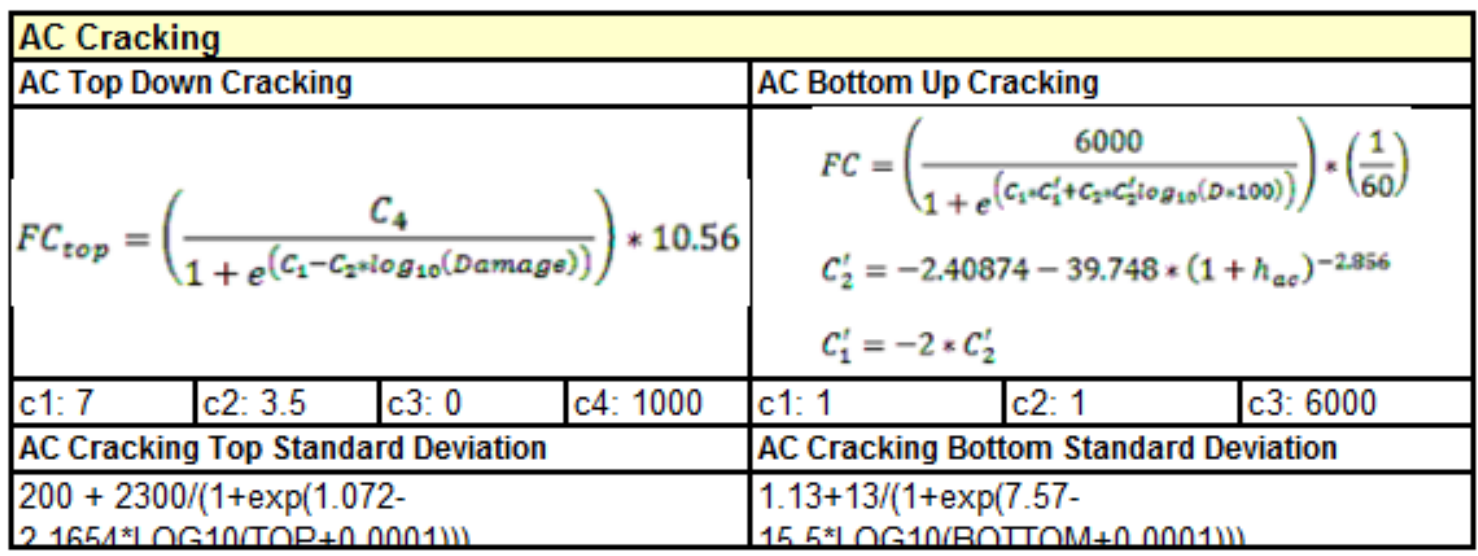

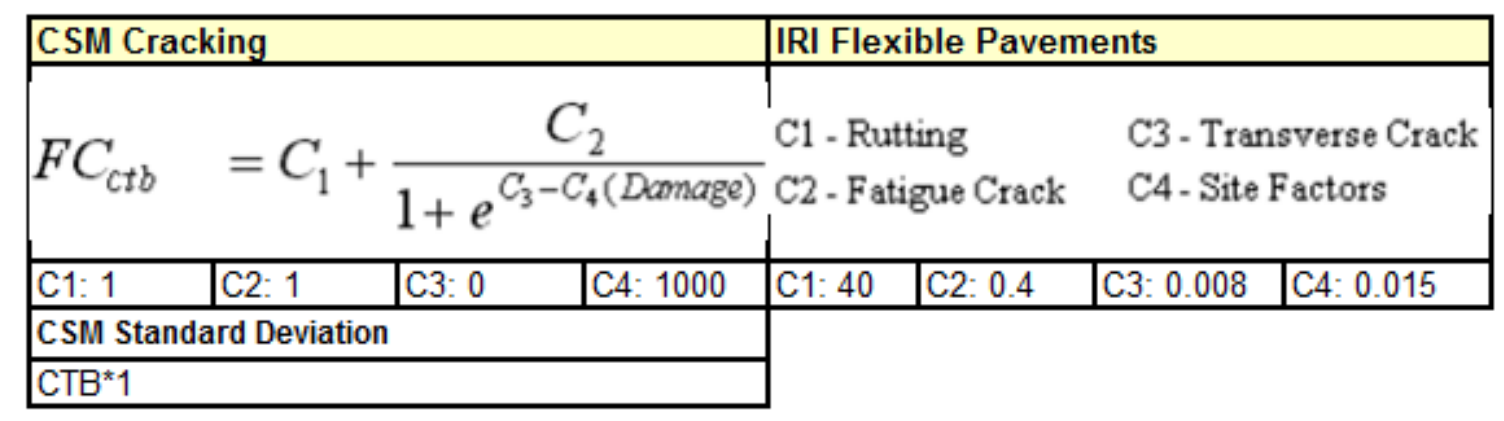




\section{Appendix A2: Mechanical Properties of Pavement Layer Materials}

\begin{tabular}{|c|c|c|}
\hline Layer 1 Flexible : DF & & \\
\hline \multicolumn{3}{|l|}{ Asphalt } \\
\hline Thickness (mm) & \multicolumn{2}{|l|}{40.0} \\
\hline Unit weight $\left(\mathrm{kg} / \mathrm{m}^{\wedge} 3\right)$ & \multicolumn{2}{|l|}{2520.0} \\
\hline \multirow[t]{4}{*}{ Poisson's ratio } & Is Calculated? & False \\
\hline & Ratio & 0.35 \\
\hline & Parameter A & - \\
\hline & Parameter B & - \\
\hline
\end{tabular}

Asphalt Dynamic Modulus (Input Level: 3)

\begin{tabular}{|l|l|}
\hline Gradation & Percent Passing \\
\hline $19 \mathrm{~mm}$-inch sieve & 100 \\
\hline $9.5 \mathrm{~mm}$ sieve & 82.5 \\
\hline $4.75 \mathrm{~mm}$ sieve & 52.5 \\
\hline $0.075 \mathrm{~mm}$ sieve & 2.5 \\
\hline
\end{tabular}

\begin{tabular}{|c|c|}
\hline Asphalt Bin & \\
\hline Parameter & Value \\
\hline Grade & Penetration Grade \\
\hline Binder Type & Pen 85-100 \\
\hline $\mathrm{A}$ & 10.8232 \\
\hline VTS & -3.621 \\
\hline
\end{tabular}

6

\begin{tabular}{|c|c|}
\hline General Info & \\
\hline Name & Talue \\
\hline Reference temperature $\left({ }^{\circ} \mathrm{C}\right)$ & 21.1 \\
\hline Effective binder content $(\%)$ & 12.4 \\
\hline Air voids $(\%)$ & 3.5 \\
\hline Thermal conductivity (watt/meter-kelvin) & 1.16 \\
\hline Heat capacity (joule/kg-kelvin) & 963 \\
\hline
\end{tabular}

\begin{tabular}{|l|l|}
\hline Identiflers \\
\hline Field & Value \\
\hline Display name/identifier & DFC \\
\hline Description of object & \\
\hline Author & \\
\hline Date Created & 40437.04167 \\
\hline Approver & \\
\hline Date approved & 40437.04167 \\
\hline State & \\
\hline District & \\
\hline County & \\
\hline Highway & \\
\hline Direction of Travel & \\
\hline From station (km) & \\
\hline To station (km) & \\
\hline Province & \\
\hline User defined field 2 & \\
\hline User defined field 3 & \\
\hline Revision Number & 0 \\
\hline
\end{tabular}

Layer 2 Flexible : HDB

\begin{tabular}{|l|l|l|}
\hline Asphalt \\
\hline Thickness $(\mathrm{mm})$ & 90.0 \\
\hline Unit weight $\left(\mathrm{kg} / \mathrm{m}^{\wedge} 3\right)$ & 2460.0 \\
\hline Poisson's ratio & Is Calculated? & False \\
\cline { 2 - 3 } & Ratio & 0.35 \\
\cline { 2 - 3 } & Parameter A & - \\
\cline { 2 - 3 } & Parameter B & - \\
\hline
\end{tabular}

\begin{tabular}{|c|c|}
\hline Gradation & Percent Passing \\
\hline $19 \mathrm{~mm}$-inch sieve & 97 \\
\hline $9.5 \mathrm{~mm}$ sieve & 63 \\
\hline $4.75 \mathrm{~mm}$ sieve & 43.5 \\
\hline $0.075 \mathrm{~mm}$ sieve & 3 \\
\hline
\end{tabular}

\begin{tabular}{|l|l|}
\hline Asphalt Binder \\
\hline Parameter & Value \\
\hline \hline Grade & Penetration Grade \\
\hline Binder Type & Pen $85-100$ \\
\hline A & 10.8232 \\
\hline VTS & -3.621 \\
\hline
\end{tabular}

\begin{tabular}{l} 
General Info \\
\begin{tabular}{|l|l|}
\hline Name & Value \\
\hline \hline Reference temperature ( $\left.{ }^{\circ} \mathrm{C}\right)$ & 21.1 \\
\hline Effective binder content (\%) & 10.9 \\
\hline Air voids (\%) & 4 \\
\hline Thermal conductivity (watt/meter-kelvin) & 1.16 \\
\hline Heat capacity (joule/kg-kelvin) & 963 \\
\hline Identifiers & \\
\hline Fleld & Value \\
\hline Display name/identifier & HDB \\
\hline Description of object & \\
\hline Author & \\
\hline Date Created & Afzal \\
\hline Approver & 40437.04167 \\
\hline Date approved & \\
\hline State & 40437.04167 \\
\hline District & \\
\hline County & \\
\hline Highway & \\
\hline Direction of Travel & \\
\hline From station (km) & \\
\hline To station (km) & \\
\hline Province & \\
\hline User defined field 2 & \\
\hline User defined field 3 & \\
\hline Revision Number & \\
\hline
\end{tabular} \\
\hline
\end{tabular}


Layer 3 Flexible : HL-8

\begin{tabular}{|l|l|l|}
\hline Asphalt \\
\hline Thickness $(\mathrm{mm})$ & 130.0 \\
\hline Unit weight $\left(\mathrm{kg} / \mathrm{m}^{\wedge} 3\right)$ & 2460.0 \\
\hline \multirow{3}{*}{ Poisson's ratio } & Is Calculated? & False \\
\cline { 2 - 3 } & Ratio & 0.35 \\
\cline { 2 - 3 } & Parameter $\mathrm{A}$ & - \\
\cline { 2 - 3 } & Parameter B & - \\
\hline
\end{tabular}

Asphalt Dynamic Modulus (Input Level: 3)

\begin{tabular}{|l|l|}
\hline Gradation & Percent Passing \\
\hline $19 \mathrm{~mm}$-inch sieve & 97 \\
\hline $9.5 \mathrm{~mm}$ sieve & 63 \\
\hline $4.75 \mathrm{~mm}$ sieve & 42.5 \\
\hline $0.075 \mathrm{~mm}$ sieve & 3 \\
\hline
\end{tabular}

\section{Asphalt Binder}

\begin{tabular}{|l|l|}
\hline Parameter & Value \\
\hline \hline Grade & Penetration Grade \\
\hline Binder Type & Pen 85-100 \\
\hline A & 10.8232 \\
\hline VTS & -3.621 \\
\hline
\end{tabular}

Layer 4 Chemically Stabilized : Cement stabilized

\begin{tabular}{|l|l|}
\hline Chemically Stabilized & 100 \\
\hline \hline Layer thickness (mm) & 0.2 \\
\hline Poisson's ratio & 2400 \\
\hline Unit weight $\left(\mathrm{kg} / \mathrm{m}^{\wedge} 3\right)$ & 13790 \\
\hline Strength & \\
\hline Elastic/resilient modulus (MPa) & \\
\hline & \\
\hline Thermal & 1172.3 \\
\hline Heat capacity (joule/kg-kelvin) & 2.16 \\
\hline Thermal conductivity (watt/meter-kelvin) &
\end{tabular}

\section{General Info}

\begin{tabular}{|l|l|}
\hline Name & Value \\
\hline \hline Reference temperature ( $\left.{ }^{\circ} \mathrm{C}\right)$ & 21.1 \\
\hline Effective binder content (\%) & 10.9 \\
\hline Air voids (\%) & 4 \\
\hline Thermal conductivity (watt/meter-kelvin) & 1.16 \\
\hline Heat capacity (joule/kg-kelvin) & 963 \\
\hline
\end{tabular}

\begin{tabular}{|l|l|}
\hline Identifiers \\
\hline Fleld & Value \\
\hline Display name/identifier & HL-8 \\
\hline Description of object & \\
\hline Author & \\
\hline Date Created & Afzal \\
\hline Approver & \\
\hline Date approved & 40437.04167 \\
\hline State & Ontario \\
\hline District & \\
\hline County & Canada \\
\hline Highway & \\
\hline Direction of Travel & \\
\hline From station (km) & \\
\hline To station (km) & \\
\hline Province & \\
\hline User defined field 2 & \\
\hline User defined field 3 & \\
\hline Revision Number & 0 \\
\hline
\end{tabular}

Revision Number

\begin{tabular}{|c|c|}
\hline \multicolumn{2}{|l|}{ Identifiers } \\
\hline Field & Value \\
\hline Display name/identifier & Cement stabilized \\
\hline Description of object & Default material \\
\hline Author & AASHTO \\
\hline Date Created & 40544 \\
\hline \multicolumn{2}{|l|}{ Approver } \\
\hline Date approved & 40544 \\
\hline \multicolumn{2}{|l|}{ State } \\
\hline \multicolumn{2}{|l|}{ District } \\
\hline \multicolumn{2}{|l|}{ County } \\
\hline \multicolumn{2}{|l|}{ Highway } \\
\hline \multicolumn{2}{|l|}{ Direction of Travel } \\
\hline \multicolumn{2}{|l|}{ From station $(\mathrm{km})$} \\
\hline \multicolumn{2}{|l|}{ To station $(\mathrm{km})$} \\
\hline \multicolumn{2}{|l|}{ Province } \\
\hline \multicolumn{2}{|l|}{ User defined field 2} \\
\hline \multicolumn{2}{|l|}{ User defined field 3} \\
\hline Revision Number & 0 \\
\hline
\end{tabular}




\section{Layer 5 Non-stabilized Base : Granular A}

\begin{tabular}{|l|l|}
\hline Unbound \\
\hline \hline Layer thickness $(\mathrm{mm})$ & 300.0 \\
\hline Poisson's ratio & 0.35 \\
\hline Coefficient of lateral earth pressure (k0) & 0.5 \\
\hline Modulus (Input Level: 3 ) \\
\hline \begin{tabular}{|l|l|}
\hline Analysis Type: & $\begin{array}{l}\text { Modrify input values by } \\
\text { temperature/moisture }\end{array}$ \\
\hline Method: & Resilient Modulus (MPa) \\
\hline Resilient Modulus (MPa) \\
\hline 250.0 \\
\hline
\end{tabular} \\
\hline
\end{tabular}

\begin{tabular}{|l|l|}
\hline Use Correction factor for NDT modulus? & - \\
\hline NDT Correction Factor: & - \\
\hline
\end{tabular}

\begin{tabular}{|l|l|}
\hline Identifiers \\
\hline Field & Value \\
\hline \hline Display name/identifier & Granular A \\
\hline Description of object & \\
\hline Author & \\
\hline Date Created & 40544 \\
\hline Approver & \\
\hline Date approved & 40544 \\
\hline State & \\
\hline District & \\
\hline County & \\
\hline Highway & \\
\hline Direction of Travel & \\
\hline From station (km) & \\
\hline To station (km) & \\
\hline Province & \\
\hline User defined field 2 & \\
\hline User defined field 3 & \\
\hline Revision Number & 0 \\
\hline
\end{tabular}

\begin{tabular}{|c|c|c|}
\hline \multicolumn{3}{|l|}{ Sieve } \\
\hline Liquid Limit & \multicolumn{2}{|l|}{6.0} \\
\hline Plasticity Index & \multicolumn{2}{|l|}{0.0} \\
\hline \multirow[t]{2}{*}{ Is layer compacted? } & \multicolumn{2}{|l|}{ True } \\
\hline & \begin{tabular}{|c|c|} 
Is User \\
Defined?
\end{tabular} & Value \\
\hline $\begin{array}{l}\text { Maximum ary unit werght } \\
\left(\mathrm{ka} / \mathrm{m}^{\wedge} 3\right)\end{array}$ & False & 2170 \\
\hline $\begin{array}{l}\text { Saturated hydraulic conductivity } \\
(\mathrm{m} / \mathrm{hr})\end{array}$ & False & $2.376 e-02$ \\
\hline Specific gravity of solids & False & 2.7 \\
\hline $\begin{array}{l}\text { Optimum gravimetric water } \\
\text { content }(\%)\end{array}$ & False & 5.7 \\
\hline
\end{tabular}

\begin{tabular}{|l|l|}
\hline \multicolumn{2}{|l||}{ User-defined Soll Water Characteristic Curve (SWCC) } \\
\hline Is User Defined? & False \\
\hline af & 3.0201 \\
\hline bf & 2.5984 \\
\hline cf & 0.7539 \\
\hline hr & 100.0000 \\
\hline Sleve Size & $\%$ Passing \\
\hline $0.001 \mathrm{~mm}$ & \\
\hline $0.002 \mathrm{~mm}$ & \\
\hline $0.020 \mathrm{~mm}$ & \\
\hline $0.075 \mathrm{~mm}$ & 5.0 \\
\hline $0.150 \mathrm{~mm}$ & \\
\hline $0.180 \mathrm{~mm}$ & \\
\hline $0.250 \mathrm{~mm}$ & \\
\hline $0.300 \mathrm{~mm}$ & 13.5 \\
\hline $0.425 \mathrm{~mm}$ & \\
\hline $0.600 \mathrm{~mm}$ & \\
\hline $0.850 \mathrm{~mm}$ & \\
\hline $1.18 \mathrm{~mm}$ & 27.5 \\
\hline $2.0 \mathrm{~mm}$ & \\
\hline $2.36 \mathrm{~mm}$ & \\
\hline $4.75 \mathrm{~mm}$ & 45.0 \\
\hline $9.5 \mathrm{~mm}$ & 61.5 \\
\hline $12.5 \mathrm{~mm}$ & 77.5 \\
\hline $19.0 \mathrm{~mm}$ & 92.5 \\
\hline $25.0 \mathrm{~mm}$ & 100.0 \\
\hline $37.5 \mathrm{~mm}$ & \\
\hline $50.0 \mathrm{~mm}$ & \\
\hline
\end{tabular}




\section{Layer 6 Subgrade : ML}

\begin{tabular}{|l|l|}
\hline Unbound \\
\hline \hline Layer thickness $(\mathrm{mm})$ & Semi-infinite \\
\hline Poisson's ratio & 0.35 \\
\hline Coefficient of lateral earth pressure $(\mathrm{k} 0)$ & 0.5 \\
\hline
\end{tabular}

Modulus (Input Level: 3 )

\begin{tabular}{|l|l|}
\hline Analysis Type: & $\begin{array}{l}\text { Modify input values by } \\
\text { temperature/moisture }\end{array}$ \\
\hline Method: & Resilient Modulus (MPa) \\
\hline Resilient Modulus (MPa) \\
\hline 35.0 \\
\hline
\end{tabular}

\begin{tabular}{|l|l|}
\hline Use Correction factor for NDT modulus? & - \\
\hline NDT Correction Factor: & - \\
\hline
\end{tabular}

\begin{tabular}{|l|l|}
\hline Identifiers & \\
\hline Field & Value \\
\hline \hline Display name/identifier & ML \\
\hline Description of object & USCS \\
\hline Author & MTO \\
\hline Date Created & 40544 \\
\hline Approver & \\
\hline Date approved & 40544 \\
\hline State & \\
\hline District & \\
\hline County & \\
\hline Highway & \\
\hline Direction of Travel & \\
\hline From station (km) & \\
\hline To station (km) & \\
\hline Province & \\
\hline User defined field 2 & \\
\hline User defined field 3 & \\
\hline Revision Number & 0 \\
\hline
\end{tabular}

\section{Sieve}

\begin{tabular}{|c|c|c|}
\hline Liquid Limit & \multicolumn{2}{|l|}{25.0} \\
\hline Plasticity Index & 5.0 & \\
\hline \multirow[t]{2}{*}{ Is layer compacted? } & True & \\
\hline & \begin{tabular}{|c|} 
Is User \\
Defined?
\end{tabular} & Value \\
\hline $\begin{array}{l}\text { Maximum dry unit weight } \\
\left(\mathrm{kg} / \mathrm{m}^{\wedge} 3\right)\end{array}$ & False & 1906.1 \\
\hline $\begin{array}{l}\text { Saturated hydraulic conductivity } \\
(\mathrm{m} / \mathrm{hr})\end{array}$ & False & $1.636 \mathrm{e}-06$ \\
\hline Specific gravity of solids & False & 2.7 \\
\hline $\begin{array}{l}\text { Optimum gravimetnc water } \\
\text { content }(\%)\end{array}$ & False & 11.8 \\
\hline
\end{tabular}

\begin{tabular}{|c|c|c|}
\hline \multicolumn{3}{|c|}{ User-defined Soil Water Characteristic Curve (SWCC) } \\
\hline Is User Defined? & & False \\
\hline af & & 68.8377 \\
\hline bf & & 0.9983 \\
\hline cf & & 0.4757 \\
\hline$\underline{\text { hr }}$ & & 500.0000 \\
\hline Sieve Size & \multicolumn{2}{|c|}{$\%$ Passing } \\
\hline \multicolumn{3}{|l|}{$0.001 \mathrm{~mm}$} \\
\hline \multicolumn{3}{|l|}{$0.002 \mathrm{~mm}$} \\
\hline \multicolumn{3}{|l|}{$0.020 \mathrm{~mm}$} \\
\hline $0.075 \mathrm{~mm}$ & \multicolumn{2}{|l|}{60.6} \\
\hline \multicolumn{3}{|l|}{$0.150 \mathrm{~mm}$} \\
\hline $0.180 \mathrm{~mm}$ & \multicolumn{2}{|l|}{73.9} \\
\hline \multicolumn{3}{|l|}{$0.250 \mathrm{~mm}$} \\
\hline \multicolumn{3}{|l|}{$0.300 \mathrm{~mm}$} \\
\hline $0.425 \mathrm{~mm}$ & \multicolumn{2}{|l|}{82.7} \\
\hline \multicolumn{3}{|l|}{$0.600 \mathrm{~mm}$} \\
\hline \multicolumn{3}{|l|}{$0.850 \mathrm{~mm}$} \\
\hline \multicolumn{3}{|l|}{$1.18 \mathrm{~mm}$} \\
\hline $2.0 \mathrm{~mm}$ & \multicolumn{2}{|l|}{89.9} \\
\hline \multicolumn{3}{|l|}{$2.36 \mathrm{~mm}$} \\
\hline $4.75 \mathrm{~mm}$ & \multicolumn{2}{|l|}{93.0} \\
\hline $9.5 \mathrm{~mm}$ & \multicolumn{2}{|l|}{95.6} \\
\hline $12.5 \mathrm{~mm}$ & \multicolumn{2}{|l|}{96.7} \\
\hline $19.0 \mathrm{~mm}$ & \multicolumn{2}{|l|}{98.0} \\
\hline $25.0 \mathrm{~mm}$ & \multicolumn{2}{|l|}{98.7} \\
\hline $37.5 \mathrm{~mm}$ & \multicolumn{2}{|l|}{99.4} \\
\hline $50.0 \mathrm{~mm}$ & \multicolumn{2}{|l|}{99.6} \\
\hline \multicolumn{3}{|l|}{$63.0 \mathrm{~mm}$} \\
\hline \multicolumn{3}{|l|}{$75.0 \mathrm{~mm}$} \\
\hline $90.0 \mathrm{~mm}$ & \multicolumn{2}{|l|}{99.8} \\
\hline
\end{tabular}




\section{Appendix B}

\section{Appendix B1: DARWin-ME output for Initial Construction for Option 2 (Trial No 3)}

\section{DARWIIE}

\section{AC8-1 Section 9_38 yr_Trial 3}

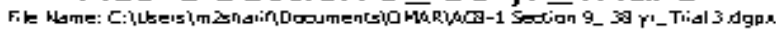

\section{Design Inputs}

Design Life: 40 year

Design Type: F lexible Pavement

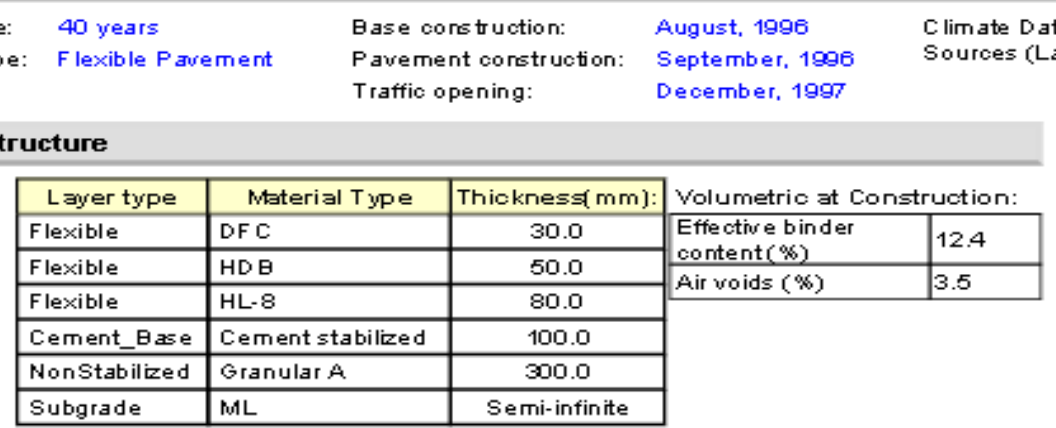

$43.107,-78.945$$$
\text { (1) }
$$

\section{Traficic}

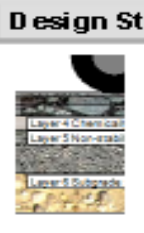

\begin{tabular}{|l|c|}
\hline \multicolumn{1}{|c|}{ Age (year) } & $\begin{array}{c}\text { Heawy Trucks } \\
\text { (cumula ive) }\end{array}$ \\
\hline 1997 (initial) & 14,124 \\
\hline 2017 (20 years) & $39,774,300$ \\
\hline 2037 (40 years) & $98,120,200$ \\
\hline
\end{tabular}

\section{Design Outputs}

D istress Prediction Summary

Distress Type
Terminal IRI (m/km)
Permanent deformation - total pavement (mm)
AC bottom up fatigue crack ing (percent)
Total Cracking (R eflective + Alligator) (percent)
AC thermal fracture (m/km)
AC top-down fatigue cracking (mukm)
Permanent deformation - AC only (mm)
Chemicalty stabilized layer - fatigue fracture (percent)

\begin{tabular}{|c|c|}
\hline $\begin{array}{c}\text { Distress ad Specified } \\
\text { Reliability }\end{array}$ \\
\hline Target & Predicted \\
\hline 2.70 & 2.70 \\
1900 & 10.05 \\
2500 & 0.00 \\
100.00 & 4.49 \\
189.40 & 0.10 \\
378.80 & 0.00 \\
6.00 & 5.37 \\
2500 & 0.98 \\
\hline
\end{tabular}

\begin{tabular}{|c|c|}
\hline \multicolumn{2}{|c|}{ Reliability (\%) } \\
\hline Target & Achieved \\
\hline 5000 & 50.19 \\
50.00 & 100.00 \\
50.00 & 100.00 \\
- & - \\
5000 & 100.00 \\
50.00 & 100.00 \\
50.00 & 63.75 \\
- & -
\end{tabular}

Criterion

Satisied?

Pass

Pass

Pass

Pass

Pass

Pass

\section{DARWIIn}

AC8-1 Section $9-38 \mathrm{yr}$ Trial 3

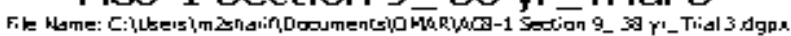

\section{D istress Charts}
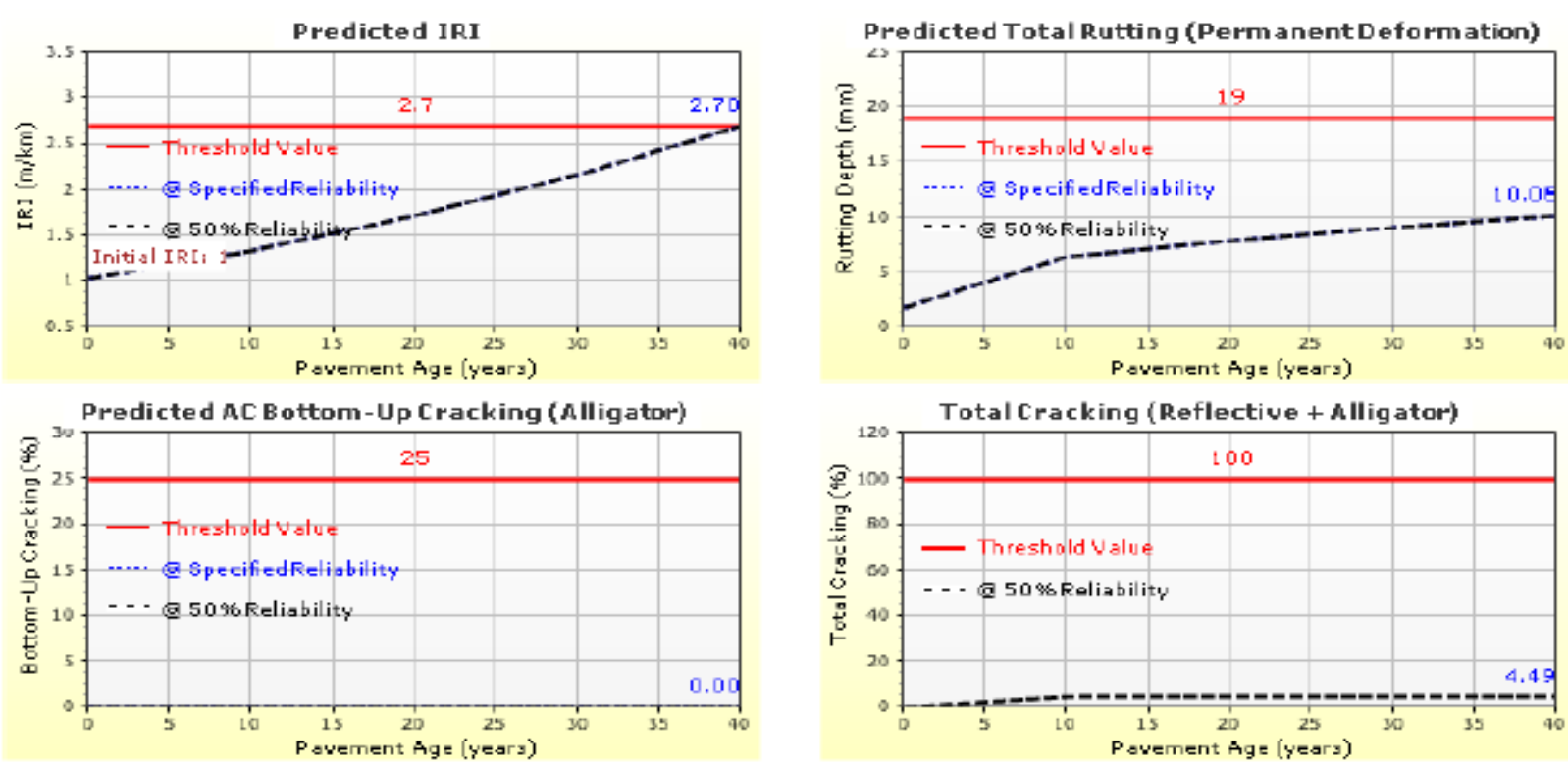
Appendix B2: DARWin-ME output for Initial Construction for Option 3 (Trial No 4)

DARWInE

Design Inputs
AC8-1 Section 9_38 yr_Trial 4

\begin{tabular}{|c|c|c|c|c|c|c|}
\hline \multirow{2}{*}{$\begin{array}{l}\text { Design Life: } \\
\text { Design Type }\end{array}$} & \multicolumn{2}{|c|}{$\begin{array}{l}38 \text { years } \\
\text { F lexible Pavement }\end{array}$} & \multirow{2}{*}{\multicolumn{2}{|c|}{$\begin{array}{l}\text { Base corstuction: } \\
\text { Pavement construction: } \\
\text { Traffic opening: }\end{array}$}} & \multirow{3}{*}{$\begin{array}{l}\text { August, } 1996 \\
\text { September, } 1996 \\
\text { December, } 1997\end{array}$} & \multirow{2}{*}{$\begin{array}{l}\text { Climate Dat } \\
\text { Sources (La }\end{array}$} \\
\hline & & & & & & \\
\hline \multicolumn{6}{|c|}{ D esign Structure } & \\
\hline \multirow{6}{*}{ thersent } & Layer type & \multicolumn{2}{|c|}{ Material Type } & Thickness( $\mathrm{mm})$ : & \multicolumn{2}{|c|}{ Volumetric at Construction: } \\
\hline & Flexible & $\mathrm{DFC}$ & & 40.0 & \multirow{2}{*}{\begin{tabular}{|l} 
Effective binder \\
content( $(\%)$ \\
Air woids ( $\%)$ \\
\end{tabular}} & 12.4 \\
\hline & Flexible & \multicolumn{2}{|l|}{$\mathrm{HDB}$} & 90.0 & & \multirow[t]{4}{*}{3.5} \\
\hline & Flexible & $\mathrm{HL}-8$ & & 130.0 & & \\
\hline & NonStabilized & \multicolumn{2}{|c|}{ Granular A } & 400.0 & & \\
\hline & Subgrade & \multicolumn{2}{|l|}{$M L$} & Semi-infinite & & \\
\hline
\end{tabular}

\section{Traffic}

\begin{tabular}{|l|c|}
\hline \multicolumn{1}{|c|}{ Age (year) } & $\begin{array}{c}\text { Heawy Trucks } \\
\text { (cumula } \mathbf{a} \text { (ve) }\end{array}$ \\
\hline 1997 (initial) & 14,124 \\
\hline 2016 (19 years) & $37,344,500$ \\
\hline 2035 (38 years) & $91,449,900$ \\
\hline
\end{tabular}

\section{Design Outputs}

\begin{tabular}{|c|c|c|c|c|c|}
\hline \multirow{2}{*}{ Distress Type } & \multicolumn{2}{|c|}{$\begin{array}{c}\text { Distress@ Specified } \\
\text { Reliability }\end{array}$} & \multicolumn{2}{|c|}{ Reliability $(\%)$} & \multirow{2}{*}{$\begin{array}{l}\text { Criterion } \\
\text { Satisfied? }\end{array}$} \\
\hline & Target & Predicted & Target & Achieved & \\
\hline Terminal IRI (m/km) & 2.70 & 2.63 & 5000 & 54.62 & Pass \\
\hline Permanent deformation - total pavement (mm) & 1900 & 11.28 & 5000 & 99.98 & Pass \\
\hline AC bottom up fatigue crack ing (percent) & 2500 & 0.59 & 5000 & 100.00 & Pass \\
\hline AC thermal fracture $(\mathrm{m} / \mathrm{km})$ & 189.40 & 2.19 & 5000 & 100.00 & Pass \\
\hline AC top-down fatigue or ack ing $(m \mathrm{~km})$ & 378.80 & 0.00 & 5000 & 100.00 & Pass \\
\hline Permanent deformation - $A C$ only $(m m)$ & 6.00 & 4.21 & 5000 & 88.84 & Pass \\
\hline
\end{tabular}
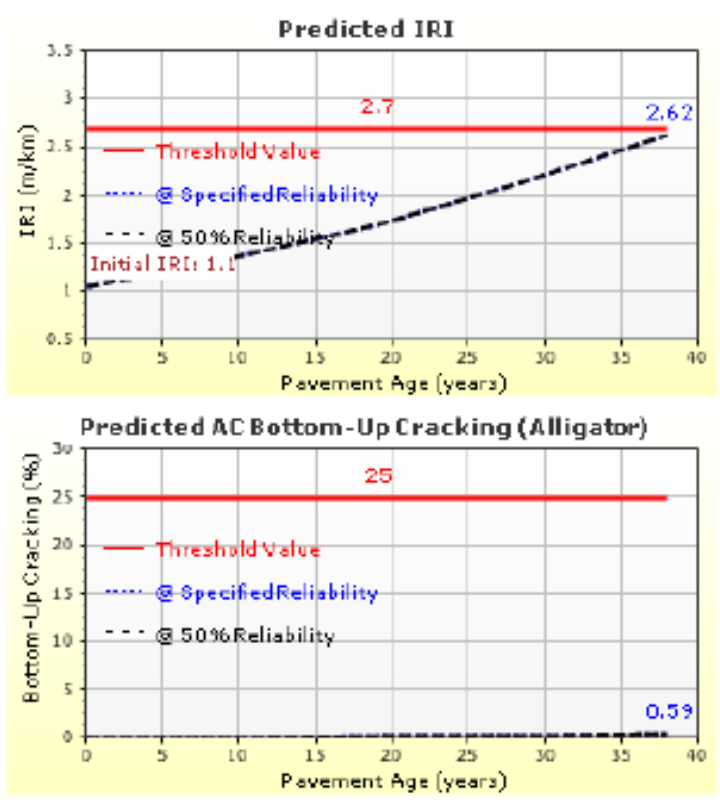
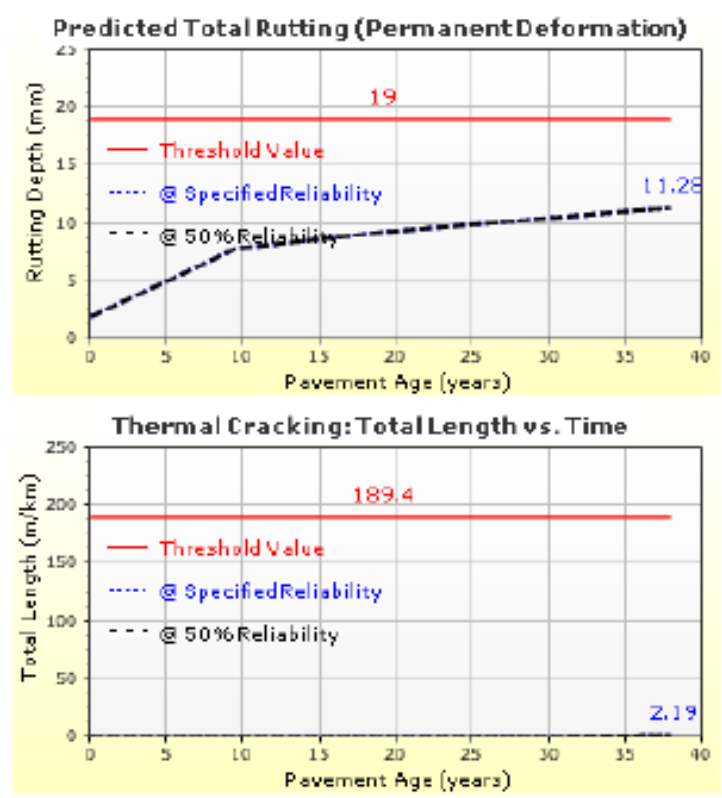
Appendix B3: DARWin-ME output for Initial Construction for Option 4(Trial No 6)

DARWǗ

\section{AC8-1 Section 9_ 25 yr_Trial 6}

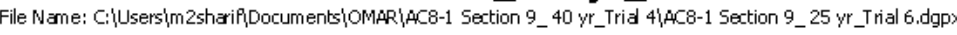

\begin{tabular}{|c|c|c|c|c|c|c|c|c|}
\hline \multicolumn{9}{|c|}{ Design Inputs } \\
\hline \multirow[t]{2}{*}{$\begin{array}{l}\text { Design Life: } \\
\text { Design Type: }\end{array}$} & \multirow{2}{*}{\multicolumn{2}{|c|}{$\begin{array}{l}25 \text { years } \\
\text { Flexible Pavement }\end{array}$}} & \multirow{2}{*}{\multicolumn{2}{|c|}{$\begin{array}{l}\text { Base construction: } \\
\text { Pavement construction: } \\
\text { Traffic opening: }\end{array}$}} & $\begin{array}{l}\text { August, } 1996 \\
\text { Sentember } 1996\end{array}$ & \multirow{2}{*}{\multicolumn{3}{|c|}{$\begin{array}{l}\text { Climate Data } \\
\text { Sources (Lat'Lon) }\end{array}$}} \\
\hline & & & & & December, 1997 & & & \\
\hline \multicolumn{7}{|c|}{ Design Structure } & \multicolumn{2}{|l|}{ Traffic } \\
\hline \multirow{5}{*}{ 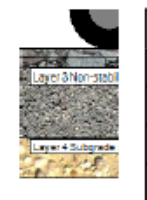 } & Layer type & \multicolumn{2}{|c|}{ Material Type } & Thickness(mm): & \multicolumn{2}{|c|}{ Volumetric at Construction: } & \multirow{2}{*}{ Age (year) } & \multirow{2}{*}{$\begin{array}{l}\text { Heaw Trucks } \\
\text { (cumulative) }\end{array}$} \\
\hline & Flexible & \multicolumn{2}{|l|}{ DFC } & 50.0 & \multirow{2}{*}{\begin{tabular}{|l} 
Effective binder \\
content $(\%)$
\end{tabular}} & \multirow{2}{*}{12.4} & & \\
\hline & Flexible & \multicolumn{2}{|l|}{$\mathrm{HL}-8$} & 70.0 & & & 1997 (initial) & 14,124 \\
\hline & NonStabilized & \multicolumn{2}{|c|}{ Granular A } & 440.0 & Air voids (\%) & 3.5 & 2009 (12 years) & $22,688,400$ \\
\hline & Subgrade & \multicolumn{2}{|l|}{$\mathrm{ML}$} & Semi-infinite & & & 2022 (25 years) & $52,619,700$ \\
\hline
\end{tabular}

\section{Design Outputs}

\begin{tabular}{|c|c|c|c|c|c|}
\hline \multirow{2}{*}{ Distress Type } & \multicolumn{2}{|c|}{$\begin{array}{c}\text { Distress \& Specified } \\
\text { Reliability }\end{array}$} & \multicolumn{2}{|c|}{ Reliability (\%) } & \multirow{2}{*}{$\begin{array}{l}\text { Criterion } \\
\text { Satisfied? }\end{array}$} \\
\hline & Target & Predicted & Target & Achieved & \\
\hline Terminal IRI $(\mathrm{m} / \mathrm{km})$ & 2.70 & 2.24 & 50.00 & 78.28 & Pass \\
\hline Permanent deformation - total pavement ( $\mathrm{mm}$ ) & 19.00 & 18.88 & 50.00 & 51.56 & Pass \\
\hline AC bottom-up fatigue cracking (percent) & 25.00 & 8.94 & 50.00 & 87.22 & Pass \\
\hline AC thermal fracture $(\mathrm{m} / \mathrm{km})$ & 189.40 & 1.66 & 50.00 & 100.00 & Pass \\
\hline AC top-down fatigue cracking $(\mathrm{m} / \mathrm{km})$ & 378.80 & 1.08 & 50.00 & 99.88 & Pass \\
\hline Permanent deformation - $\mathrm{AC}$ only ( $\mathrm{mm}$ ) & 6.00 & 4.21 & 50.00 & 88.84 & Pass \\
\hline
\end{tabular}

\section{Distress Charts}
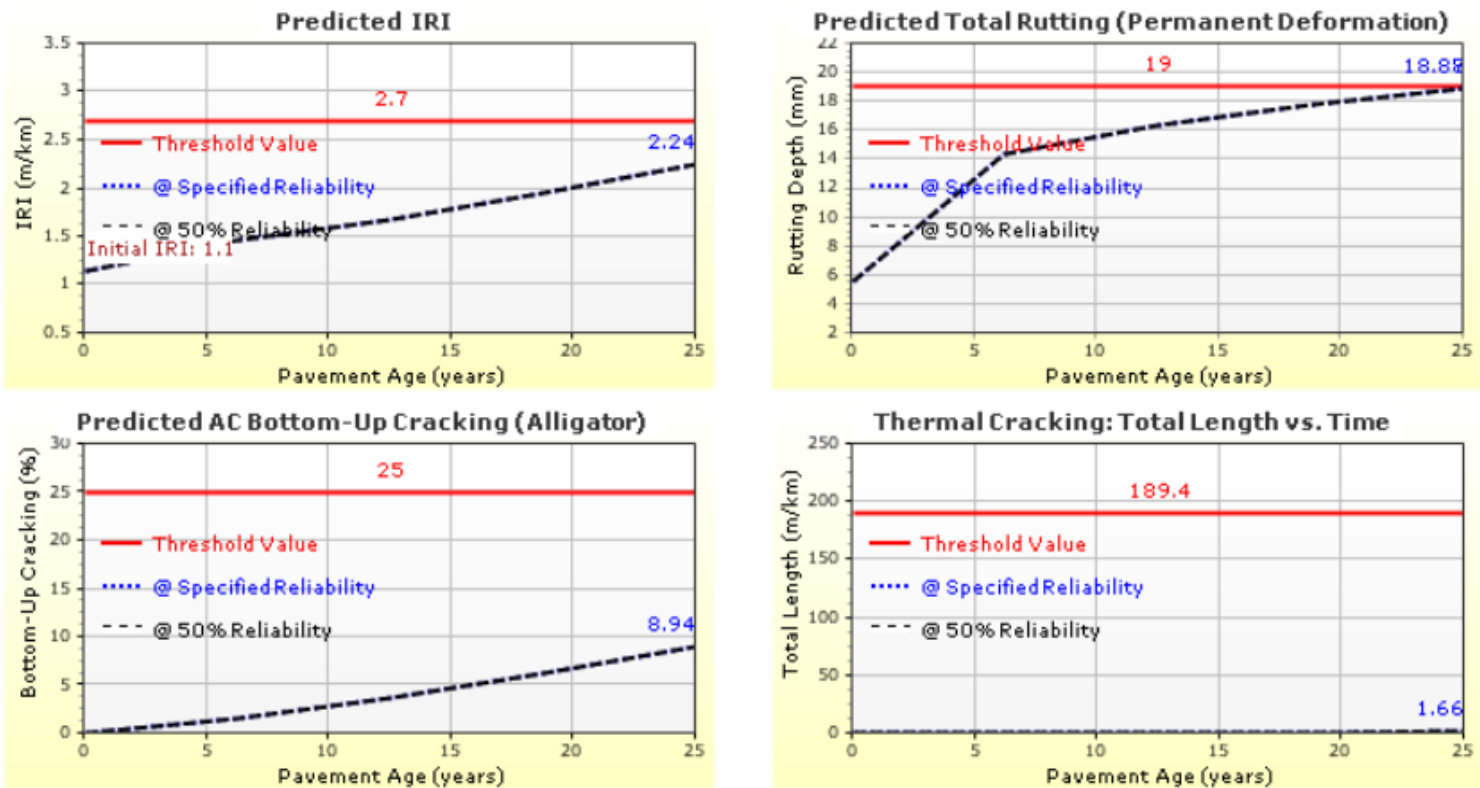


\section{Appendix B4 : DARWin-ME output for Initial Construction for Option 5 (Trial No 7)}

DARWIIn
AC8-1 Section 9_33 yr_Trial 7

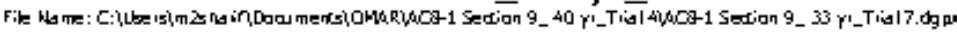

\begin{tabular}{|c|c|c|c|c|c|c|c|c|}
\hline \multicolumn{9}{|c|}{ Design Inputs } \\
\hline $\begin{array}{l}\text { Design Life: } \\
\text { Design Type: }\end{array}$ & \multicolumn{2}{|c|}{$\begin{array}{l}33 \text { years } \\
F \text { lexible } P \text { avement }\end{array}$} & \multicolumn{2}{|c|}{$\begin{array}{l}\text { Base constuction: } \\
\text { Pavement corstruction: } \\
\text { Traffic opening: }\end{array}$} & $\begin{array}{l}\text { August, } 1996 \\
\text { September, } 1996 \\
\text { December, } 1997\end{array}$ & \multicolumn{3}{|c|}{$\begin{array}{l}\text { Climate Data } \\
\text { Sources (Lat/Lon) }\end{array}$} \\
\hline \multicolumn{7}{|c|}{ D esign Structure } & \multicolumn{2}{|l|}{ Traffic } \\
\hline \multirow{3}{*}{ 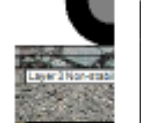 } & \multirow{2}{*}{\begin{tabular}{|l|} 
Layer type \\
Flexible \\
\end{tabular}} & \multicolumn{2}{|c|}{ Material Type } & Thickness $(\mathrm{mm})$ : & \multicolumn{2}{|c|}{ Volumetric at Construction: } & \multirow{2}{*}{ Age (year) } & \multirow{2}{*}{$\begin{array}{l}\text { Heavy Trucks } \\
\text { (cumulaive) }\end{array}$} \\
\hline & & DF C & & 50.0 & \multirow{2}{*}{$\begin{array}{l}\text { Effective binder } \\
\text { content }(\%)\end{array}$} & \multirow{2}{*}{12.4} & & \\
\hline & Flexible & HL-8 & & 70.0 & & & 1997 (initial) & 14,124 \\
\hline \multirow{2}{*}{ infers } & NonStabilized & Grant & & 300.0 & \multirow[t]{2}{*}{ Air voids (\%) } & \multirow{2}{*}{3.5} & 2013 (16 years) & $31,478,900$ \\
\hline & Subgrade & $M L$ & & Semi-infinite & & & 2030 (33 years) & $75,586,600$ \\
\hline
\end{tabular}

\section{Design Outputs}

\begin{tabular}{|c|c|c|c|c|c|}
\hline \multirow[t]{2}{*}{ Distress Type } & \multicolumn{2}{|c|}{$\begin{array}{c}\text { Distress (9) Specified } \\
\text { Reliability }\end{array}$} & \multicolumn{2}{|c|}{ Reliability $(\%)$} & \multirow{2}{*}{$\begin{array}{c}\text { Criterion } \\
\text { Satisfied? }\end{array}$} \\
\hline & Target & Predicted & Target & Achieued & \\
\hline Terminal IRI (m/km) & 2.70 & 2.64 & 5000 & 53.39 & Pass \\
\hline Permanent deformation - total pavement (mm) & 1900 & 17.57 & 5000 & 69.04 & Pass \\
\hline AC bottomr up fatigue crack ing (percent) & 2500 & 19.20 & 5000 & 65.93 & Pass \\
\hline AC thermal fracture $(\mathrm{m} / \mathrm{km})$ & 189.40 & 3.34 & 5000 & 100.00 & Pass \\
\hline AC top-down fatigue crack ing (mukm) & 378.80 & 3.60 & 5000 & 97.73 & Pass \\
\hline Permanent deformation - $A C$ only (mm) & $6 . \infty$ & 4.84 & 5000 & 75.88 & Pass \\
\hline
\end{tabular}

D istress Charts
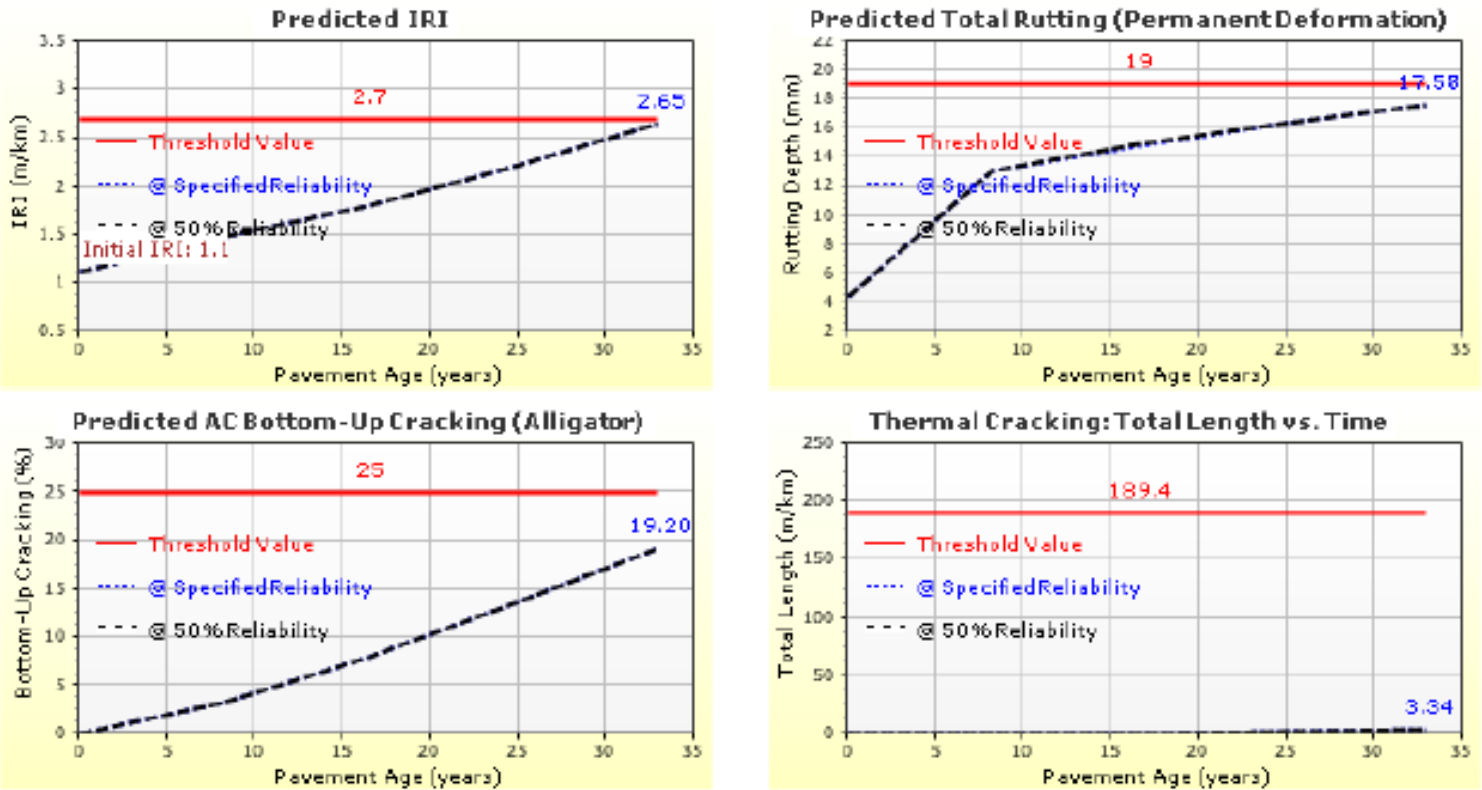


\section{Appendix C}

\section{Appendix C1: DARWin-ME output for overlay for Option 2 (Trial No 3)}

\section{DARWAfF -1 Section 9_ 38 yr_Overlay for Trial 3_revised local calibration}

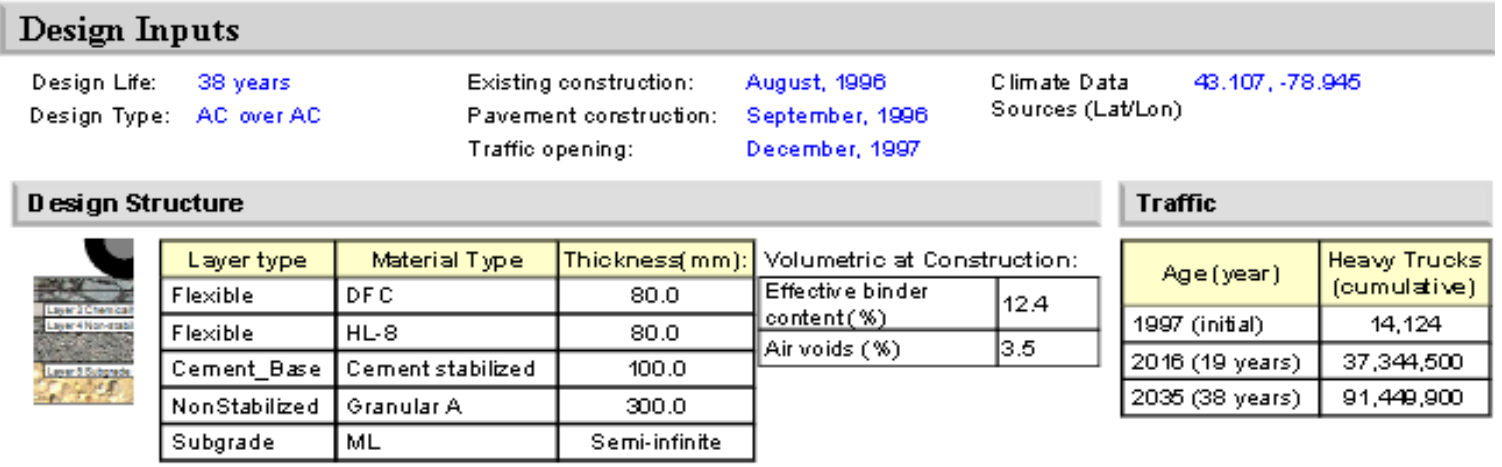

\section{Design Outputs}

\begin{tabular}{|c|c|c|c|c|c|}
\hline \multirow{2}{*}{ Distress Type } & \multicolumn{2}{|c|}{$\begin{array}{c}\text { Distress @ Specified } \\
\text { Reliability }\end{array}$} & \multicolumn{2}{|c|}{ Reliability (\%) } & \multirow{2}{*}{$\begin{array}{l}\text { Criterion } \\
\text { Satisfied? }\end{array}$} \\
\hline & Target & Predicted & Target & Achieved & \\
\hline Terminal IRI (m/km) & 2.70 & 2.67 & 5000 & 51.72 & Pass \\
\hline Permanent deformation-total pavement (mm) & 1900 & 13.59 & 5000 & 98.40 & Pass \\
\hline Total Cracking (R eflective + Alligator) (percent) & 100.00 & 6.69 & $\cdot$ & $\cdot$ & - \\
\hline AC thermal fracture $(\mathrm{m} / \mathrm{km})$ & 189.40 & 0.12 & 5000 & 100.00 & Pass \\
\hline AC bottorr up fatigue crack ing (percent) & 2500 & 0.00 & 5000 & 100.00 & Pass \\
\hline AC top-down fatigue er ack ing $(\mathrm{mkm})$ & 378.80 & 0.00 & 5000 & 100.00 & Pass \\
\hline Permanent deformation - $A C$ only (mm) & 6.00 & 5.52 & 50.00 & 60.37 & Pass \\
\hline Chemically stabilized layer - fatigue fracture (percent) & 2500 & 11.40 & - & - & . \\
\hline
\end{tabular}

D istress Charts
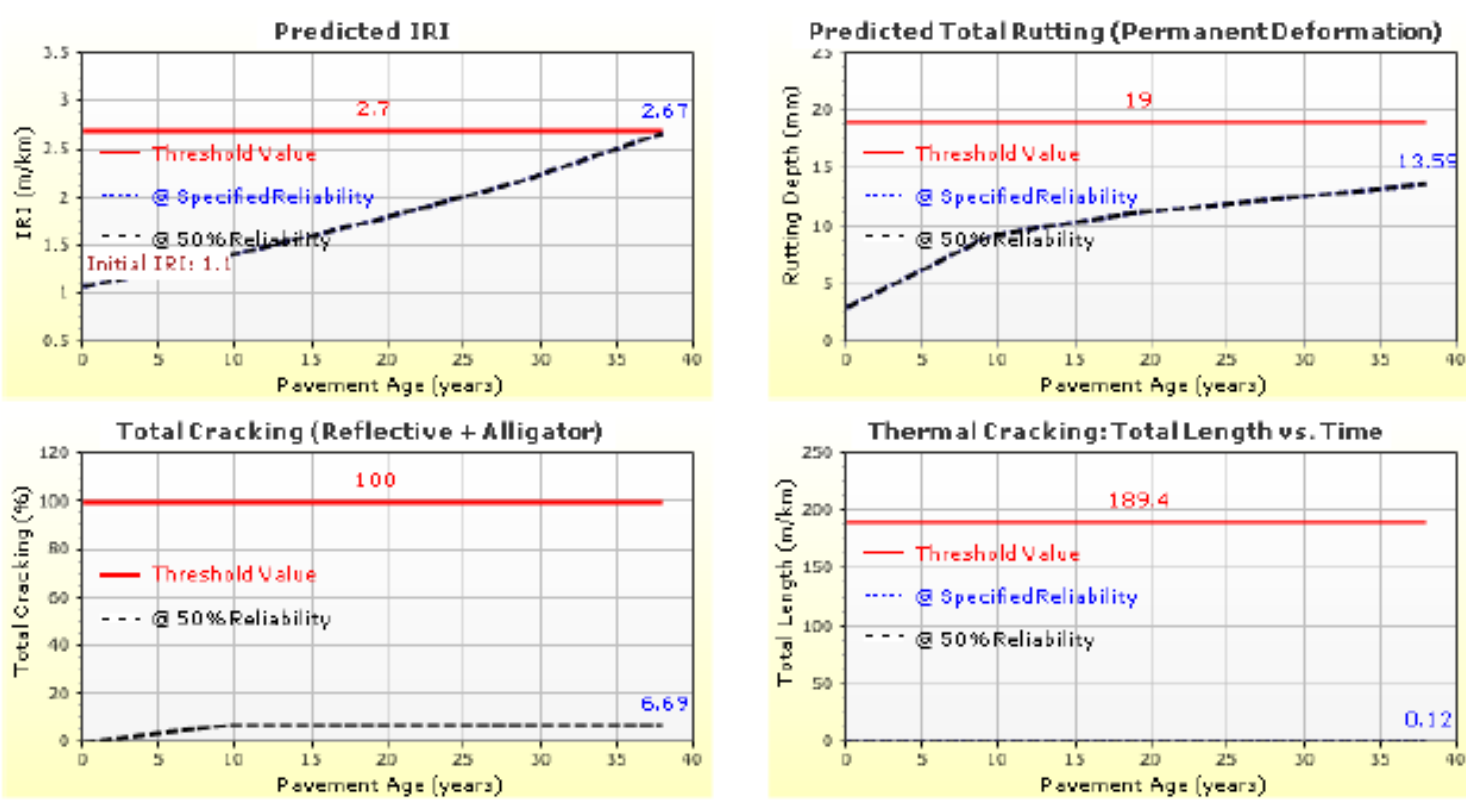
Appendix C2: DARWin-ME output for overlay for Option 3 (Trial No 4)

DARWin

AC8-1 Section 9_ 38 yr_0verlay design for Trial 4

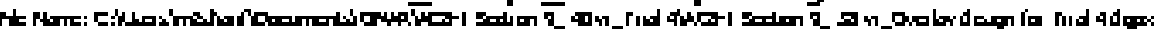

\section{Design Ip uts}

Desbn Ut: Isyas

Design Type: AC Cuer AOC

\begin{tabular}{|c|c|c|}
\hline $\begin{array}{l}\text { Eds tra cors huclon: } \\
\text { Parmenl are hudon: }\end{array}$ & $\begin{array}{l}\text { AUDUEI, } 1565 \\
\text { Eep tember, } 15 e 5\end{array}$ & $\begin{array}{l}\text { Clmale Dab } 43.10,-78945 \\
\text { Bourat }\end{array}$ \\
\hline
\end{tabular}

Tralkz operina:

Deamber, 1997
Do Ilgn structure

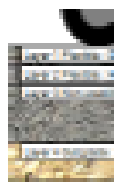

\begin{tabular}{|c|c|c|}
\hline Layer typo & Matoral Tup o & T hlahn o caim m) \\
\hline Flexble & DFC & 130 \\
\hline Flexble & HL- & 130 \\
\hline Monstolltred & Granda & Dه \\
\hline subrade & $M L$ & Eemifntilk \\
\hline
\end{tabular}

Trathe

\begin{tabular}{|c|c|}
\hline ang & $\begin{array}{l}\text { Hos w Tru ah } \\
\text { (au mula t wo) }\end{array}$ \\
\hline 1597 (1) & 14,124 \\
\hline ه16(19yeas) & 37,350 \\
\hline Ins(rsyeas) & 91,449,50 \\
\hline
\end{tabular}

\section{Design Outp uts}

Cito II Predlction summ ar;

\begin{tabular}{|c|c|c|c|c|c|}
\hline \multirow[t]{2}{*}{ Clıtro I T; pen } & \multicolumn{2}{|c|}{$\begin{array}{c}\text { Cat to II go spacitiod } \\
\text { Rellablit; }\end{array}$} & \multicolumn{2}{|c|}{ Billabill b; ("40) } & \multirow{2}{*}{$\begin{array}{l}\text { Criterion } \\
\text { satiledi }\end{array}$} \\
\hline & Targat & Predle tad & Target & Achle ved & \\
\hline Teming IR. I (unnkm) & 2.70 & 20 & sam & 54.54 & Pass \\
\hline Pemarenl dex́malon - lobl payemenl (mm) & 19.6 & 11.70 & sam & 9958 & Pass \\
\hline Tob c rosire (R.e telle + Albalor) (peranl & $1 m$ & 퐁 & - & $\cdot$ & - \\
\hline AC rermat tashre (mikm) & 189.40 & 0.16 & sam & 1m & Pas \\
\hline AC bolkm-lp tibur asodira iperan & $\mathbf{2 5 . m}$ & QD1 & $\operatorname{san}$ & 1m & Pas \\
\hline 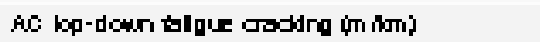 & 3850 & 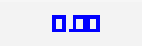 & sam & 1mm & Pass \\
\hline Pemarenldexomalon - AC orb (̂mm) & 600 & $4+D_{4}$ & sam & 918 & Pas \\
\hline
\end{tabular}
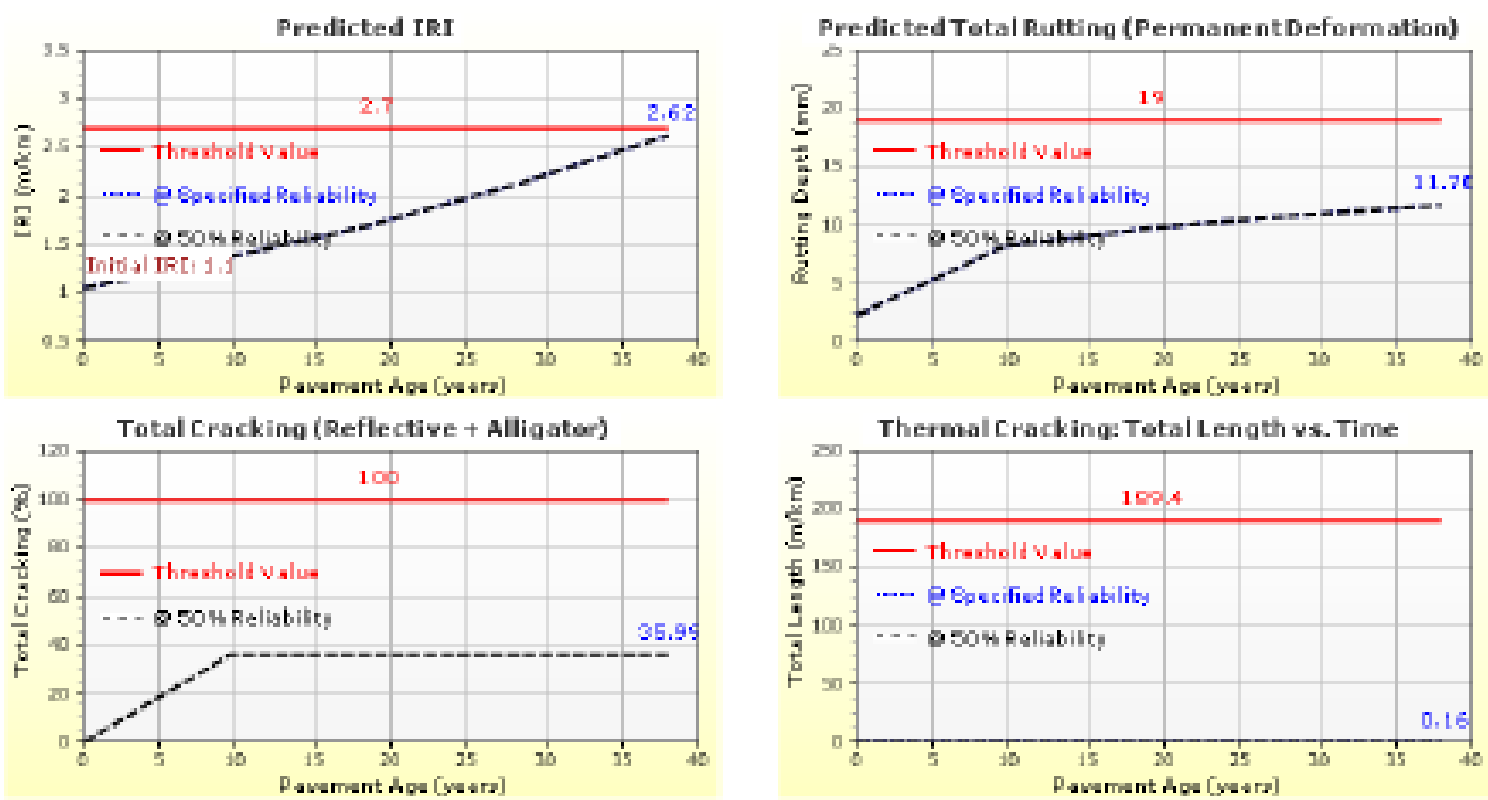
Appendix C3: DARWin-ME output for overlay for Option 4 (Trial No 6)

DARWIIn

AC8-1 Section 9_ 16 yr_overlay design for Trial 6

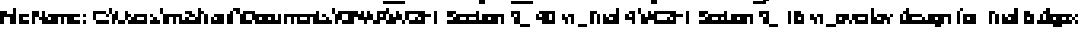

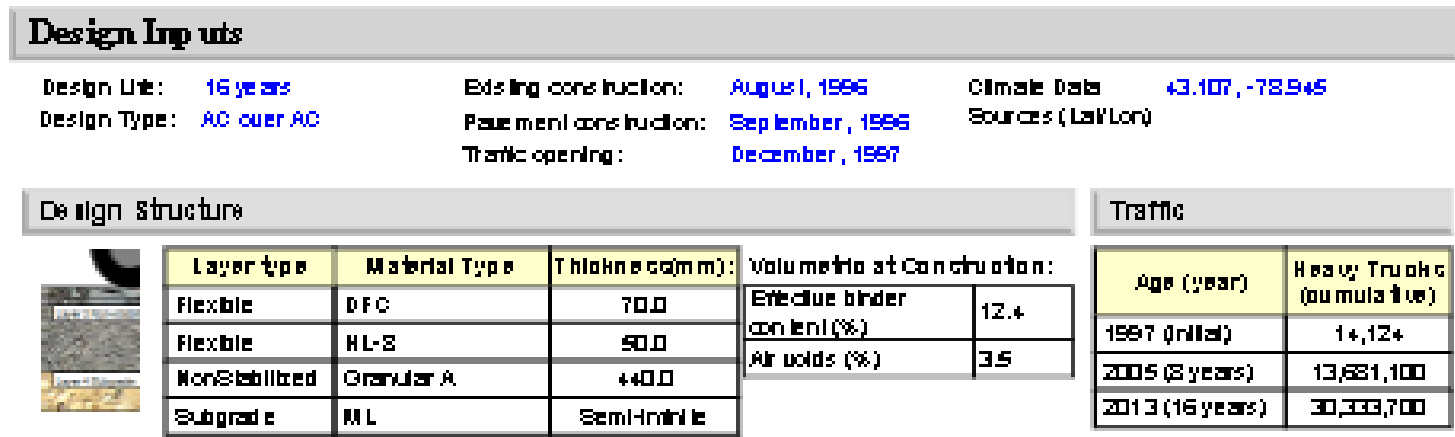

\section{Design Outp uts}

Dito II Prediction summ ar;

\begin{tabular}{|c|c|c|c|c|c|}
\hline \multirow{2}{*}{ Clıtre I T; pe } & \multicolumn{2}{|c|}{$\begin{array}{c}\text { Clite II es Specitied } \\
\text { Rellablit; }\end{array}$} & \multicolumn{2}{|c|}{ 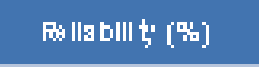 } & \multirow{2}{*}{$\begin{array}{l}\text { Criterion } \\
\text { satiled? }\end{array}$} \\
\hline & Targat & Pradle tad & Target & Acille ved & \\
\hline Teming IR. I (unnikm) & 2.70 & 187 & sam & 96.14 & Pass \\
\hline Pemarenl dexomalon - lobs payemenl (mm) & $19 . \mathbf{m}$ & 1835 & som & s8. & Pass \\
\hline Tota C rodira (R.etelle + Albabr) (perand & $10 m$ & $3+57$ & $\cdot$ & - & $\cdot$ \\
\hline Ac rermat tachere (mikm) & 139.4 & 口四 & $\operatorname{san}$ & 1m & Pass \\
\hline AC bolkm-u tilgue asodra ineran & $\mathbf{2 5 . m}$ & QD1 & $\operatorname{san}$ & 1mm & Pass \\
\hline 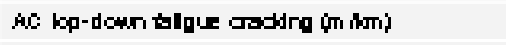 & 385 & 0.76 & som & 9957 & Pass \\
\hline Pemarenl dekrmalon-AC ortiónm) & 600 & 3.71 & sam & 95.76 & Pass \\
\hline
\end{tabular}
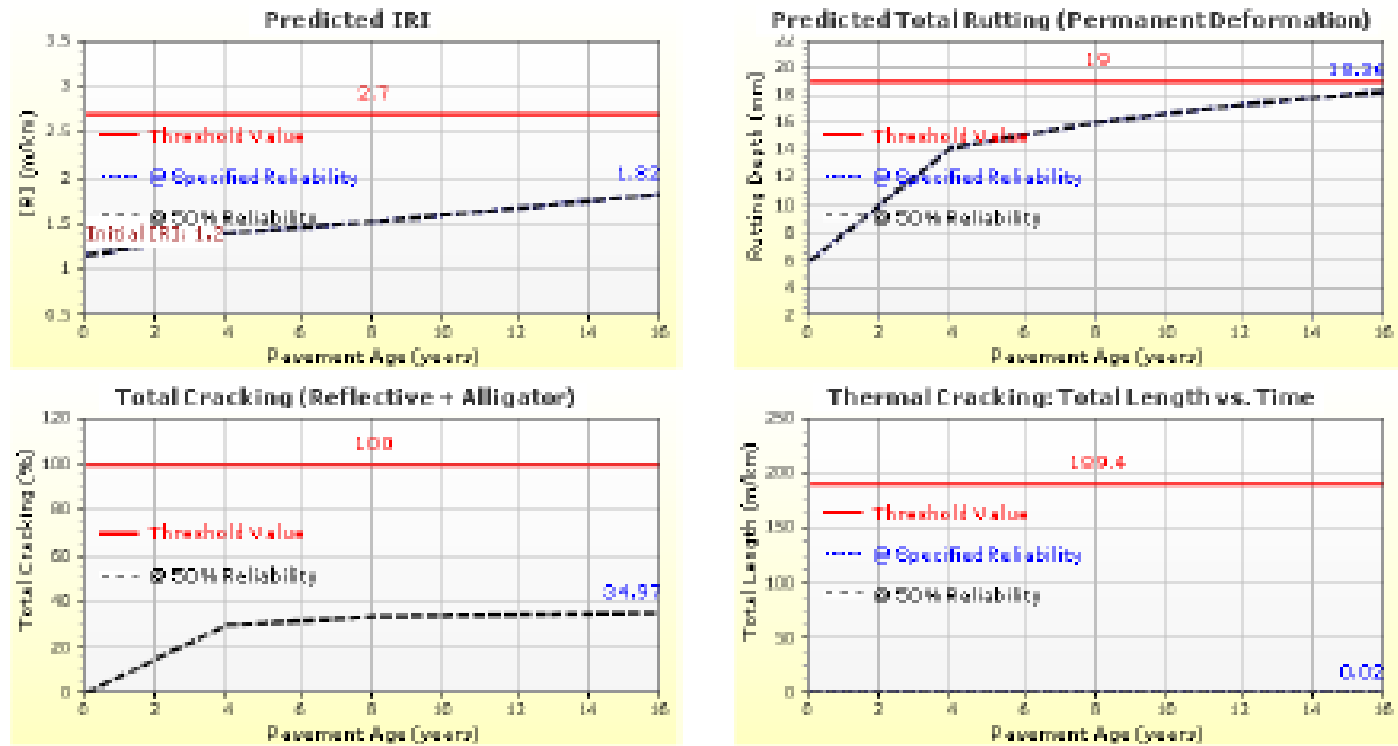


\section{Appendix C4: DARWin-ME output for overlay for Option 5 (Trial No 7)}

DARWin $\quad$ AC8-1 Section $9 \_25$ yr_Overlay design for Trial 7

\section{Design Inputs}

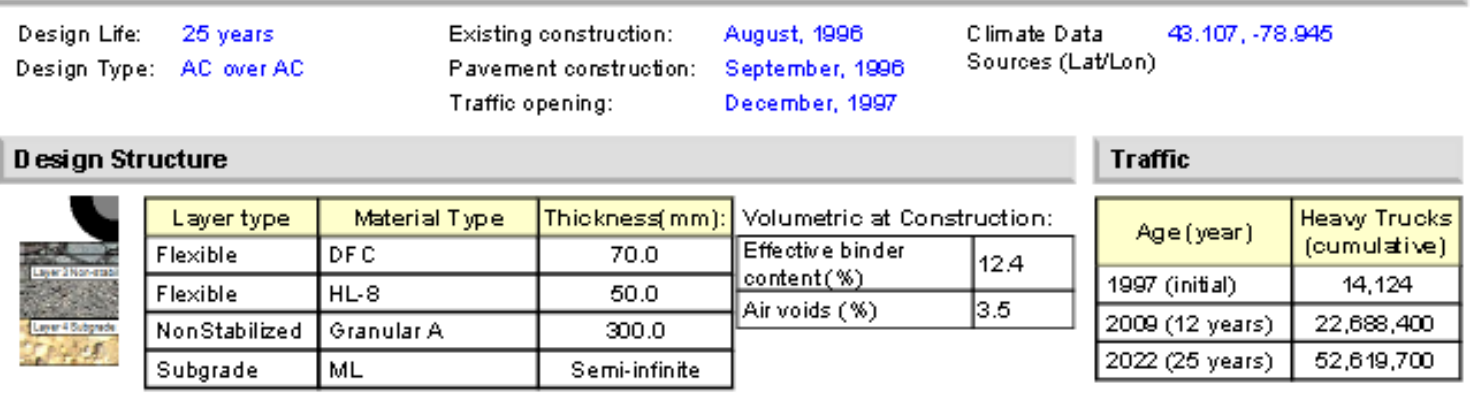

\section{Design Outputs}

\section{D istress Prediction Summary}

Distress Type

Terminal IRI $(\mathrm{m} / \mathrm{km})$

Permanent deformation - total pavement (mm)

Total Cracking (R eflective + Alligator) (percent)

$A C$ thermal fracture $(\mathrm{m} / \mathrm{km})$

$A C$ bottomr up fatigue crack ing (percent)

AC top-down fatigue crack ing (mkm)

Permanent deformation- $A C$ only $(m m)$

\begin{tabular}{|c|c|c|c|c|}
\hline \multicolumn{2}{|c|}{$\begin{array}{c}\text { Distress@ Specified } \\
\text { Reliability }\end{array}$} & \multicolumn{2}{|c|}{ Reliability (\%) } & \multirow{2}{*}{$\begin{array}{l}\text { Criterion } \\
\text { Satisfied? }\end{array}$} \\
\hline Target & Predicted & Target & Achieved & \\
\hline 2.70 & 2.15 & 50.00 & 83.42 & Pass \\
\hline 1900 & 17.73 & 5000 & 67.08 & Pass \\
\hline 100.00 & 39.29 & $\cdot$ & - & - \\
\hline 189.40 & 0.06 & 50.00 & 100.00 & Pass \\
\hline 2500 & 0.03 & 5000 & 100.00 & Pass \\
\hline 378.80 & 2.18 & 5000 & 99.14 & Pass \\
\hline 6.00 & 4.74 & 50.00 & 78.16 & Pass \\
\hline
\end{tabular}
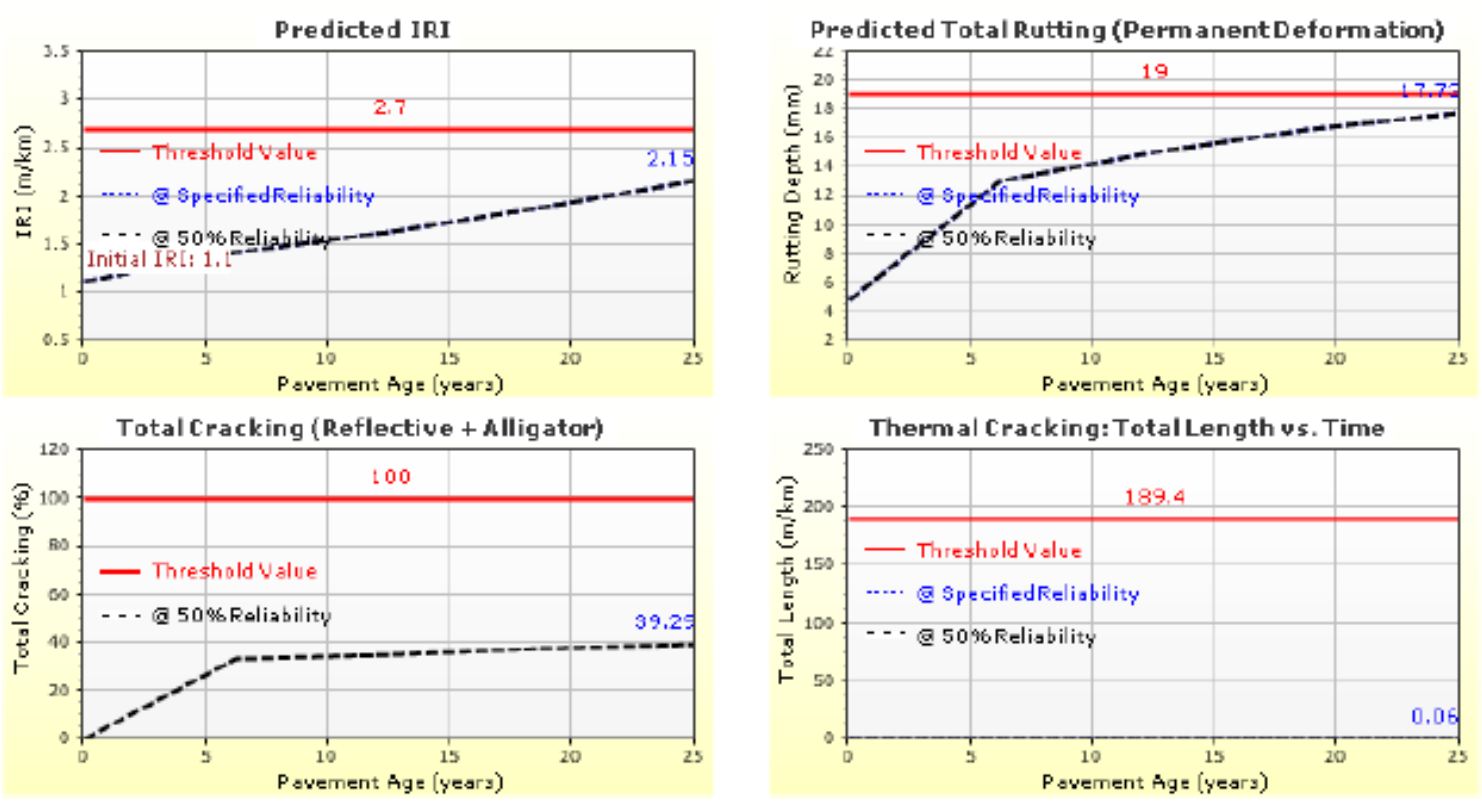